University of Rhode Island

DigitalCommons@URI

Open Access Dissertations

2017

\title{
Understanding the Formation and Evolution of Lithium-Ion Battery Solid Electrolyte Interphase
}

Bharathy Subramanian Parimalam

University of Rhode Island, bparimalam@outlook.com

Follow this and additional works at: https://digitalcommons.uri.edu/oa_diss

\section{Recommended Citation}

Subramanian Parimalam, Bharathy, "Understanding the Formation and Evolution of Lithium-Ion Battery Solid Electrolyte Interphase" (2017). Open Access Dissertations. Paper 659.

https://digitalcommons.uri.edu/oa_diss/659

This Dissertation is brought to you for free and open access by DigitalCommons@URI. It has been accepted for inclusion in Open Access Dissertations by an authorized administrator of DigitalCommons@URI. For more information, please contact digitalcommons-group@uri.edu. 
UNDERSTANDING THE FORMATION AND EVOLUTION OF LITHIUM-ION

BATTERY SOLID ELECTROLYTE INTERPHASE

BY

BHARATHY SUBRAMANIAN PARIMALAM

A DISSERTATION SUBMITTED IN PARTIAL FULFILLMENT OF THE

REQUIREMENTS FOR THE DEGREE OF

DOCTOR OF PHILOSOPHY IN CHEMISTRY

UNIVERSITY OF RHODE ISLAND

2017 


\section{DOCTOR OF PHILOSOPHY IN CHEMISTRY}

OF

BHARATHY SUBRAMANIAN PARIMALAM

\section{APPROVED}

\section{Dissertation Committee}

Major Professor: Brett Lucht

William Euler

Dave Heskett

Nasser H. Zawia

DEAN OF THE GRADUATE SCHOOL

UNIVERSITY OF RHODE ISLAND 


\begin{abstract}
Lithium ion batteries are widely used as energy storage devices in a variety of products such as smartphones, tablets, laptops and other portable electronics. Thanks to their high energy density and cyclability, they are currently being used by and developed for electric vehicles. There is a growing need for cost reduction; increase in energy density; wider operating temperature range; and improved safety characteristics of the batteries.

Organic carbonates are the primary solvents used in lithium-ion battery electrolytes along with electrolyte additives. The reversibility of current lithium-ion batteries is dependent upon the electrolyte used in the batteries. During the initial charging cycles of the cell, a solid electrolyte interface (SEI) is formed by reduction of organic carbonates, electrolyte salts and/or electrolyte additives on the surface of the graphitic anode in lithium-ion batteries. The generation of a stable anode SEI prevents continuous electrolyte reduction on the surface of the anode. The SEI functions as a Li ion conductor but an electrical insulator.

The reduction reactions of the electrolytes on the graphitic anode surface have been investigated for many years and it been proposed to contain a complicated mixture of products including lithium oxalate, lithium alkoxides, and lithium oxide from the carbonate solvents and $\mathrm{LiF}$ and lithium fluorophosphates from the reduction of $\mathrm{LiPF}_{6}$. Similar ambiguity exists about the components of SEI formed from electrolyte additives and other electrolyte salts. Despite the extensive investigations, the structure, formation mechanisms and evolution of the SEI are poorly understood. Understanding the mechanisms of the reduction reactions of organic carbonates, electrolyte salts and
\end{abstract}


electrolyte additives along with the products of the reactions which result in the generation of the SEI is essential for the development of safer lithium-ion batteries with wider operating temperature range.

Lithium naphthalenide has been investigated as a one electron reducing agent for organic carbonates solvents, some of the most robust additives and salts used in lithium ion battery electrolytes. The reaction precipitates have been analyzed by IRATR, XPS and solution NMR spectroscopy. The evolved gases and the volatile components have been analyzed by GC-MS. The reduction products of ethylene carbonate and propylene carbonate are lithium ethylene dicarbonate (LEDC) and ethylene and lithium propylene dicarbonate (LPDC) and propylene, respectively. The reduction products of diethyl and dimethyl carbonate are lithium ethyl carbonate (LEC) and ethane and lithium methyl carbonate(LMC) and methane, respectively. Electrolyte additives, FEC and VC reductively decompose to $\mathrm{HCO}_{2} \mathrm{Li}, \mathrm{Li}_{2} \mathrm{C}_{2} \mathrm{O}_{4}, \mathrm{Li}_{2} \mathrm{CO}_{3}$, and polymerized VC. All the fluorine containing salts generate $\mathrm{LiF}$ upon reduction. In addition to $\mathrm{LiF}, \mathrm{LiBF}_{4}$ generates $\mathrm{Li}_{x} \mathrm{~B}_{\mathrm{y}} \mathrm{F}_{\mathrm{z}}$ species; $\mathrm{LiBOB}$ and $\mathrm{LiDFOB}$ generate lithium oxalate and boron-oxalatoesters; $\mathrm{LiPF}_{6}$ yields $\mathrm{LiPF}_{2}$ species and LiTFSI produces lithium bis[N-(trifluoromethylsulfonylimino)] trifluoromethanesulfonate.

The poor thermal stability of the SEI layer has been attributed to exothermic reactions between lithium alkyl carbonates and $\mathrm{LiPF}_{6}$. While the relationship between capacity fade and SEI instability is clear, and there have been some investigations of SEI component evolution, the mechanism of SEI component decomposition is complicated by the presence of many different components. The thermal stability of $\mathrm{Li}_{2} \mathrm{CO}_{3}, \mathrm{LMC}$, and $\mathrm{LEDC}$ in the presence of $\mathrm{LiPF}_{6}$ in dimethyl carbonate (DMC), a 
common salt and solvent, respectively, in lithium ion battery electrolytes, has been investigated to afford a better understanding of the evolution of the SEI. The residual solids from the reaction mixtures have been characterized by a combination of $\mathrm{X}$-ray photoelectron spectroscopy (XPS) and infrared spectroscopy with attenuated total reflectance (IR-ATR), while the solution and evolved gases have been investigated by nuclear magnetic resonance (NMR) spectroscopy and gas chromatography with mass selective detection (GC-MS). The thermal decomposition of $\mathrm{Li}_{2} \mathrm{CO}_{3}$ and $\mathrm{LiPF}_{6}$ in $\mathrm{DMC}$ yields $\mathrm{CO}_{2}, \mathrm{LiF}$, and $\mathrm{F}_{2} \mathrm{PO}_{2} \mathrm{Li}$. The thermal decomposition of LMC and LEDC with $\mathrm{LiPF}_{6}$ in $\mathrm{DMC}$ results in the generation of a complicated mixture including $\mathrm{CO}_{2}, \mathrm{LiF}$, ethers, phosphates, and fluorophosphates. 


\section{ACKNOWLEDGMENTS}

I would like to thank Professor Brett L. Lucht for the opportunity to do $\mathrm{PhD}$ and his guidance, patience, and support throughout. I would also like to thank all the past and present members of the Lucht's group for their discussions, feedbacks, and help, especially, Cao Nguyen, Taeho Yoon, Mengyun Nie, Rahul Kadam, Yingnan Dong, and Navid Chapman.

I am immensely grateful to the doctoral committee members, Prof. William Euler, Prof. David Heskett, Prof. Arijit Bose for their time and efforts. I would like to acknowledge the University of Rhode Island chemistry department for providing instrumentation, resources, and teaching assistantship. Dr. Susan Geldart has been a pleasure to work with. I am thankful to all the friends I made during my $\mathrm{PhD}$ for the good times, help and sitting through my practice presentations.

Finally, a big thanks goes to my brother, parents, and relatives for believing in me, supporting beyond their means and constant encouragement. 


\section{PREFACE}

This thesis is written in manuscript format. The first chapter is an introduction to lithium ion batteries; Chapter 2 was published in the ECS Electrochemistry Letters; Chapter 3 was published in the Chemistry of Materials; Chapter 4 is written in manuscript format, and may be published in the future; and Chapter 5 was published in the Journal of Physical Chemistry C. 


\section{TABLE OF CONTENTS}

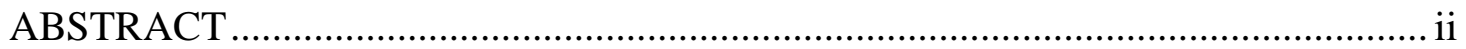

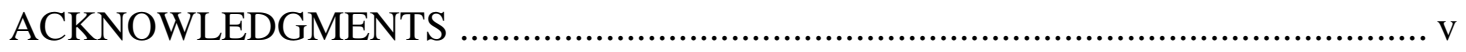

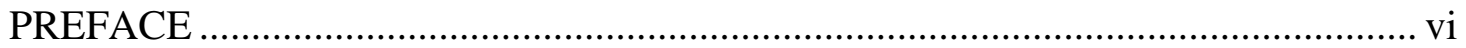

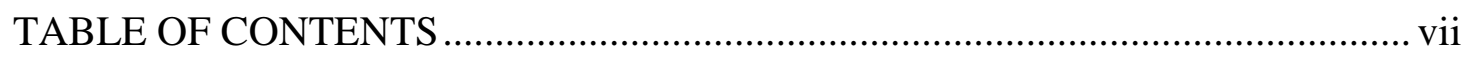

LIST OF FIGURES, SCHEMES AND TABLES ………….................................... ix

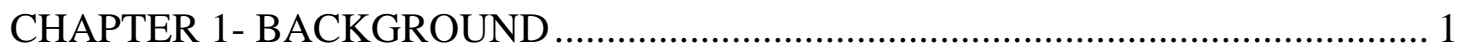

INTRODUCTION TO LITHIUM ION BATTERIES ........................................................

COMPONENTS OF A TYPICAL LITHIUM ION BATTERY ………………………….....

STATEMENT OF THE PROBLEM AND PROPOSED SOLUTIONS .................................. 3

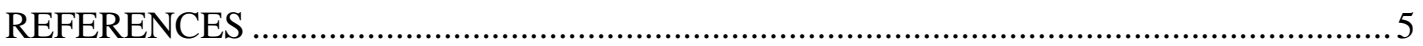

CHAPTER 2 - REDUCTION REACTIONS OF CARBONATE SOLVENTS FOR

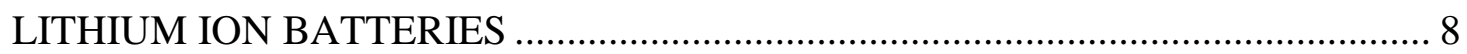

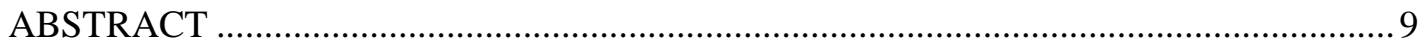

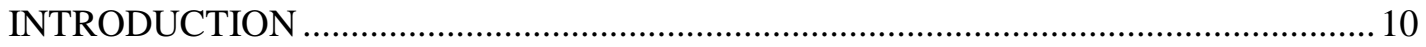

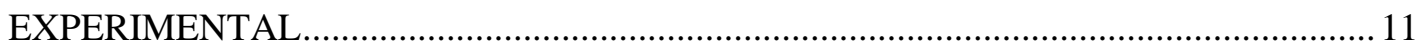

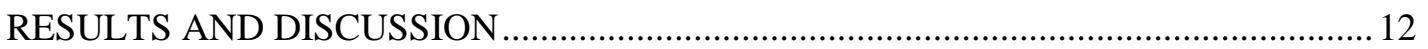

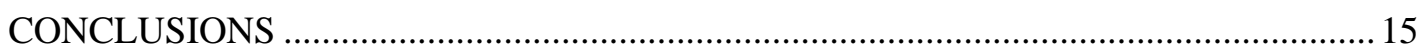

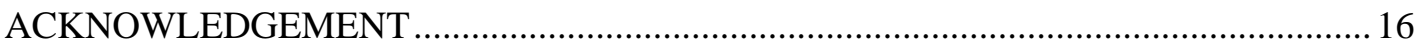

REFERENCES ……………………………………………………………....... 17

CHAPTER 3 - FLUOROETHYLENE CARBONATE AND VINYLENE

CARBONATE REDUCTION: UNDERSTANDING LITHIUM-ION BATTERY

ELECTROLYTE ADDITIVES AND SOLID ELECTROLYTE INTERPHASE

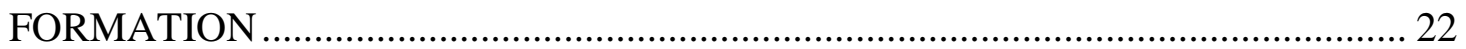

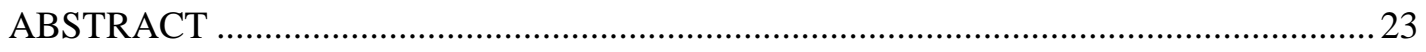

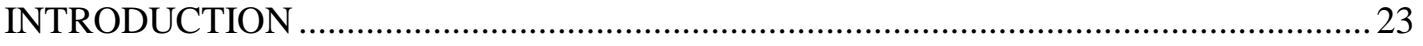

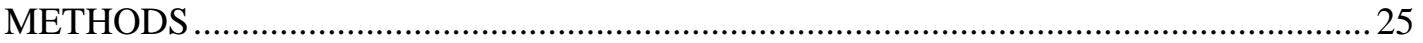

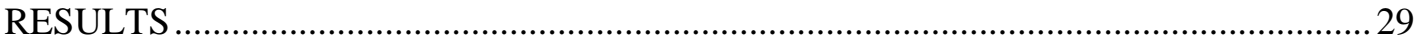




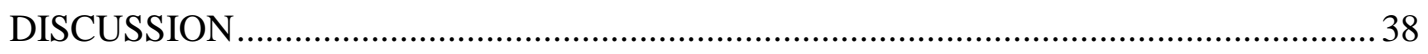

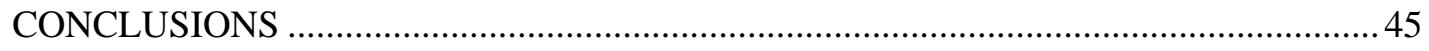

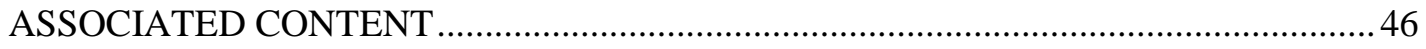

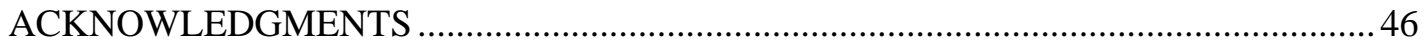

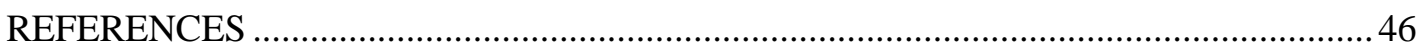

CHAPTER 4 - REDUCTION REACTIONS OF ELECTROLYTE SALTS FOR

LITHIUM ION BATTERIES: $\mathrm{LiBF}_{4}, \mathrm{LiDFOB}, \mathrm{LiBOB}, \mathrm{LiPF}_{6}$ \& LiTFSI ............... 62

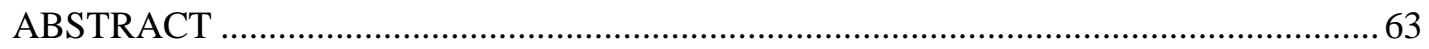

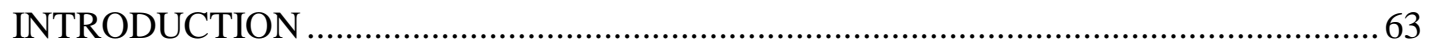

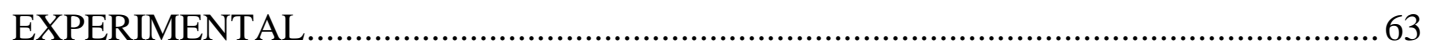

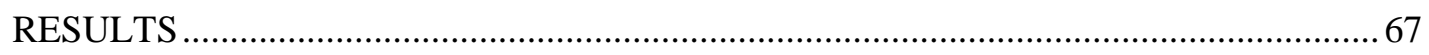

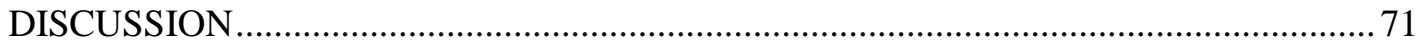

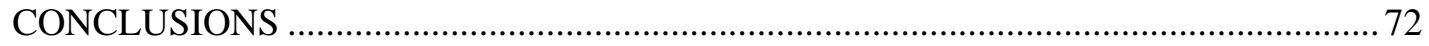

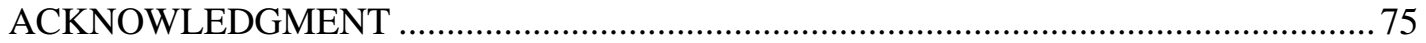

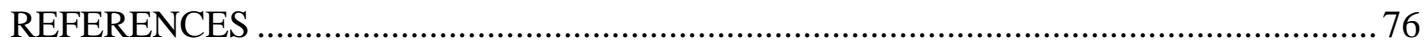

CHAPTER 5 - DECOMPOSITION REACTIONS OF ANODE SOLID

ELECTROLYTE INTERPHASE (SEI) COMPONENTS WITH LiPF

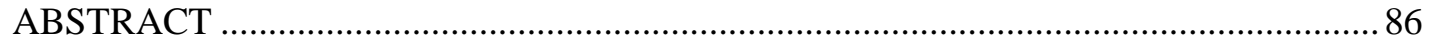

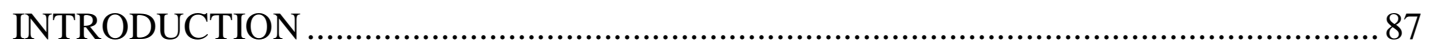

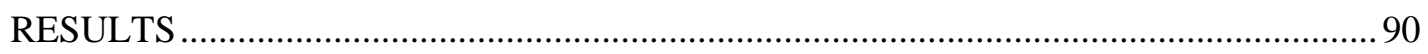

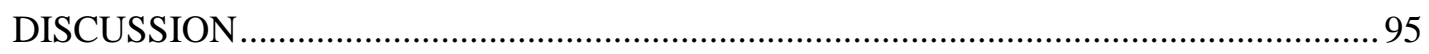

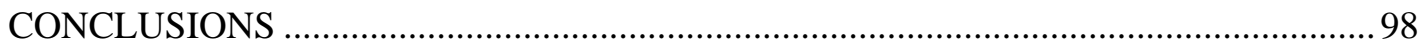

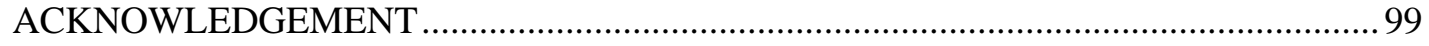

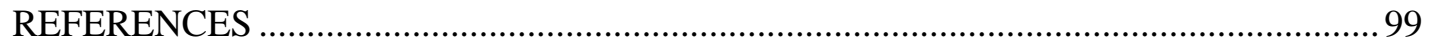




\section{LIST OF FIGURES, SCHEMES AND TABLES}

FIGURE/SCHEME/TABLE

PAGE

Figure 2.1. ${ }^{1} \mathrm{H}$ NMR (top) and ${ }^{13} \mathrm{C}$ NMR (bottom) spectra of precipitates from the reaction of lithium naphthalenide with carbonate solvents: (a) EC, (b) PC, (c) DMC and (d) DEC 20

Figure 2.2. FTIR spectra of the precipitates of the lithium naphthalenide reduction of carbonates.

Figure 3.1. XPS spectra of the (a) FEC and (b) VC precipitates obtained through reduction of FEC and VC using deuterated naphthalene. Deconvolutions of the spectra are shown in black. .54

Figure 3.2. ssNMR spectra of the precipitates obtained through reduction of (a) FEC and (b) VC using deuterated naphthalene. .56

Figure 3.3. ${ }^{13} \mathrm{C}$ ssNMR experiments performed on (a) FEC and (b) VC precipitates. (ai) ${ }^{13} \mathrm{C}$ single pulse, (a-ii) ${ }^{19} \mathrm{~F}-{ }^{13} \mathrm{C}$ cross-polarization, $\mathrm{CP}$, with contact time of $1000 \mu \mathrm{s}$, (a-iii) dipolar dephasing (interrupted decoupling) contact time of $1000 \mu \mathrm{s}$ and interrupted delay times of $\mathrm{d}=40,20$, and $10 \mu \mathrm{s}$. (b-i) ${ }^{13} \mathrm{C}$ single pulse, (b-ii) ${ }^{7} \mathrm{Li}^{-13} \mathrm{C} \mathrm{CP}$ with contact time of $2000 \mu \mathrm{s}$, (b-iii) dipolar dephasing with contact time of $1000 \mu \mathrm{s}$ and delay times of $\mathrm{d}=60,20,10$, and $0 \mu \mathrm{s}$

Figure 3.4. FTIR spectra of the precipitates obtained through reduction of (a) FEC and (b) VC using nondeuterated naphthalene.

Figure 3.5. Proposed FEC/VC reduction products. A possible structure for a crosslinking site of poly $(\mathrm{VC})$ is indicated.

Figure 4.1. Structures of the electrolyte salts

Figure 4.2. Solution NMR spectra of the solids from the Li[NAP] reduction of

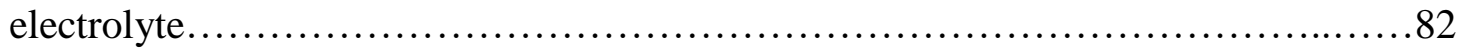

Figure 4.3. FTIR spectra of the solids from the Li[NAP] reduction of LiBOB and LiDFOB. .83

Figure 4.4. XPS spectra of the solids from the Li[NAP] reduction of $\mathrm{LiBF}_{4}$, and $\mathrm{LiPF}_{6}$ .84

Figure 5.1. ${ }^{19} \mathrm{~F}$ and ${ }^{31} \mathrm{P}$ NMR spectra of sample (a) $0.65 \mathrm{M} \mathrm{LiPF}_{6} / \mathrm{DMC}$ (b) $\mathrm{Li}_{2} \mathrm{CO}_{3}$ in $0.65 \mathrm{M} \mathrm{LiPF}_{6} / \mathrm{DMC}$ (c) $\mathrm{LMC}$ in $0.65 \mathrm{M} \mathrm{LiPF}_{6} / \mathrm{DMC}$ and (d) LEDC in $0.65 \mathrm{M}$ $\mathrm{LiPF}_{6} / \mathrm{DMC} \mathrm{s}$ after 48 hours of storage at $55^{\circ} \mathrm{C}$ 
Figure 5.2. FTIR spectra of the pure $\mathrm{Li}_{2} \mathrm{CO}_{3}, \mathrm{LMC}$, LEDC, and dried precipitates obtained from (a) $\mathrm{Li}_{2} \mathrm{CO}_{3}$ in $0.65 \mathrm{M} \mathrm{LiPF}_{6} / \mathrm{DMC}$ (b) $\mathrm{LMC}$ in $0.65 \mathrm{M} \mathrm{LiPF}_{6} / \mathrm{DMC}$ and (c) $\mathrm{LEDC}$ in $0.65 \mathrm{M} \mathrm{LiPF}_{6} / \mathrm{DMC}$ samples after 48 hours of storage at $55^{\circ} \mathrm{C}$ 106

Figure 5.3. F1s, P2p, C1s and O1s XPS spectra of the residues obtained from (a) $\mathrm{Li}_{2} \mathrm{CO}_{3}$

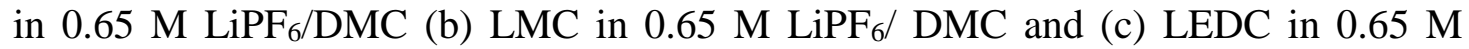

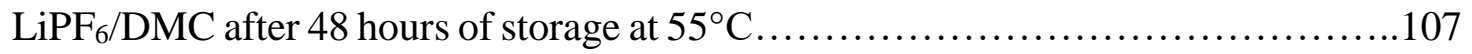

Scheme 2.1 Reduction mechanisms of EC, PC, DMC and DEC .................... 19

Scheme 3.1. Possible Reaction Schemes Consistent with the Chemical Signatures Detected by XPS, ssNMR, FTIR, and GC-MS ............................61

Table 3.1. Relative Elemental Concentrations from XPS Analysis...................55

Table 3.2. ${ }^{13} \mathrm{C}$ ssNMR Assignment for Peaks A-I Labeled in Figure 3.3............. 58

Table 5.1. ${ }^{19} \mathrm{~F}$ and ${ }^{31} \mathrm{P}$ NMR spectral data of the decomposition products............105 


\section{CHAPTER 1- BACKGROUND}

\section{INTRODUCTION TO LITHIUM ION BATTERIES}

A battery is constituted by several electrochemical cells connected in series or parallel. A cell is composed of an anode, a cathode, and an electrolyte. Primary electrochemical cells can convert chemical energy into electrical energy, whereas secondary electrochemical cells can perform reversible chemical/electrical energy conversion in both directions. A variety of consumer electronics, ignition systems, hybrid/electric vehicles utilize secondary batteries for energy storage. The free energy change of the net cell reaction matches the electrical energy generated or consumed by the cell. In other words, the amount of electrical energy stored per kg of the battery depends on the cell potential (V) and the specific capacity $\left(\mathrm{A} \mathrm{h} \mathrm{kg}^{-1}\right)$, which in turn depends on the cell chemistry.

Lithium ion batteries (LIBs) currently outperform other commercial secondary battery systems, due to their high energy density and long cycle life. Average energy density of a typical lithium battery ranges around $150 \mathrm{Whkg}^{-1}$, with the nominal voltage of $3.7 \mathrm{~V}$, much higher than other commercial secondary battery systems: nickel-metal hydride batteries, $75 \mathrm{Whkg}^{-1}, 1.2 \mathrm{~V}$; nickel-cadmium batteries, $\sim 50 \mathrm{Whkg}^{-1}, 1.2 \mathrm{~V}$; and lead-acid batteries, $25 \mathrm{Whkg}^{-1}, 2.1 \mathrm{~V} .{ }^{1}$ Lithium ion batteries are currently used in consumer electronics, hybrid electric vehicles and developed for grid storage and electric vehicles. Despite the growing dominance as the energy storage technology, LIBs face challenges in cost reduction; increasing energy density; widening the operating temperature range; and improving the safety characteristics. 


\section{COMPONENTS OF A TYPICAL LITHIUM ION BATTERY}

LIBs are composed of an anode, graphitic carbon or silicon-carbon composite coated on a copper current collector; a cathode, lithium transition metal oxide coated on an aluminum current collector; a separator, porous polypropylene/polyethylene or ceramic-polymer blends; and an electrolyte solution, $\mathrm{LiPF}_{6}$ dissolved in 3/7: v/v mix of ethylene carbonate and ethylmethyl carbonate along with a cocktail of proprietary additives. Active materials on anode and cathode are generally porous and contain a few percent of binders, sodium carboxymethyl cellulose/ styrene butadiene rubber or polyvinylidene fluoride; and conductive carbon, super C.

Common anode active materials are natural graphite, mesocarbon microbeads, and silicon-carbon composite materials and common cathode active materials are $\mathrm{LiCoO}_{2}, \mathrm{LiNi}_{1 / 3} \mathrm{Mn}_{1 / 3} \mathrm{Co}_{1 / 3} \mathrm{O}_{2}$, and $\mathrm{LiFePO}_{4}$. The active materials are responsible for the reversible electrical/chemical energy conversion. Representative half/full reactions are displayed below. New materials are constantly explored and optimized to improve both the cell voltage and energy density. ${ }^{2}$

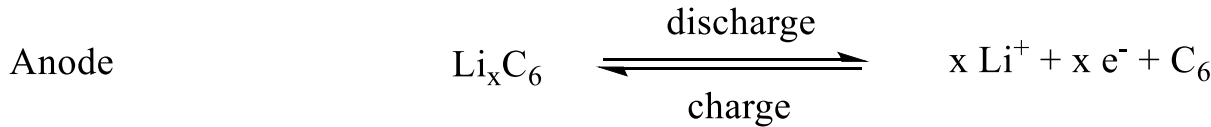

$$
\begin{aligned}
& \text { Cathode } \mathrm{xLi}^{+}+\mathrm{xe}^{-}+\mathrm{Li}_{1-\mathrm{x}} \mathrm{MO}_{2} \stackrel{\text { discharge }}{\stackrel{\text { charge }}{\rightleftharpoons}} \mathrm{LiMO}_{2} \\
& \text { Total reaction } \mathrm{Li}_{\mathrm{x}} \mathrm{C}_{6}+\mathrm{Li}_{1-\mathrm{x}} \mathrm{MO}_{2} \stackrel{\text { discharge }}{\stackrel{\text { charge }}{\rightleftharpoons}} \mathrm{C}_{6}+\mathrm{LiMO}_{2}
\end{aligned}
$$


Both anode and cathode active materials are porous to improve the rate performance. Binders ensure the mechanical integrity of the active materials and the conductive carbon improves the electronic contact of the active materials with the current collectors. The separator electronically insulates the cathode and anode from short circuit, while facilitating sufficient ionic conductivity. Organic carbonate based electrolytes with $\mathrm{LiPF}_{6}$ exhibit large electrochemical windows compatible with the working potential of the anode/ cathode and conduct lithium ions at high rates. ${ }^{3}$

\section{STATEMENT OF THE PROBLEM AND PROPOSED SOLUTIONS}

Organic carbonates are the primary solvents used in lithium-ion battery electrolytes along with electrolyte additives. The reversibility of current lithium-ion batteries is dependent upon the electrolyte used in the batteries. ${ }^{4}$ During the initial charging cycles of the cell a solid electrolyte interface (SEI) is formed by reduction of organic carbonates, electrolyte salts and/or electrolyte additives on the surface of the graphitic anode in lithium-ion batteries. The generation of a stable anode SEI prevents continuous electrolyte reduction on the surface of the anode. The SEI functions as a $\mathrm{Li}$ ion conductor but an electrical insulator. ${ }^{3}$

The reduction reactions of carbonates on the graphitic anode surface have been investigated for many years. Initially a single two electron reduction mechanism of propylene carbonate to generate $\mathrm{Li}_{2} \mathrm{CO}_{3}$ and propylene was proposed, ${ }^{5}$ later Aurbach and co-workers proposed two sequential one electron reduction reactions of cyclic carbonates to generate lithium alkyl carbonates and alkenes. ${ }^{6}$ Numerous other researchers have investigated the composition of the SEI on graphitic anodes in lithium

ion batteries. ${ }^{7-17}$ In addition to lithium alkyl carbonates and lithium carbonate, the SEI 
has been proposed to contain a complicated mixture of products including lithium oxalate, lithium alkoxides, and lithium oxide from the carbonate solvents and $\mathrm{LiF}$ and lithium fluorophosphates from the reduction of $\mathrm{LiPF}_{6}{ }^{7-17}$ Similar ambiguity exists about the components of SEI formed from electrolyte additives and other electrolyte salts. Capacity fade at elevated temperature is connected to the exothermic reactions between lithium alkyl carbonates and $\mathrm{LiPF}_{6} .{ }^{16,18}$ While the relationship between capacity fade and SEI instability is clear, ${ }^{16,18,19}$ the characterization of SEI component decomposition is complicated by the presence of many different components. Despite the extensive investigations, the structure, formation mechanisms, and the evolution of the SEI are poorly understood. Mechanistic understanding of the formation and evolution of the SEI components is essential for the development of safer lithium-ion batteries with wider operating temperature range.

The research presented in this thesis focuses on investigating lithium naphthalenide, a well-known one electron reducing agent, as a model compound for the lithiated graphite surface. Various carbonate solvents, electrolyte salts, and additives have been reduced with lithium naphthalenide, generating SEI components in largescale. Ability to generate the SEI components from isolated sources and in large scale facilitate robust characterization and deduction of formation mechanisms. Large-scale decomposition of three major SEI components (lithium carbonate, lithium methyl carbonate, and lithium ethylene dicarbonate) in isolation with simplified electrolyte at elevated temperature is investigated. The products are analyzed by a combination of solution Nuclear Magnetic Resonance (NMR) Spectroscopy and Infra-Red spectroscopy with Attenuated Total Reflectance (IR-ATR), X-ray Photoelectron 
Spectroscopy (XPS) and Gas Chromatography with Mass Selective detection (GC-MS).

The results provide significant insights into the formation and decomposition mechanism of the anode SEI.

\section{REFERENCES}

(1) Tarascon, J.-M.; Armand, M. Issues and Challenges Facing Rechargeable Lithium Batteries. Nature 2001, 414, 359-367.

(2) Whittingham, M. S. Ultimate Limits to Intercalation Reactions for Lithium Batteries. Chem. Rev. 2014, 114, 11414-11443.

(3) $\mathrm{Xu}, \mathrm{K}$. Nonaqueous Liquid Electrolytes for Lithium-Based Rechargeable Batteries. Chem. Rev. 2004, 104, 4303-4418.

(4) Fong, R. Studies of Lithium Intercalation into Carbons Using Nonaqueous Electrochemical Cells. J. Electrochem. Soc. 1990, 137, 2009.

(5) Dey, A. N.; Sullivan, B. P. The Electrochemical Decomposition of Propylene Carbonate on Graphite. J. Electrochem. Soc. 1970, 117, 222-224.

(6) Aurbach, D.; Daroux, M. L.; Faguy, P. W.; Yeager, E. Identification of Surface Films Formed on Lithium in Propylene Carbonate Solutions. J. Electrochem. Soc. 1987, 134, 1611-1620.

(7) Ein-Eli, Y. A New Perspective on the Formation and Structure of the Solid Electrolyte Interface at the Graphite Anode of Li-Ion Cells. Electrochem. solidstate Lett. 1999, 2, 212-214.

(8) Zhuang, G. V; Ross, P. N. Analysis of the Chemical Composition of the Passive Film on Li-Ion Battery Anodes Using Attentuated Total Reflection Infrared Spectroscopy. Electrochem. Solid-State Lett. 2003, 6, A136--A139. 
(9) Xu, K.; Zhuang, G. V; Allen, J. L.; Lee, U.; Zhang, S. S.; Ross, P. N.; Jow, T. R. Syntheses and Characterization of Lithium Alkyl Mono-and Dicarbonates as Components of Surface Films in Li-Ion Batteries. J. Phys. Chem. B 2006, 110, $7708-7719$.

(10) Gireaud, L.; Grugeon, S.; Laruelle, S.; Pilard, S.; Tarascon, J.-M. Identification of Li Battery Electrolyte Degradation Products through Direct Synthesis and Characterization of Alkyl Carbonate Salts. J. Electrochem. Soc. 2005, 152, A850--A857.

(11) Laruelle, S.; Pilard, S.; Guenot, P.; Grugeon, S.; Tarascon, J.-M. Identification of Li-Based Electrolyte Degradation Products through DEI and ESI HighResolution Mass Spectrometry. J. Electrochem. Soc. 2004, 151, A1202--A1209.

(12) Verma, P.; Maire, P.; Novák, P. A Review of the Features and Analyses of the Solid Electrolyte Interphase in Li-Ion Batteries. Electrochim. Acta 2010, 55, $6332-6341$.

(13) Peled, E. The Electrochemical Behavior of Alkali and Alkaline Earth Metals in Nonaqueous Battery Systems the Solid Electrolyte Interphase Model. J. Electrochem. Soc. 1979, 126, 2047-2051.

(14) Aurbach, D. Review of Selected Electrode--Solution Interactions Which Determine the Performance of Li and Li Ion Batteries. J. Power Sources 2000, $89,206-218$.

(15) Winter, M. The Solid Electrolyte Interphase--the Most Important and the Least Understood Solid Electrolyte in Rechargeable Li Batteries. Zeitschrift für Phys. Chemie Int. J. Res. Phys. Chem. Chem. Phys. 2009, 223, 1395-1406. 
(16) Herstedt, M.; Abraham, D. P.; Kerr, J. B.; Edström, K. X-Ray Photoelectron Spectroscopy of Negative Electrodes from High-Power Lithium-Ion Cells Showing Various Levels of Power Fade. Electrochim. Acta 2004, 49, 5097-5110.

(17) Zhuang, G. V; Xu, K.; Yang, H.; Jow, T. R.; Ross, P. N. Lithium Ethylene Dicarbonate Identified as the Primary Product of Chemical and Electrochemical Reduction of EC in 1.2 M LiPF6/EC: EMC Electrolyte. J. Phys. Chem. B 2005, $109,17567-17573$.

(18) Ryou, M.-H.; Lee, J.-N.; Lee, D. J.; Kim, W.-K.; Jeong, Y. K.; Choi, J. W.; Park, J.-K.; Lee, Y. M. Effects of Lithium Salts on Thermal Stabilities of Lithium Alkyl Carbonates in SEI Layer. Electrochim. Acta 2012, 83, 259-263.

(19) Guéguen, A.; Streich, D.; He, M.; Mendez, M.; Chesneau, F. F.; Novák, P.; Berg, E. J. Decomposition of LiPF6 in High Energy Lithium-Ion Batteries Studied with Online Electrochemical Mass Spectrometry. J. Electrochem. Soc. 2016, 163, A1095--A1100. 


\section{CHAPTER 2 - REDUCTION REACTIONS OF CARBONATE SOLVENTS FOR LITHIUM ION BATTERIES}

Daniel M. Seo, Dinesh Chalasani, Bharathy S. Parimalam, Rahul Kadam, Mengyun Nie and Brett L. Lucht

Department of Chemistry, University of Rhode Island, Kingston, RI 02881

The following is published in the ECS Electrochemistry Letters, and is presented here in manuscript format. 


\begin{abstract}
Lithium naphthalenide has been investigated as a one electron reducing agent for organic carbonates solvents used in lithium ion battery electrolytes. The reaction precipitates have been analyzed by IR-ATR and solution NMR spectroscopy and the evolved gases have been analyzed by GC-MS. The reduction products of ethylene carbonate and propylene carbonate are lithium ethylene dicarbonate and ethylene and lithium propylene dicarbonate and propylene, respectively. The reduction products of diethyl and dimethyl carbonate are lithium ethyl carbonate and ethane and lithium methyl carbonate and methane, respectively. Lithium carbonate is not observed as a reduction product.
\end{abstract}




\section{INTRODUCTION}

Organic carbonates are the primary solvents used in lithium-ion battery electrolytes. The reversibility of current lithium-ion batteries is dependent upon the electrolyte used in the batteries. ${ }^{1}$ During the initial charging cycles of the cell a solid electrolyte interface (SEI) is formed by reduction of organic carbonates on the surface of the graphitic anode in lithium-ion batteries. The generation of a stable anode SEI prevents continuous electrolyte reduction on the surface of the anode. The SEI functions as a Li ion conductor but an electrical insulator. ${ }^{2}$ Understanding the mechanisms of the reduction reactions of organic carbonates along with the products of the reactions which result in the generation of the SEI is essential for the development of better lithium-ion batteries.

The reduction reactions of carbonates on the graphitic anode surface have been investigated for many years. Initially a single two electron reduction mechanism of propylene carbonate to generate $\mathrm{Li}_{2} \mathrm{CO}_{3}$ and propylene was proposed, ${ }^{3}$ later Aurbach and co-workers proposed two sequential one electron reduction reactions of cyclic carbonates to generate lithium alkyl carbonates and alkenes. ${ }^{4}$ Numerous other researchers have investigated the composition of the SEI on graphitic anodes in lithium ion batteries. ${ }^{5-15}$ In addition to lithium alkyl carbonates and lithium carbonate, the SEI has been proposed to contain a complicated mixture of products including lithium oxalate, lithium alkoxides, and lithium oxide from the carbonate solvents and $\mathrm{LiF}$ and lithium fluorophosphates from the reduction of $\mathrm{LiPF}_{6}{ }^{5-15}$ Despite the extensive investigations, the structure and formation mechanisms of the SEI are poorly understood. 
A detailed analysis of binder free graphitic anodes cycled in simplified electrolytes composed of a single carbonate solvent and $\mathrm{LiPF}_{6}$ has been reported. ${ }^{16,17}$ These investigations suggest that the initial reduction reaction of the carbonates generate lithium alkyl carbonates and $\mathrm{LiF}$ as the predominant components of the anode SEI. As an expansion of these investigations, lithium naphthalenide, a well-known one electron reducing agent, has been investigated as a model compound for the lithiated graphite surface. Various carbonate solvents including ethylene carbonate (EC), propylene carbonate (PC), diethyl carbonate (DEC), and dimethyl carbonate (DMC) have been reduced with lithium naphthalenide. All reactions result in precipitation and gas evolution. The precipitates have been analyzed by solution Nuclear Magnetic Resonance (NMR) Spectroscopy and Infra-Red spectroscopy with Attenuated Total Reflectance (IR-ATR). The evolved gasses have been analyzed by Gas Chromatography with Mass Selective detection (GC-MS). The results provide insight into the formation mechanism and structure of the anode SEI.

\section{EXPERIMENTAL}

All reagents were used without further purification. Reagents and solvents were purchased from Sigma-Aldrich. Battery grade EC, PC, DMC and DEC are obtained from BASF. All the reactions and purifications are performed in a nitrogen filled glovebox. The Li-naphthalenide reduction reactions with carbonate solvents utilizes procedures as previously reported. ${ }^{16}$ The solids were dissolved in deuterium oxide $\left(\mathrm{D}_{2} \mathrm{O}\right.$, $99.96 \%$ from sealed vial) in an Ar glovebox and ${ }^{1} \mathrm{H}$ and ${ }^{13} \mathrm{C}$ NMR spectra of the solutions were acquired on a Bruker $300 \mathrm{MHz}$ spectrometer. Residual $\mathrm{H}_{2} \mathrm{O}$ is used for a reference at $4.8 \mathrm{ppm}$. The Infrared (IR-ATR) spectra of the solids were acquired in 
attenuated total reflection mode on a Bruker tensor 27 instrument equipped with germanium crystal. The gas analysis is performed by evacuating the head space of the reaction flask. The evolved gases are analyzed using a $2.5 \mathrm{~mL}$ gas tight GC syringe on Thermo trace GC-Ultra equipped with mass selective detector-ISQ. The mass spectra were compared with NIST library.

\section{RESULTS AND DISCUSSION}

\section{NMR Spectra Of Precipitates}

The molecular structures of the precipitates formed in the reaction between lithium naphthalenide and various carbonates are analyzed via a combination of ${ }^{1} \mathrm{H},{ }^{13} \mathrm{C}$ NMR and IR-ATR spectroscopy. As previously reported, the ${ }^{1} \mathrm{H}$ NMR spectrum of the reduction product of EC contains a singlet at $3.6 \mathrm{ppm}$ characteristic of $\left(-\mathrm{OCH}_{2} \mathrm{CH}_{2} \mathrm{O}-\right)$ and peaks at 62.5 and $161.1 \mathrm{ppm}$ in the ${ }^{13} \mathrm{C}$ NMR spectrum, characteristic of $\left(-\mathrm{CH}_{2} \mathrm{O}-\right)$ and a $\mathrm{C}=\mathrm{O}$, respectively (Figure 2.1).${ }^{16}$ The resonances match those previously reported for lithium ethylene dicarbonate (LEDC). ${ }^{7}$ The reaction produces LEDC in high yield $95 \%$, and no other products are observed. The ${ }^{1} \mathrm{H}$ and ${ }^{13} \mathrm{C}$ NMR spectra of the precipitate formed by the reaction of lithium naphthalenide with PC is provided in Figure 2.1. The ${ }^{1} \mathrm{H}$ NMR spectrum contains a doublet at $1.1 \mathrm{ppm}$ characteristic of a $\mathrm{CH}_{3}$ coupled to a single proton and multiplet at $3.4 \mathrm{ppm}$ characteristic of a $\mathrm{CH}_{2}$ and a second multiplet at $3.8 \mathrm{ppm}$ characteristic of a $\mathrm{CH}$. The ${ }^{13} \mathrm{C}$ NMR spectrum contains four peaks located at 18.7, 67.3, 68.6 and $163.5 \mathrm{ppm}$ which are characteristic of a $\mathrm{CH}_{3}$, $\mathrm{CH}_{2}, \mathrm{CH}$ and $\mathrm{C}=\mathrm{O}$, respectively. The peaks are consistent with those previously reported for independently prepared lithium propylene dicarbonate (LPDC). ${ }^{7}$ The LPDC is isolated in a similarly high yield $\sim 75 \%$. 
In addition to analysis of the reduction products of cyclic carbonates, the reduction of dialkyl carbonates has been investigated. The ${ }^{1} \mathrm{H}$ NMR spectra of the reaction product of the Lithium naphthalenide reduction of DMC is provided in Figure 2.1. A single ${ }^{1} \mathrm{H}$ NMR signal is observed at $3.3 \mathrm{ppm}$ consistent with $\mathrm{OCH}_{3}$. The corresponding ${ }^{13} \mathrm{C}$ NMR spectrum (Figure 2.1) contains two signals at 48.5 and 159.9 ppm characteristic of $\mathrm{OCH}_{3}$ and $\mathrm{C}=\mathrm{O}$, respectively. The spectra match those previously reported for lithium methyl carbonate (LMC). ${ }^{7}$ The ${ }^{1} \mathrm{H}$ NMR spectrum of the precipitate formed in reaction between Lithium naphthalenide and DEC contains a triplet at 1.1 ppm and a quartet at $3.5 \mathrm{ppm}$ characteristic of $\mathrm{OCH}_{2} \mathrm{CH}_{3}$ (Figure 2.1), while the ${ }^{13} \mathrm{C}$ NMR spectrum contains three resonances at 18.73, 69.04 and $154.26 \mathrm{ppm}$ consistent with the presence of $\mathrm{OCH}_{2} \mathrm{CH}_{3}$ and $\mathrm{C}=\mathrm{O}$. Again, the spectra match those previously reported for lithium ethyl carbonate (LEC). ${ }^{7}$

The NMR spectra of the carbonate reduction products also contain residual solvent, THF or $\mathrm{Et}_{2} \mathrm{O}$, from the reaction and purification process. While, complete removal of the solvent and increasing the purity of the lithium alkyl carbonates, has been attempted, the lithium alkyl carbonates have poor stability under the purification conditions and decompose to generate $\mathrm{Li}_{2} \mathrm{CO}_{3}$ and lithium alkoxides. This is primarily evidenced by the loss of the $\mathrm{C}=\mathrm{O}$ peaks of the lithium alkyl carbonates (154-163 ppm) and the appearance of the $\mathrm{Li}_{2} \mathrm{CO}_{3}$ at $168.1 \mathrm{ppm}$. Interestingly, in initial reduction product exclusively contains the lithium alkyl carbonates with no observed lithium carbonate. This suggests that the observation of $\mathrm{Li}_{2} \mathrm{CO}_{3}$ on the surface of graphite anodes in lithium ion batteries results from the thermal, Lewis base catalyzed, or Lewis acid catalyzed decomposition of the initially formed lithium alkyl carbonates. It is also 
surprising, that despite the sensitivity to decomposition, when lithium alkyl carbonates are dissolved in $\mathrm{D}_{2} \mathrm{O}$ freshly opened from a sealed ampoule in an Argon filled glove box and stored in a sealed NMR tube, the lithium alkyl carbonates are stable for several days. This suggests that the lithium alkyl carbonates are sensitive to trace Lewis basic or Lewis acidic impurities which initiate decomposition, but relatively stable in pure oxygen free water.

\section{FTIR Analysis of Precipitates}

FTIR spectra of the precipitates formed during the lithium naphthalenide reduction of carbonate solvents are provided in Figure 2.2. All of the IR spectra contain an absorption at $\sim 1650 \mathrm{~cm}^{-1}$ characteristic of $\mathrm{LiOCO}_{2} \mathrm{R}$ in lithium alkyl carbonates. The remaining spectral features of the products match the independently prepared lithium alkyl carbonates, (LEDC, LPDC, LMC, and LEC), as previously reported. ${ }^{7}$ In addition to the peaks characteristic of lithium alkyl carbonates, a weak absorption is observed at

$\sim 1450 \mathrm{~cm}^{-1}$ characteristic of $\mathrm{Li}_{2} \mathrm{CO}_{3}$. While there appears to be some $\mathrm{Li}_{2} \mathrm{CO}_{3}$ present in all spectra, lithium alkyl carbonates decompose to form $\mathrm{Li}_{2} \mathrm{CO}_{3}$, as discussed above. Thus, the thermal, Lewis acid, or Lewis Base catalyzed decomposition of lithium alkyl carbonates is the most likely source of $\mathrm{Li}_{2} \mathrm{CO}_{3}$ since $\mathrm{Li}_{2} \mathrm{CO}_{3}$ is not observed in the ${ }^{13} \mathrm{C}$ NMR spectra of fresh reduction products. In addition, all of the samples have increases in the intensity of the absorption of $\mathrm{Li}_{2} \mathrm{CO}_{3}$ upon exposure to air.

\section{GC-MS ANALYSIS OF GASES}

Upon reaction of lithium naphthalenide with carbonates. significant gas evolution is observed. The gases evolved during reaction were analyzed by GC-MS. Analysis of the evolved gas during the reduction of EC confirms that the gas produced 
is ethylene. Reaction of PC results in similar gas evolution and the gaseous product is propylene. The two cyclic carbonates have very similar reaction mechanisms which are consistent with those originally proposed by Aurbach and co-workers. ${ }^{4}$ The reduction follows two sequential single electron transfer reactions (Scheme 2.1). The first electron generates a radical anion, the second electron generates lithium alkylene dicarbonates and an alkene.

Related gas evolution was observed for the dialkyl carbonates DMC and DEC. However, instead of observing alkenes as the gaseous reduction products, alkanes are observed. The observed gaseous products are methane and ethane for DMC and DEC, respectively. The reduction reaction of the dialkyl carbonates is related to the cyclic carbonates (Scheme 2.1). The first electron generates a lithium alkyl carbonate and an alkyl radical. The next step of the reaction is unclear. The alkyl radical may abstract $\mathrm{H} \cdot$ or a second electron could result in the generation of a carbanion $\left(\mathrm{R}:^{-}\right)$which reacts with residual acidic species to yield an alkane. All of the observed gasses have been previously characterized as gasses evolved during the initial formation cycles of lithium ion batteries. ${ }^{18}$

\section{CONCLUSIONS}

A combination of NMR and IR spectral data of the reaction precipitates and the GC-MS analysis of the gaseous products affords the development of reduction mechanisms for the cyclic and dialkyl carbonates (Scheme 2.1). The reduction reactions of the cyclic carbonates result in the generation of lithium alkylene dicarbonates and an alkene while the reduction reactions of dialkyl carbonates generate lithium alkyl carbonates and an alkane. The mechanisms are consistent with those proposed by 
Aurbach and co-workers. ${ }^{4}$ There is no evidence for the generation of either $\mathrm{Li}_{2} \mathrm{CO}_{3}$ or $\mathrm{CO}_{2}$ during the initial reduction reactions. It is well known that the anode SEI changes upon additional cycling and thermal abuse. ${ }^{14}$ One component of these changes is likely the thermal, Lewis acid or Lewis base catalyzed decomposition of lithium alkyl carbonates. Significant efforts were expended attempting to investigate the thermal decomposition mechanisms of lithium alkyl carbonates prepared via lithium naphthalenide reduction reactions. Unfortunately, due to the extreme sensitivity of the lithium alkyl carbonates to trace Lewis acidic or Lewis basic impurities, a systematically investigation of the decomposition mechanism was precluded. The thermal, base, or acid catalyzed decomposition of lithium alkyl carbonates results in the generation of $\mathrm{Li}_{2} \mathrm{CO}_{3}, \mathrm{CO}_{2}$, and lithium alkoxides. These decomposition reactions occur within lithium ion cells upon additional cycling especially at elevated temperature or in the presence of trace water. However, the decomposition reactions can also occur during ex-situ analysis of cycled electrodes.

\section{ACKNOWLEDGEMENT}

The authors gratefully acknowledge funding from Department of Energy Office of Basic Energy Sciences EPSCoR Implementation award (DE-SC0007074). 


\section{REFERENCES}

1. R. Frong, U. von Sacken and J. R. Dahn, J. Electrochem. Soc. 137(7), 2009 (1990).

2. K. Xu, Chem. Rev. 104, 4303 (2004).

3. A. N. Dey and B. P. Sullivan, J. Electrochem. Soc. 117(2), 219 (1970).

4. D. Aurbach, M. L. Daroux, P. W. Faguy and E. J. Yeager, J. Electrochem. Soc. 134(7), 1611 (1987).

5. Y. Ein-Eli, Electrochem. Solid-State Lett. 2, 212 (1999).

6. G. V. Zhuang and P. N. Ross, Electrochem. Solid-State Lett. 6, A136 (2003).

7. K. Xu, G. V. Zhuang, J. L. Allen, U. Lee, S. S. Zhang, P. N. Ross and T. R. Jow, J. Phys. Chem. B 110, 7708 (2006).

8. L. Gireaud, S. Grugeon, S. Laruelle, S. Pillard and J.-M. Tarascon, J. Electrochem. Soc. 152(5), A850 (2005).

9. S. Laruelle, S. Pilard, L. Guenot, S. Grugeon and J.-M. Tarascona, J. Electrochem. Soc. 151(6), A1209 (2004).

10. P. Verma, P. Maire and P. Novak, Electrochim. Acta. 55, 6332 (2010).

11. E. Peled, J. Electrochem. Soc. 126(12), 2047 (1979).

12. D. Aurbach, J. Power Sources 89(2), 206 (2000).

13. M. Winter, Z. Phy. Chem. 223, 1395 (2009).

14. M. Herstedt, D. P. Abraham, J. B. Kerr and K. Edstrom, Electrochem. Acta 49, 5097 (2004).

15. G. V. Zhuang, K. Xu, H. Yang, T. R. Jow and P. N. Ross, J. Phys. Chem. B 109, 17567 (2005). 
16. M. Nie, D. Chalasani, D. P. Abraham, Y. Chen, A. Bose and B. L. Lucht J. Phys. Chem. C. 117, 1257 (2013).

17. M. Nie, D. P. Abraham, D. M. Seo, Y. Chen, A. Bose and B. L. Lucht J. Phys. Chem. C. $117,25381(2013)$.

18. M. Onuki, S. Kinoshita, Y. Sakata, M. Yanagidate, Y. Otake, M. Ue and M. Deguchi, J. Electrochem. Soc. 155, A794 (2008). 


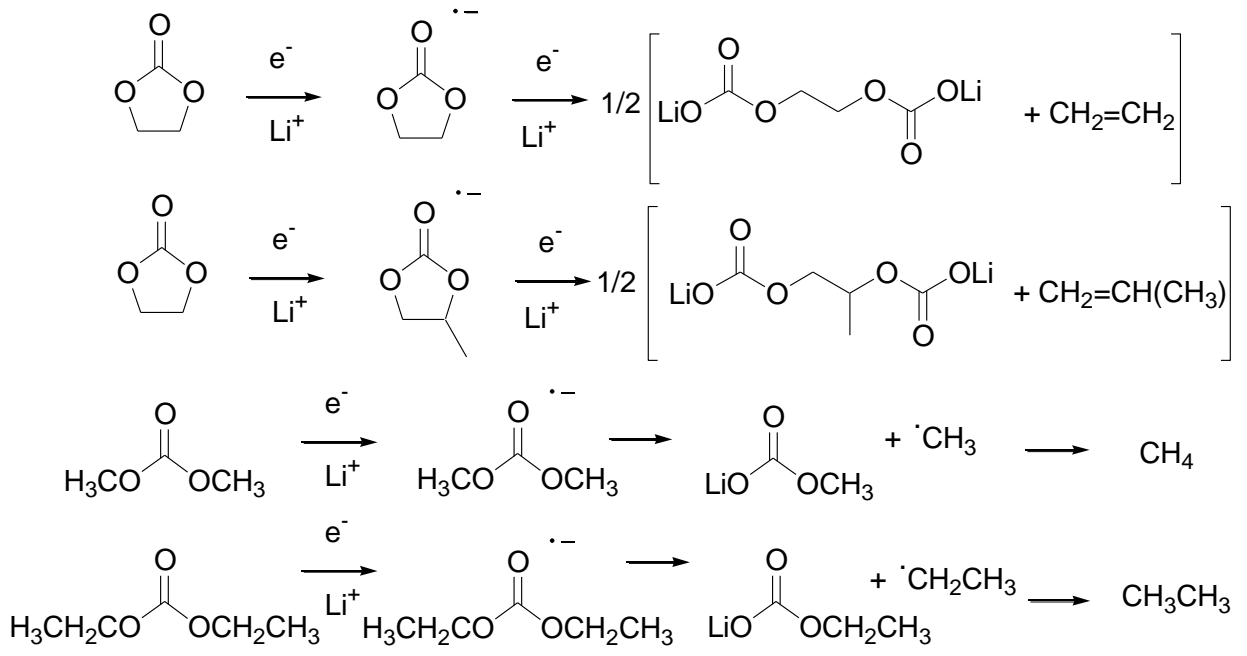

Scheme 2.1 Reduction mechanisms of EC, PC, DMC and DEC. 

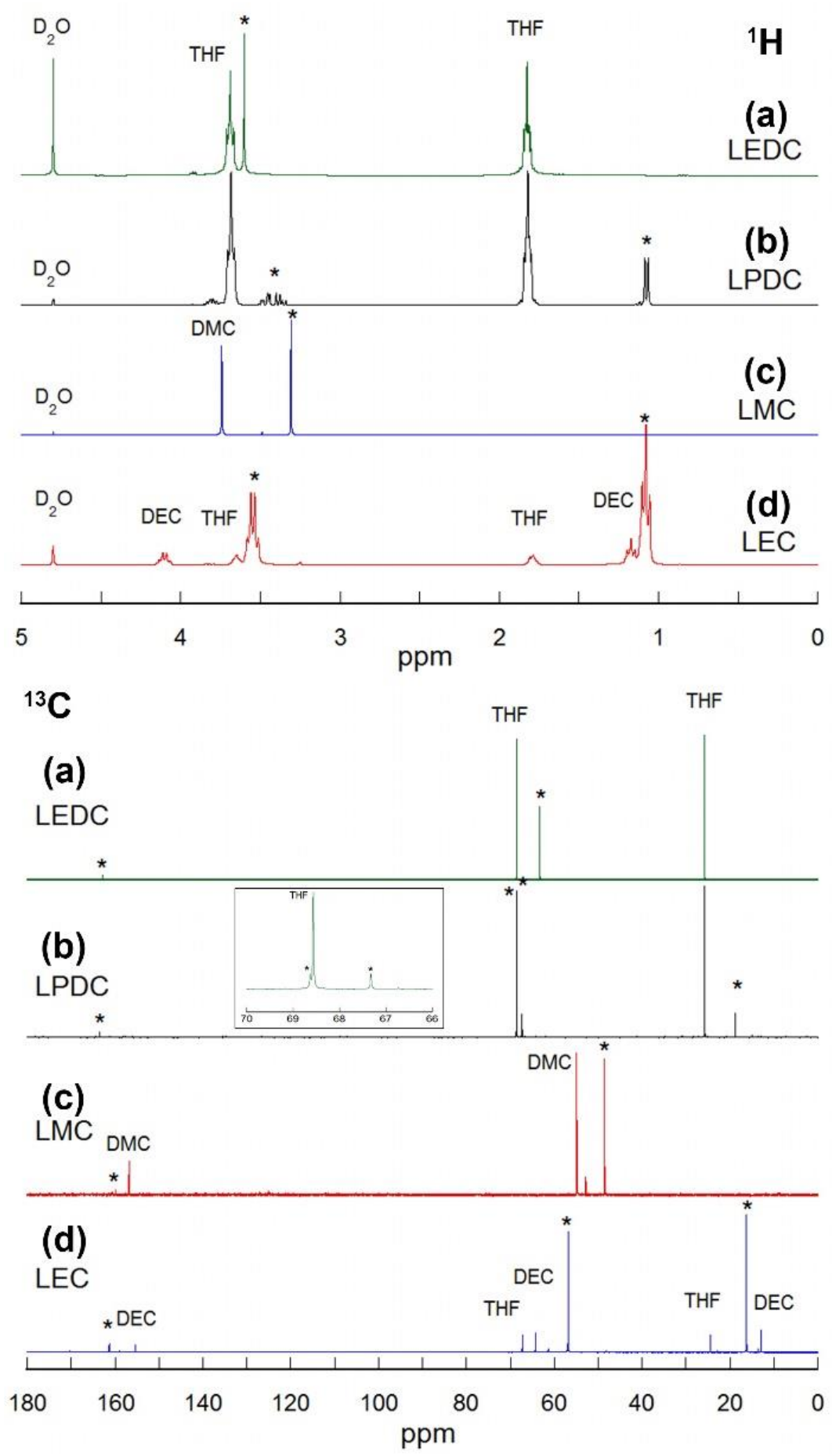

Figure 2.1. ${ }^{1} \mathrm{H}$ NMR (top) and ${ }^{13} \mathrm{C}$ NMR (bottom) spectra of precipitates from the reaction of lithium naphthalenide with carbonate solvents: (a) EC, (b) PC, (c) DMC and (d) DEC. (asterisk mark '*' indicates main product.) 


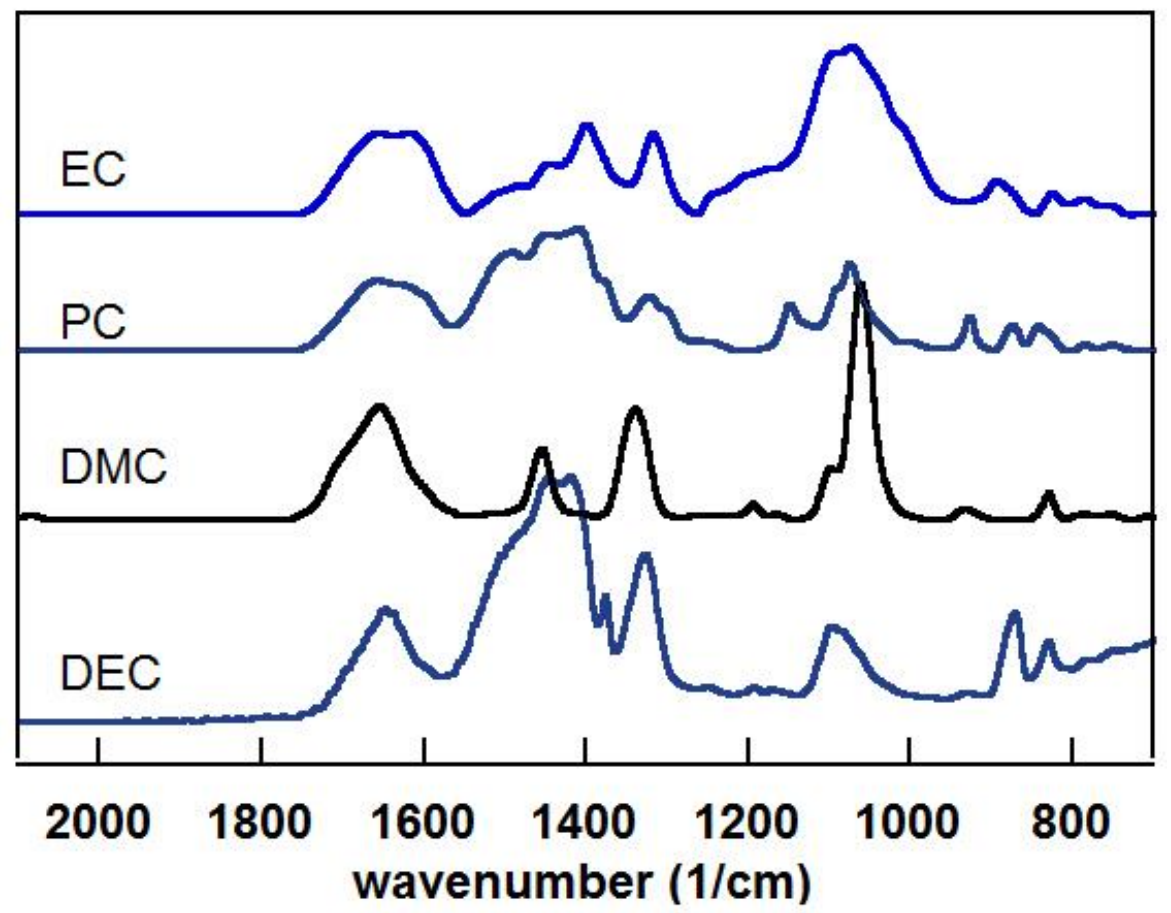

Figure 2.2. FTIR spectra of the precipitates of the lithium naphthalenide reduction of carbonates. 


\title{
CHAPTER 3 - FLUOROETHYLENE CARBONATE AND VINYLENE CARBONATE REDUCTION: UNDERSTANDING LITHIUM-ION BATTERY ELECTROLYTE ADDITIVES AND SOLID ELECTROLYTE INTERPHASE FORMATION
}

\author{
Alison L. Michan, ${ }^{\dagger}$ Bharathy. S. Parimalam, ${ }^{+}$Michal Leskes,${ }^{\dagger}$ Rachel N. Kerber,${ }^{\dagger}$ \\ Taeho Yoon, Clare P. Grey, ${ }^{\prime}$ and Brett L. Lucht ${ }^{*, t}$ \\ ${ }^{\dagger}$ Department of Chemistry, University of Cambridge, Lensfield Road, Cambridge, CB2 \\ IEW, United Kingdom \\ $¥$ Department of Chemistry, University of Rhode Island, Kingston, Rhode Island \\ 02881, United States
}

The following is published in the journal, Chemistry of Materials, and is presented here in manuscript format. 


\section{ABSTRACT}

We have synthesized the products of fluoroethylene carbonate (FEC) and vinylene carbonate (VC) via lithium naphthalenide reduction. By analyzing the resulting solid precipitates and gas evolution, our results confirm that both FEC and VC decomposition products include $\mathrm{HCO}_{2} \mathrm{Li}, \mathrm{Li}_{2} \mathrm{C}_{2} \mathrm{O}_{4}, \mathrm{Li}_{2} \mathrm{CO}_{3}$, and polymerized VC. For FEC, our experimental data supports a reduction mechanism where FEC reduces to form $\mathrm{VC}$ and $\mathrm{LiF}$, followed by subsequent $\mathrm{VC}$ reduction. In the $\mathrm{FEC}$ reduction product, $\mathrm{HCO}_{2} \mathrm{Li}$, $\mathrm{Li}_{2} \mathrm{C}_{2} \mathrm{O}_{4}$, and $\mathrm{Li}_{2} \mathrm{CO}_{3}$ were found in smaller quantities than in the $\mathrm{VC}$ reduction product, with no additional fluorine environments being detected by solid-state nuclear magnetic resonance or X-ray photoelectron spectroscopy analysis. With these additives being practically used in higher (FEC) and lower (VC) concentrations in the base electrolytes of lithium-ion batteries, our results suggest that the different relative ratios of the inorganic and organic reduction products formed by their decomposition may be relevant to the chemical composition and morphology of the solid electrolyte interphase formed in their presence.

\section{INTRODUCTION}

Additives are widely used to improve performance of Li-ion batteries, offering an economically viable method of performance enhancement compatible with existing manufacturing infrastructure. ${ }^{1}$ Generally, the function of additives is sacrificial: they are reduced at different voltage potentials compared to the base electrolytes to which they are added, forming decomposition products that are incorporated into a protective layer

on electrodes. ${ }^{1-5}$ This protective layer is called the solid electrolyte interphase (SEI). ${ }^{6,7}$ The formation of a stable SEI is essential for all Li-ion batteries, preventing further 
electrolyte decomposition, thereby underlying capacity retention. ${ }^{1,5-8}$ The SEI also represents an electronically insulating barrier between the electrodes and electrolyte, with its composition, thickness, and structure influencing the lithium transport across the interphase. ${ }^{9,10}$ The performance enhancement achieved by the use of additives in the base electrolyte of Li-ion batteries is therefore linked to the chemical species formed in their decomposition which are incorporated into the SEI. A fundamental understanding of how specific additives improve and alter the SEI would allow further insight into favorable SEI properties.

Two additives that have been widely studied include fluoroethylene carbonate (FEC) and vinylene carbonate (VC). These additives have been used with electrode materials including $\mathrm{Si}$, improving capacity retention. ${ }^{5,11-18}$ Although it is widely accepted that these additives improve performance, there remains some debate regarding their decomposition mechanisms and the resulting SEI. It is believed that one key aspect of their favorable SEI formation is due to their decomposition into semicarbonate or organic species. ${ }^{1,4,19-23}$ Theoretical predictions indicate FEC and VC may yield very similar reduction products, ${ }^{24-26}$ and a key difference between these additives is thought to relate to $\mathrm{LiF}$ as a major species in the presence of FEC..$^{13,27,28}$ The typical concentrations used to achieve performance enhancement differ, with VC used in lower concentrations of approximately $2-5 \%$ compared with FEC that can be used in higher concentrations up to $50 \%$. $^{1,5,16,18,29}$

Practically, the SEI layer is extremely air-sensitive. ${ }^{30,31}$ Moreover, with a thickness of less than $100 \mathrm{~nm}$, it is very difficult to study experimentally. Here, our strategy is to synthesize the reduction products of FEC and VC in order to 
experimentally confirm their reduction products. Lithium naphthalenide (Li-Nap), a well-known reducing agent, is known to react with solvents in a similar manner to those which may occur on lithiated anodes. ${ }^{32}$ It is used here to reduce FEC and VC, modeling a reduction process in a similar manner to that which may occur in a lithium-ion battery. Solid products are analyzed with X-ray photoelectron spectroscopy (XPS), solid-state NMR (ssNMR), and Fourier transform infrared spectroscopy (FTIR). Gas evolution is monitored using gas chromatography mass spectrometry (GC-MS). The many techniques provide chemical signatures for future work. Viable reactions to form the detected decomposition products are proposed. For FEC, we propose a reduction scheme where FEC reduces to form $\mathrm{LiF}$ and $\mathrm{VC}$, followed by further reduction of $\mathrm{VC}$ to polymerized $\mathrm{VC}(\operatorname{poly}(\mathrm{VC}))$. The poly $(\mathrm{VC})$ contains repeating $\mathrm{EC}$ units joined by cross-linking sites; our analysis shows no evidence for $\mathrm{F}-\mathrm{C}$ bonds in the polymer. $\mathrm{HCO}_{2} \mathrm{Li}, \mathrm{Li}_{2} \mathrm{C}_{2} \mathrm{O}_{4}$, and $\mathrm{Li}_{2} \mathrm{CO}_{3}$ are also found in small quantities. For $\mathrm{VC}$, we detect lithium environments of $\mathrm{HCO}_{2} \mathrm{Li}, \mathrm{Li}_{2} \mathrm{C}_{2} \mathrm{O}_{4}$, and $\mathrm{Li}_{2} \mathrm{CO}_{3}$, in addition to poly(VC).

\section{METHODS}

Synthesis. All reagents were used as obtained, without further purification. Batterygrade VC and FEC were obtained from BASF. Naphthalene $\left(99^{+} \%\right.$, Scintillation grade) and THF (Anhydrous, 99.9\%) were purchased from Acros organics. Lithium discs were obtained from MTI Corporation. Preparation of the reducing agent and the reduction reaction were carried out inside a nitrogen-filled glovebox. Li-Nap $(0.546 \mathrm{M})$ solution in THF was prepared with 10 mol \% excess naphthalene. Lithium foils were added to naphthalene solution of THF and stirred overnight at room temperature. The solution 
turned green in a few minutes after the addition of lithium metal and became dark green after stirring overnight.

$1.52 \mathrm{~g}$ of FEC was reduced with $1 \mathrm{~mol}$ equiv of Li-Nap. The solution turned yellowish brown immediately and was left stirring overnight. The overhead gas was analyzed using GCMS. Precipitate was separated with centrifugal separation and washed with diethyl ether. It was further dried under vacuum overnight at room temperature and produced $1.44 \mathrm{~g}$ of light yellow powder.

$1.24 \mathrm{~g}$ of VC was reduced with 1 mol equiv of Li-Nap. The solution turned dark brown immediately and was left stirring overnight. The overhead gas was analyzed using GC-MS. Precipitate was separated with centrifugal separation and washed with diethyl ether. It was further dried under vacuum overnight at room temperature and produced $1.50 \mathrm{~g}$ of brown powder. The synthesis was performed using both deuterated and nondeuterated naphthalene yielding two sets of samples.

XPS. XPS spectra of the dried precipitates were acquired using a thermo scientific $\mathrm{K}$ alpha XPS instrument. Samples were made into circular pellets with a press and transferred from the glovebox to the XPS chamber using a vacuum transfer module without exposure to air. $\mathrm{C} 1 \mathrm{~s}, \mathrm{O} 1 \mathrm{~s}$, and $\mathrm{Li} 1 \mathrm{~s}$ spectra were obtained from the VC precipitate, whereas $\mathrm{C} 1 \mathrm{~s}, \mathrm{O} 1 \mathrm{~s}, \mathrm{Li} 1 \mathrm{~s}$, and $\mathrm{F}$ 1s spectra were acquired from the FEC precipitate. An Argon flood gun was used to avoid surface charge accumulation during sample analysis. The binding energy was corrected on the basis of the $\mathrm{C} 1 \mathrm{~s}$ of hydrocarbon at $284.8 \mathrm{eV}$. The data was processed and analyzed using the Thermo Avantage, XPS Peak 4.1 and the Origin software. 
ssNMR. Multinuclear ssNMR spectra were obtained on 16.4 T Bruker Avance III 700 MHz and 11.7 T Bruker Avance III 500 MHz spectrometers. Samples were packed in an Ar glovebox (typically $\mathrm{O}_{2}$ and $\mathrm{H}_{2} \mathrm{O}<0.1 \mathrm{ppm}$ ), avoiding any exposure to ambient air, into rotors of $1.3,3.2$, and $4 \mathrm{~mm}$ outer diameters. Magic-angle spinning (MAS) frequencies ranged from 10 to $60 \mathrm{kHz}$, spinning under $\mathrm{N}_{2} \cdot{ }^{1} \mathrm{H}$ and ${ }^{13} \mathrm{C}$ chemical shifts were externally referenced to adamantane $\left({ }^{1} \mathrm{H} 1.9 \mathrm{ppm},{ }^{13} \mathrm{C} 38.5 \mathrm{ppm}, \mathrm{CH}_{2}\right)$ and ${ }^{7} \mathrm{Li}$ and ${ }^{19} \mathrm{~F}$ to $\mathrm{LiF}\left({ }^{7} \mathrm{Li}-1 \mathrm{ppm},{ }^{19} \mathrm{~F}-204 \mathrm{ppm}\right) .{ }^{33,34}$ The data were processed using the Bruker TOPSPIN software and analyzed using the dmfit software. ${ }^{35}$ Typical radio frequency (RF) field strengths used were $\left({ }^{1} \mathrm{H}\right) 90-100 \mathrm{kHz},\left({ }^{7} \mathrm{Li}\right) 80-125 \mathrm{kHz},\left({ }^{19} \mathrm{~F}\right) 80-125 \mathrm{kHz}$, and $\left({ }^{13} \mathrm{C}\right) 80-120 \mathrm{kHz}$.

Each of the FEC and VC precipitates were investigated using ${ }^{1} \mathrm{H},{ }^{7} \mathrm{Li}$, and ${ }^{19} \mathrm{~F}$ ssNMR, using $1.3 \mathrm{~mm}$ rotors and $60 \mathrm{kHz}$ spinning frequency. ${ }^{13} \mathrm{C}$ ssNMR experiments were performed using larger 3.2 and $4 \mathrm{~mm}$ rotors and spinning frequencies ranging from 10 to $12 \mathrm{kHz}$. The larger samples provided greater sensitivity. The ${ }^{13} \mathrm{C}$ spectra were acquired using sweptfrequency two-pulse phase modulation (swfTPPM) ${ }^{36}{ }^{1} \mathrm{H}$ decoupling at $80-100 \mathrm{kHz}$. Direct excitation ${ }^{13} \mathrm{C}$ experiments provided quantitative information. ${ }^{1} \mathrm{H}-{ }^{13} \mathrm{C},{ }^{7} \mathrm{Li}-{ }^{13} \mathrm{C}$, and ${ }^{19} \mathrm{~F}-{ }^{13} \mathrm{C}$ correlation experiments were used to probe spatial proximity of these nuclei by transferring magnetization from ${ }^{1} \mathrm{H},{ }^{7} \mathrm{Li}$, and ${ }^{19} \mathrm{~F}$ nuclei by cross-polarization to $\mathrm{C}$ nuclei. Dipolar dephasing (interrupted decoupling) ${ }^{1} \mathrm{H}-{ }^{13} \mathrm{C}$ crosspolarization experiments allowed differentiation between protonated and nonprotonated environments. ${ }^{34,37}$ Further ssNMR experimental details are given in the Supporting Information. 
FTIR. FTIR analysis was performed on each of the precipitates prepared with nondeuterated naphthalene. FTIR spectra of the dried precipitates were acquired on a Bruker Tensor 27 spectrometer, equipped with germanium crystal, in attenuated total reflectance (IR-ATR) mode. Samples were transferred using airtight vials, and the spectrometer was operated inside a nitrogen filled glovebox to avoid sample exposure to ambient air. Each spectrum was acquired with 128 scans from 700 to $4000 \mathrm{~cm}^{-1}$ at the spectral resolution of $4 \mathrm{~cm}^{-1}$. The data was processed and analyzed using the OPUS and Origin software.

GC-MS Analysis of Gases. The analysis of evolved gases during the reaction was performed on thermo trace GC-Ultra equipped with Agilent poroplot amines column and a mass selective detector-ISQ. Gas analysis was performed by extracting the head space of the reaction flask with a $10 \mu \mathrm{L}$ GC syringe. Helium was used as carrier gas at a flow rate of $1.5 \mathrm{~mL} / \mathrm{min}$. The initial column temperature was $50{ }^{\circ} \mathrm{C}$, and the temperature was ramped at $10^{\circ} \mathrm{C} / \mathrm{min}$ to $220^{\circ} \mathrm{C}$ and held at that temperature for $20 \mathrm{~min}$ with the total run time of $37 \mathrm{~min}$. The mass spectra obtained on these gases were compared to the NIST library to determine their molecular structures.

Dilute Reduction Reactions. $8.00 \mathrm{~mL}$ of $0.273 \mathrm{M}$ FEC in THF was stirred vigorously, and $1.00 \mathrm{~mL}$ of $0.546 \mathrm{M}$ lithium naphthalenide solution in THF was added drop by drop to the solution at room temperature. The dark green color of the lithium naphthalenide disappeared instantaneously as it contacted the FEC solution, and the reaction mixture turned turbid yellow from clear and colorless. The reaction mixture was analyzed with Agilent 6890-5973N GC equipped with an Agilent 5973N mass selective detector. Helium was used as carrier gas at a flow rate of $24 \mathrm{~mL} / \mathrm{min}$. The initial column 
temperature was $40{ }^{\circ} \mathrm{C}$, and the temperature was ramped at $10{ }^{\circ} \mathrm{C} / \mathrm{min}$ to $200{ }^{\circ} \mathrm{C}$ and held at that temperature for $2 \mathrm{~min}$ with the total run time of $18 \mathrm{~min}$. The mass spectra obtained were compared to the NIST library to determine their molecular structures. Computational Methods. Chemical shifts were calculated using density functional theory (DFT) using Gaussian $09^{38}$ and estimated using ChemNMR implemented in ChemBioDraw 13.0; see Table S1. ChemNMR approximates ${ }^{13} \mathrm{C}$ and ${ }^{1} \mathrm{H}$ chemical shifts with respect to TMS. For all DFT calculations, the hybrid functional B3LYP ${ }^{39,40}$ and 6$311 \mathrm{G}++(\mathrm{d}, \mathrm{p})$ basis sets were used, ${ }^{41,42}$ in combination with tight convergence. Frequency calculations were performed to confirm ground state convergence. The absolute NMR shift values were referenced to calculations performed for adamantane and $\mathrm{LiF}$ as in the experiment. Further computational details are given in the Supporting Information.

\section{RESULTS}

$X P S$. The chemical composition of the FEC and VC precipitates is first examined by XPS, with Figure 3.1 showing the XPS spectra of $\mathrm{C} 1 \mathrm{~s}, \mathrm{O} 1 \mathrm{~s}$, and $\mathrm{F} 1 \mathrm{~s}$ for each of the FEC and VC precipitates. The relative elemental concentrations of the FEC and VC precipitates are summarized in Table 3.1 and show that the FEC precipitate contains smaller relative quantities of species containing $\mathrm{C}$ and $\mathrm{O}$ than the VC precipitate. Results from previous XPS studies of the SEI, ${ }^{18,32,43-45}$ and potential products identified in theoretical studies of the reduction 20,24-26 reactions, are used to help assign the XPS 
spectra. We note that the residual naphthalene and THF in the system may contribute to the overall signal seen in the $\mathrm{C}$ 1s spectra $(\mathrm{C}=\mathrm{C}, \mathrm{C}-\mathrm{C}$, and $\mathrm{C}-\mathrm{O})$.

F1s Core Peaks. For the FEC precipitate, the dominant peak at $684.8 \mathrm{eV}$ in the $\mathrm{F} 1 \mathrm{~s}$ spectrum is assigned to $\mathrm{LiF}$. The asymmetry of the peak, extending to $689 \mathrm{eV}$, suggests the possibility of a minor additional fluorine environment but a more distinct shoulder at approximately $688 \mathrm{eV}$ would be expected if significant amounts of either residual FEC or a fluorinated organic species was present. ${ }^{29,46}$ This XPS assignment is discussed further in the context of the ${ }^{19} \mathrm{~F}$ ssNMR (reported later).

C1s Core Peaks. For both the FEC and VC precipitates, the deconvolutions of the spectra show peaks at approximately $291.0,290.0,288.5,286.8$, and $284.8 \mathrm{eV}$, the relative intensities of these peaks differing between the samples. On the basis of the binding energies, the $291.0 \mathrm{eV}$ peak is assigned to $\mathrm{ROCO}_{2} \mathrm{R}$ and the $290.0 \mathrm{eV}$ peak to $\mathrm{Li}_{2} \mathrm{CO}_{3}{ }^{21,44}$ The peak at $288.5 \mathrm{eV}$ is assigned to $\mathrm{CO}_{2}$ environments contained in $\mathrm{HCO}_{2} \mathrm{Li}$ and/or $\mathrm{Li}_{2} \mathrm{C}_{2} \mathrm{O}_{4}$, while the peaks at lower binding energies of 286.8 and $284.8 \mathrm{eV}$ indicate $\mathrm{C}-\mathrm{O}$ and $\mathrm{C}-\mathrm{C}$ bonds, respectively. $\mathrm{Li}_{2} \mathrm{CO}_{3}$ has a larger contribution in the $\mathrm{VC}$ precipitate compared with the FEC precipitate, also seen by ${ }^{7} \mathrm{Li}$ and ${ }^{13} \mathrm{C}$ ssNMR later. In addition, the relative signal intensity of the $\mathrm{HCO}_{2} \mathrm{Li} / \mathrm{Li}_{2} \mathrm{C}_{2} \mathrm{O}_{4}$ peak is larger in the $\mathrm{VC}$ precipitate, these carboxylate environments being confirmed by ${ }^{13} \mathrm{C}$ ssNMR in the VC sample, discussed further. The combination of the $291.0 \mathrm{eV}\left(\mathrm{ROCO}_{2} \mathrm{R}\right)$ peak and larger contribution at $286.8 \mathrm{eV}(\mathrm{C}-\mathrm{O})$ indicate alkyl carbonate environments, similar environments being previously assigned to poly(VC)..$^{21,45,47-49}$

O1s Core Peaks. For the FEC precipitate, the dominant peak is centered at $532.8 \mathrm{eV}$, characteristic of a mixture of $\mathrm{C}=\mathrm{O}$ and $\mathrm{C}-\mathrm{O}$ environments. In contrast, the $\mathrm{VC}$ 
precipitate shows a central peak centered at $532 \mathrm{eV}$ assigned to a carbonate contained in $\mathrm{Li}_{2} \mathrm{CO}_{3}$, alkyl carbonate, and/or carboxylate contained in $\mathrm{HCO}_{2} \mathrm{Li}$ or $\mathrm{Li}_{2} \mathrm{C}_{2} \mathrm{O}_{4}$. The shift between the FEC and VC spectra indicates different relative quantities of local O environments contained in the samples, the shift toward lower binding energy in the $\mathrm{VC}$ precipitate being consistent with the $\mathrm{C} 1 \mathrm{~s}$ spectrum indicating larger relative amounts of $\mathrm{Li}_{2} \mathrm{CO}_{3}$.

Solid State NMR. Multinuclear ssNMR. Direct excitation ${ }^{1} \mathrm{H},{ }^{7} \mathrm{Li}$, and ${ }^{19} \mathrm{~F}$ multinuclear ssNMR measurements of the FEC and VC precipitates (Figure 3.2) were performed. The ${ }^{1} \mathrm{H}$ ssNMR spectra both show similar overlapping resonances with shifts of 1.5, 3.6, and 4.6/4.8 ppm. These resonances are more easily assigned using the additional information and larger chemical shift dispersion provided by ${ }^{13} \mathrm{C}$ ssNMR experiments (discussed further). The VC sample shows a minor resonance at $8.3 \mathrm{ppm}$. This distinctive shift is consistent with an assignment of $\mathrm{HCO}_{2} \mathrm{Li}$ or similar environment based on previous work by Leskes et al. ${ }^{50}$ We note that residual THF may contribute to the signals of 1.5 and $3.6 \mathrm{ppm}$. In the ${ }^{7} \mathrm{Li}$ ssNMR spectra, each of the samples show a resonance near $0 \mathrm{ppm}$, the signal being consistent with the presence of $\mathrm{Li}_{2} \mathrm{CO}_{3}, \mathrm{Li}_{2} \mathrm{C}_{2} \mathrm{O}_{4}$, and $\mathrm{HCO}_{2} \mathrm{Li}$. The assignment is based on both previous ${ }^{7} \mathrm{Li}$ ssNMR measurements of lithium salts ${ }^{50,51}$ and the ${ }^{13} \mathrm{C}$ ssNMR results of this study. In the FEC precipitate, $\mathrm{F}(-203$ $\mathrm{ppm})$ and ${ }^{7} \mathrm{Li}(-1.0 \mathrm{ppm})$ resonances clearly indicate the presence of LiF. No additional resonances are seen in the $19 \mathrm{~F}$ spectrum. In contrast to the XPS spectrum, the larger chemical shift dispersion of the ${ }^{19} \mathrm{~F}$ ssNMR spectrum allows for a definitive assignment of any ${ }^{19} \mathrm{~F}$ environments; the ssNMR result here is consistent with the XPS assignment of $\mathrm{LiF}$ in the $\mathrm{F} 1 \mathrm{~s}$ spectrum. 
${ }^{13} \mathrm{C}$ ssNMR of FEC Precipitates. For the FEC precipitate, direct excitation ${ }^{13} \mathrm{C}$ ssNMR experiments (Figure 3.3a-i) show relative quantities of carbon environments, labeled C through F. The large chemical shift dispersion allows the different functional groups to be assigned based on their chemical shifts, with the labeled ${ }^{13} \mathrm{C}$ spectral peaks summarized in Table 3.2.

Resonance C (155 ppm) is characteristic of a $\mathrm{ROCO}_{2} \mathrm{R}$ carbonate environment (also seen in the C 1s XPS spectra). Resonance D (100 ppm) is assigned to a protonated C environment, adjacent to two OR groups. Resonance E (74 ppm) is assigned to a protonated $\mathrm{C}$ environment adjacent to a single $\mathrm{O}$. Resonance $\mathrm{F}$ (40 ppm) is characteristic of an environment with $\mathrm{C}$ not adjacent to $\mathrm{O}$ and is assigned to $\mathrm{RCH}_{2} \mathrm{R}^{\prime}$, its broad line width being characteristic of a distribution of similar environments. Resonances assigned to residual naphthalene and THF are labeled. Additional experiments (see Supporting Information) were performed at two different magic angle spinning frequencies $(10$ and $12 \mathrm{kHz}$ ) and field strengths $(500$ and $700 \mathrm{MHz})$ to confirm the spinning sideband peak positions. These peaks are indicated by asterisks and do not represent distinct resonances.

The ${ }^{19} \mathrm{~F}-{ }^{13} \mathrm{C}$ cross-polarization experiment, Figure $3.3 \mathrm{a}-\mathrm{ii}$, is used to identify chemical environments where ${ }^{19} \mathrm{~F}$ and ${ }^{13} \mathrm{C}$ are in close spatial proximity: the ssNMR experiment uses through-space magnetization transfer from the former to the latter. Interestingly, only a low intensity resonance (E) at approximately $74 \mathrm{ppm}$ is seen in the ${ }^{19} \mathrm{~F}-{ }^{13} \mathrm{C}$ cross-polarization experiment (Figure 3.3a-ii): no peaks are observed in the region of $110 \mathrm{ppm}$ where a $\mathrm{C}-\mathrm{F}$ group may be expected to resonate. The ${ }^{13} \mathrm{C}$ results are consistent with the ${ }^{19} \mathrm{~F}$ ssNMR and $\mathrm{F}$ 1s XPS results showing a single resonance 
assigned to LiF. The signal detection of resonance $\mathrm{E}$ indicates $\mathrm{LiF}$ is in close proximity to this $\mathrm{C}$ environment. $\mathrm{A}^{7} \mathrm{Li}^{-13} \mathrm{C}$ experiment was also attempted, but no signal was detected: the null result is in agreement with the ${ }^{7} \mathrm{Li}$ ssNMR assignment (Figure 3.2) showing that very little $\mathrm{Li}_{2} \mathrm{CO}_{3}$ (or similar environment resonating near $0 \mathrm{ppm}$ in the ${ }^{7} \mathrm{Li}$ spectrum) is present in the FEC precipitate. ${ }^{1} \mathrm{H}^{-13} \mathrm{C}$ cross-polarization experiments, Figure 3.3a-iii, were performed, further confirming the ${ }^{13} \mathrm{C}$ assignments. The signal intensity in these experiments depend on the dynamics of the functional groups and the molecules in the SEI, and spatial proximity of ${ }^{1} \mathrm{H}$ and ${ }^{13} \mathrm{C}$ nuclei. Following a similar strategy used in our previous paper to assign different carbon local environments, ${ }^{52}$ a delay time is introduced following the cross-polarization step in the experiment to perform a dipolar dephasing (interrupted decoupling) experiment, the experimental details being described in the Supporting Information. When the delay times are varied in the experiment, different $\mathrm{C}$ functional groups can be identified on the basis of their attenuation rates. Protonated $\mathrm{C}$ is attenuated more rapidly than non-protonated C. Also, the signal intensities for rigid $\mathrm{CH} / \mathrm{CH}_{2}$ environments attenuate more rapidly than signal from mobile species such as rotating $\mathrm{CH}_{3}$ methyl groups (due to a reduced dipolar coupling). The results of the experiments here confirm the assignment of resonance $\mathrm{C}$ to $\mathrm{ROCO}_{2} \mathrm{R}$, a species that does not have directly bonded protons and is not attenuated in the relatively short delays used in the experiment. In contrast, each of the resonances $\mathrm{D}, \mathrm{E}$, and $\mathrm{F}$ show pronounced attenuation, these resonances decaying at similar rates (with increased dephasing delay times) confirming that they correspond to $\mathrm{CH}$ and $\mathrm{CH}_{2}$ groups. 
${ }^{13} \mathrm{C}$ sNMR of VC Precipitates. For the VC precipitate, direct excitation ${ }^{13} \mathrm{C}$ ssNMR experiments (Figure 3.3b-i) show a similar spectral signature to the FEC precipitate but with additional resonances A, B, G, H, and I detected. Note that the ssNMR spinning sideband (from the deuterated naphthalene, labeled D-Napth.) shifts in the spectrum, compared to the FEC precipitate, as it was acquired at a different field strength. Resonance A (179 ppm) is characteristic of a carboxyl $\mathrm{RCO}_{2} \mathrm{Li}$ environment. Given that the distinctive ${ }^{1} \mathrm{H}$ shift of $\mathrm{HCO}_{2} \mathrm{Li}$ was detected in the ${ }^{1} \mathrm{H}$ ssNMR spectrum of the VC precipitate, the signal is assigned to $\mathrm{HCO}_{2} \mathrm{Li}$. $\mathrm{CH}_{3} \mathrm{CH}_{2} \mathrm{CO}_{2} \mathrm{Li}$, if present, would also contribute to the signal. The overlapping carbonate resonances B (172/170 ppm) are assigned to $\mathrm{Li}_{2} \mathrm{C}_{2} \mathrm{O}_{4}$ and $\mathrm{Li}_{2} \mathrm{CO}_{3}$, respectively. The resonance $\mathrm{G}(36 \mathrm{ppm})$ is assigned to a distribution of $\mathrm{RCH}_{2} \mathrm{R}^{\prime}$ environments. The minor peak $\mathrm{H}(20 \mathrm{ppm})$ is characteristic of $\mathrm{CH}_{3} \mathrm{CH}_{2} \mathrm{R}$ or alternatively a $\mathrm{C}_{3} \mathrm{CH}-$ group adjacent to an $\mathrm{O}$ as indicated in Table 3.2. The minor peak $\mathrm{I}(13 \mathrm{ppm})$ is characteristic of $\mathrm{CH}_{3} \mathrm{R}$ environments; the resonance likely has some contribution from residual diethyl ether $\left(\mathrm{CH}_{3} \mathrm{CH}_{2}-\mathrm{O}-\mathrm{CH}_{2} \mathrm{CH}_{3}\right)$ used to rinse the precipitates during synthesis. However, reactions forming these environments in minor quantities may also contribute to the signal.

The ${ }^{7} \mathrm{Li}^{-13} \mathrm{C}$ cross-polarization experiment (Figure $3.3 \mathrm{~b}$-ii) indicates the $\mathrm{Li}^{+}$ coordination environments by the carboxyl and carbonate groups. The broad resonance of $\mathrm{A}$ is consistent with the $\mathrm{HCO}_{2} \mathrm{Li}$ assignment. The majority of the signal contributing to the asymmetric peak at $\mathrm{B}$ is assigned to $\mathrm{Li}_{2} \mathrm{CO}_{3}$, the small shoulder being assigned to $\mathrm{Li}_{2} \mathrm{C}_{2} \mathrm{O}_{4}$. The ${ }^{7} \mathrm{Li}$ ssNMR spectra are consistent with these assignments (Figure 3.2).

In the dipolar dephasing experiment (Figure 3.3b-iii), the carbonate resonances B (assigned to $\mathrm{Li}_{2} \mathrm{CO}_{3}$ and $\mathrm{Li}_{2} \mathrm{C}_{2} \mathrm{O}_{4}$ ), which do not have directly bonded protons, are not 
attenuated in the experiment. In contrast, resonances D, E, and G show pronounced attenuation, at similar rates of decay (with increased dephasing times), indicating $\mathrm{CH}$ and $\mathrm{CH}_{2}$ groups, confirming the protonated $\mathrm{C}$ assignments (Table 3.2). The two sharp resonances $\mathrm{H}$ (at the same position as a naphthalene spinning sideband, as indicated by an asterisk) and I show signal attenuation consistent with their assignments in Table 3.2, the $\mathrm{CH}_{3} \mathrm{R}$ environment being expected to attenuate more slowly. The Supporting Information contains a ${ }^{1} \mathrm{H}^{-13} \mathrm{C} \mathrm{CP}$ spectrum, performed at lower field, which helped separate the isotropic resonances and sidebands and confirmed the presence of peaks $\mathrm{H}$ and I. No significant attenuation of resonance A is seen in the dipolar dephasing experiment (Figure 3.3b-iii), which is not consistent with its assignment solely to $\mathrm{HCO}_{2} \mathrm{Li}$. This spectrum was collected at a higher magnetic field strength than the spectra shown in Figure 3.3b-i,-ii, and there is now a severe overlap with the now much more intense D-Napth. spinning sideband (labeled with an asterisk), this signal not being attenuated in the dephasing experiment. Similarly, no attenuation is expected for an acetate resonance.

FTIR. FTIR spectra of the precipitates obtained on reduction of FEC and VC are displayed in Figure 3.4, confirming chemically bonded groups assigned in our XPS and ssNMR spectra. Our assignment here is based on comparison of the spectra to related studies. ${ }^{18,32,44,47}$ The FEC and VC reduction products have similar FTIR signatures, with some relative intensity differences at approximately $1300,1400-1500$, and $1750 \mathrm{~cm}^{-1}$. In addition to the $\mathrm{VC} / \mathrm{FEC}$ reduction products, some residual naphthalene is seen (788, $3064 \mathrm{~cm}^{-1}$ ). In each of the samples, the previously assigned $\mathrm{Li}_{2} \mathrm{CO}_{3}$ is again observed 
$\left(878,1449\right.$, and $\left.1488 \mathrm{~cm}^{-1}\right)$. As also seen by ${ }^{13} \mathrm{C}$ ssNMR (Figure $3.3 \mathrm{~b}-\mathrm{ii}$ ) and the $\mathrm{C} 1 \mathrm{~s}$ XPS spectra (Figure 3.1), the $\mathrm{Li}_{2} \mathrm{CO}_{3}$ is more prevalent in the VC sample.

In the FEC reduction product, peaks for carbonate $\mathrm{C}=\mathrm{O}\left(1795 \mathrm{~cm}^{-1}\right)$ and $\mathrm{C}-\mathrm{O}$ $\left(1080,1171 \mathrm{~cm}^{-1}\right)$ bonds are seen. These peaks are assigned to bonds contained in $\mathrm{ROCO}_{2} \mathrm{R}$ environments, resembling those assigned to a poly(VC) product in our previous study. ${ }^{18}$ Peaks for carboxylate $\mathrm{C}=\mathrm{O}\left(1598 \mathrm{~cm}^{-1}\right)$ and $\mathrm{C}-\mathrm{O}\left(1402 \mathrm{~cm}^{-1}\right)$ bonds are also seen, these absorptions being consistent with a mixture of $\mathrm{HCO}_{2} \mathrm{Li}$ and/or $\mathrm{Li}_{2} \mathrm{C}_{2} \mathrm{O}_{4}{ }^{44}$ In the $\mathrm{VC}$ reduction product, similar peaks for carbonate $\mathrm{C}=\mathrm{O}\left(1793 \mathrm{~cm}^{-1}\right)$ and $\mathrm{C}-\mathrm{O}\left(1077,1172 \mathrm{~cm}^{-1}\right)$ bonds and carboxylate $\mathrm{C}=\mathrm{O}\left(1619 \mathrm{~cm}^{-1}\right)$ and $\mathrm{C}-\mathrm{O}(1428$ $\mathrm{cm}^{-1}$ ) bonds are assigned to poly(VC) and $\mathrm{HCO}_{2} \mathrm{Li}_{2} / \mathrm{Li}_{2} \mathrm{C}_{2} \mathrm{O}_{4}$, respectively. Recall that the signature for $\mathrm{HCO}_{2} \mathrm{Li}$ was also seen in the ${ }^{1} \mathrm{H}$ and ${ }^{13} \mathrm{C}$ ssNMR (Figures 3.2 and 3.3) and XPS C 1s (Figure 3.1) spectra. With $\mathrm{HCO}_{2} \mathrm{Li}$ only being detected in the VC sample by ssNMR and the stronger peak intensity at $1660 \mathrm{~cm}^{-1}$ in the $\mathrm{VC}$ precipitate, the $\mathrm{HCO}_{2} \mathrm{Li}$ likely resonates at the higher frequency of $1660 \mathrm{~cm}^{-1}$ and $\mathrm{Li}_{2} \mathrm{C}_{2} \mathrm{O}_{4}$ at a lower frequency of $1600 \mathrm{~cm}^{-1}$.

To gain further insight into the decomposition mechanisms, an additional experiment was performed with a half molar equivalent of $\mathrm{Li}-\mathrm{Nap}$, providing FTIR spectra comparable to that of Figure 3.4 (see Supporting Information). The spectra show much weaker intensities for the peaks assigned to $\mathrm{Li}_{2} \mathrm{CO}_{3}, \mathrm{Li}_{2} \mathrm{C}_{2} \mathrm{O}_{4}$, and $\mathrm{HCO}_{2} \mathrm{Li}$, relative to the peaks assigned to $\mathrm{ROCO}_{2} \mathrm{R}$ environments assigned to poly( $\left.\mathrm{VC}\right)$, revealing a Li concentration dependence in the formation of these inorganics.

GC-MS Analysis of Gases. GC-MS analysis was performed, providing more insight for the reduction mechanisms of FEC and VC, resulting in the solid precipitates. For FEC, 
the reduction with $\mathrm{Li}-\mathrm{Nap}$ yields a mixture of $\mathrm{CO}$ and $\mathrm{CO}_{2}$. The ratio of $\mathrm{CO}$ to $\mathrm{CO}_{2}$ peak areas is 1:4.4. For VC, the reduction with Li-Nap yielded carbon monoxide as the only gaseous product (i.e., no $\mathrm{CO}_{2}$ was detected), $\mathrm{CO}_{2}$ having been detected previously. ${ }^{45,47}$ The absence of $\mathrm{CO}_{2}$ detection was attributed to its consumption in further reactions, the experiment being performed in a closed system, with an abundance of $\mathrm{Li}$.

Proposed Reduction Products. On the basis of the above analysis, we propose that the reduction product poly $(\mathrm{VC})$ is present in the precipitates of both $\mathrm{FEC}$ and $\mathrm{VC}$, as well as $\mathrm{Li}_{2} \mathrm{C}_{2} \mathrm{O}_{4}, \mathrm{Li}_{2} \mathrm{CO}_{3}$, and $\mathrm{HCO}_{2} \mathrm{Li}$, Figure 3.5. The relative ratio of these products differs for $\mathrm{VC}$ and FEC.

The $\mathrm{ROCO}_{2} \mathrm{R}$ environment observed in the XPS, ssNMR (Table 3.2, fragment C), and FTIR spectra is assigned to the repeating EC units of the poly(VC). The $\mathrm{C}-\mathrm{O}$ environments seen by XPS and corresponding protonated C environments adjacent to one $\mathrm{O}$ seen by ${ }^{13} \mathrm{C}$ ssNMR (Table 3.2, fragment $\mathrm{E}$ ) are also assigned to the repeating EC units of poly $(\mathrm{VC})$. The repeating $\mathrm{EC}$ units of the poly(VC) may terminate with a $\mathrm{CH}_{3}$ group and contribute to the ${ }^{13} \mathrm{C}$ ssNMR signal of resonance $\mathrm{H}$ (Table 3.2). ${ }^{13} \mathrm{C}$ ssNMR resonance $\mathrm{D}$, assigned to protonated $\mathrm{C}$ environments adjacent to two OR groups, indicates the possibility of a cross-linking site for poly(VC) (seen in Figure 3.5). The cross-linking site may also contain $\mathrm{C}$ environments adjacent to one $\mathrm{O}$, contributing to resonance $\mathrm{E}$. The signals from the distribution of carbons not adjacent to $\mathrm{O}$ (Table 3.2, fragments $\mathrm{F}-\mathrm{I}$ ) are assigned to the cross-linking site; the assignment for these peaks would vary according to the crosslinking terminations. Note that the broad peaks of the ${ }^{13} \mathrm{C}$ ssNMR spectra (Figure 3.3) indicate a distribution of local environments. A labeled structure and calculated ${ }^{13} \mathrm{C}$ and ${ }^{1} \mathrm{H}$ NMR chemical shifts of the proposed poly(VC) 
structure that support the assignment are included in Figures S4-S6. Additional structures with similar functional groups that are consistent with the NMR chemical signatures and assigned fragments (Table 3.2) cannot be ruled out completely. Note that while the direct excitation ${ }^{13} \mathrm{C}$ ssNMR spectra is a quantitative result (Figure 3.3-i), an accurate deconvolution was not attainable due to combined factors of weak resonances, strong background signal, and the presence of residual solvents.

\section{DISCUSSION}

Overall, our ssNMR, XPS, and FTIR experiments show complementary evidence for the presence of poly(VC) in the reduction products of both FEC and VC (possible reactions in Scheme 3.1-i,-ii). While similar species were seen in each of the precipitates, a clear difference was seen with respect to the relative quantities of inorganic $\mathrm{Li}$ environments. In particular, we detected $\mathrm{HCO}_{2} \mathrm{Li}, \mathrm{Li}_{2} \mathrm{C}_{2} \mathrm{O}_{4}$, and $\mathrm{Li}_{2} \mathrm{CO}_{3}$ in higher concentrations in the VC precipitate than in the FEC precipitate. For the FEC precipitate, the majority of $\mathrm{Li}$ was contained in $\mathrm{LiF}$, with the relative quantities of the Li environments being confirmed by the quantitative ${ }^{7} \mathrm{Li}$ ssNMR spectrum (Figure 3.2). Definitive assignments for C-groups and fluorinated-species contained in the reduction products were aided by the large chemical shift dispersion of the ${ }^{13} \mathrm{C}$ and ${ }^{19} \mathrm{~F}$ ssNMR spectra. ssNMR spectra was complementary to the XPS analysis, which has higher sensitivity but contained overlapping peaks in the spectra. The carboxylate environments was only observed in the VC precipitate (and not the FEC precipitate) by ssNMR, this result being attributed to the small concentrations of the carboxylate environments in the FEC precipitate. This is consistent with the XPS (see Table 3.1), showing smaller relative quantities of species containing $\mathrm{C}$ and $\mathrm{O}$ in the FEC precipitate 
than in the VC precipitate. In contrast, carbonate resonances were seen in both the VC and FEC precipitate by ssNMR, supporting the presence of poly(VC) in each of the samples (the proposed poly(VC) structure containing repeating EC units and a crosslinking site, Figure 3.5 ). The carboxylate and carbonate assignments in the ${ }^{13} \mathrm{C}$ ssNMR and $\mathrm{C} 1 \mathrm{~s} / \mathrm{O} 1 \mathrm{~s}$ XPS spectra were further supported by the detection of these chemical bonds in the FTIR spectra. We note that the results in this study only show the presence of an LiF fluorine environment, contradicting the results in previous XPS studies where additional organo-fluoride environments were seen and attributed to the reduction of FEC; for example, Etacheri et al. observed a central $\mathrm{F} 1 \mathrm{~s}$ peak assigned to $\mathrm{LiF}$ at approximately $685 \mathrm{eV}$ and organic fluorides at approximately $688 \mathrm{eV} \cdot{ }^{29}$ Our XPS result shows a single resonance assigned to $\mathrm{LiF}$, with no clear shoulder in the spectra. Our ${ }^{19} \mathrm{~F}$ SsNMR results, which have the advantage of a larger chemical shift dispersion, are in agreement with our XPS results. Moreover, we have performed ${ }^{19} \mathrm{~F}-{ }^{13} \mathrm{C}$ ssNMR crosspolarization experiments and have not detected any signal in the region where $\mathrm{C}-\mathrm{F}$ bonds would be expected in the ssNMR spectrum (Figure 3.3a-ii). In addition, we have also not seen any evidence for volatile fluorine-containing hydrocarbons by GCMS.

Proposed Reduction Mechanisms. Possible reaction schemes to form the products proposed on the basis of the experimental data are outlined in Scheme 1. We stress that there are likely multiple competing pathways and viable reactions also leading to reduction products with similar chemical signatures.

For the reduction of $\mathrm{VC}$, Scheme 3.1-i, a possible first step of the reaction is the reduction of $\mathrm{VC}$ to generate a radical anion followed by loss of $\mathrm{CO}_{2}$ and generation of the vinyloxy radical anion. The vinyloxy radical anion could initiate the polymerization 
of $\mathrm{VC}$ but more likely scavenges $\mathrm{H}^{+}$to generate the vinyloxy radical which has been reported as the intermediate species in the FEC reduction by Shkrob et al. ${ }^{53}$ The reactive vinyloxy radical can initiate the polymerization of $\mathrm{VC}$ to generate poly $(\mathrm{VC})$ via a radical polymerization reaction. The presence of the residual vinyl group from the vinyloxy radical can then polymerize via a radical polymerization mechanism to generate the cross-linked polymer.

With the reduction products detected being nearly identical to FEC, the difference being the LiF product, similar reduction mechanisms are expected. One possible mechanism for the reaction of FEC is nearly identical to the reaction of $\mathrm{VC}$, except that the first step of the reaction involves the reduction of FEC to generate $\mathrm{VC}, \mathrm{LiF}$, and $1 / 2$ $\mathrm{H}_{2}$, Scheme 3.1-ii. We note that $\mathrm{LiF}$ was generated nearly quantitatively via the Li-Nap reduction of FEC in our experiments. While we were unable to observe $\mathrm{H}_{2}$ generation, as the mass of $\mathrm{H}_{2}$ is below the detection limit of our GC-MS, the detection of $\mathrm{H}_{2}$ during the reduction of FEC was previously reported as part of the 4 electron reduction mechanism of FEC by Jung et al. ${ }^{54}$ The rapid polymerization of the VC generated from FEC can be explained by VC being more reactive under the reductive conditions than FEC. Additional experiments to confirm the FEC reduction mechanism were performed; when the Li-Nap reduction of FEC was conducted under very dilute conditions, with a large excess of FEC, trace quantities of VC (in addition to the previously reported products) were observed, supporting the reductive conversion of FEC to VC. The reaction mixtures obtained from reduction of dilute FEC with lithium naphthalenide contain a new peak in the GC trace at $3.10 \mathrm{~min}$. The MS of the new peak matches the MS in the NIST library for VC (see Supporting Information). The intensity of the VC 
peak increased with decreasing FEC concentration: when the FEC concentration was $0.134 \mathrm{M}$, the intensity of the VC peak was $1.0 \times 10^{4}$ (total ion current); after the concentration of FEC decreased to $0.055 \mathrm{M}$, the intensity of the VC peak increased to $1.1 \times 10^{5}$ (total ion current). The systematic increase in the VC concentration, with a decrease in the FEC concentration, is consistent with the trapping of a reactive intermediate. Interestingly, when 0.5 equiv of Li-Nap was reacted with FEC, only 0.5 equiv of FEC was reduced; in contrast, addition of 0.5 equiv of Li-Nap to VC resulted in the reduction of all of the VC. These observations are consistent with a stoichiometric reduction of FEC and a catalytic reduction of $\mathrm{VC}$. We also note that the approximate 2:1 ratio of $\mathrm{CO}_{2}$ to $\mathrm{H}_{2}$ previously observed by Jung et al. ${ }^{54}$ correlates well with our proposed mechanisms in (i) and (ii). Further work is ongoing to explore the reduction mechanisms in greater detail.

We note that Shkrob et al. ${ }^{53}$ have detected the vinyloxy radical in our proposed reaction Scheme 3.1-i in their radiolysis experiments and have concluded that the singleelectron reaction of $\mathrm{FEC}+\mathrm{Li}+\mathrm{e}^{-} \rightarrow \mathrm{LiF}+\mathrm{CO}_{2}+\cdot \mathrm{CH}_{2} \mathrm{CHO}$ is viable. However, the reaction is inconsistent with our observation of a $\mathrm{VC}$ intermediate and the observation of $\mathrm{H}_{2}$ evolution by Jung et al.54 In addition, the absence of $\mathrm{C}-\mathrm{F}$ environments detected in our study (albeit on chemically reduced FEC) contradicts subsequent reactions they have proposed. We note however that the conditions by which reduction occurs, radiolysis vs chemical reduction, may result in different reaction products.

Comparison with SEI Studies. Our results show strong similarities to previous SEI studies where these additives have been used in the electrolyte of cycled cells, the similarities validating the technique of using the naphthalene reduced products as a 
model to study the SEI formed in Li-ion cells. For example, in a study by El Ouatani et al., ${ }^{21}$ the degradation of $\mathrm{VC}$ was analyzed by using XPS analysis of $\mathrm{LiCoO}_{2}$ /graphite electrodes prepared in a Li-ion cell with $\mathrm{LiPF}_{6}$ in $1 \mathrm{~mol} \mathrm{~L}^{-1}$ pure $\mathrm{VC}$ electrolyte. Their C 1s XPS spectra showed degradation products at $291.3 \mathrm{eV}\left(\mathrm{CO}_{3}\right), 287.8 \mathrm{eV}\left(\mathrm{CO}_{2}\right)$, and $\sim 286.6 \mathrm{eV}(\mathrm{CO})$, the peak positions agreeing with those observed in this study. Here, we have assigned the VC degradation products to poly(VC) (291.0 and $286.8 \mathrm{eV})$ and $\mathrm{HCO}_{2} \mathrm{Li} / \mathrm{Li}_{2} \mathrm{C}_{2} \mathrm{O}_{4}(288.5 \mathrm{eV})$, the latter assignment being supported by our ${ }^{13} \mathrm{C}$ ssNMR results. We note that the differences in intensity for the peaks at 290 and $287.8 \mathrm{eV}$, for our data compared with that of El Ouatani et al., are likely due to differences in the concentration of the $\mathrm{CO}_{2}$ reduction products $\left(\mathrm{Li}_{2} \mathrm{CO}_{3}, \mathrm{HCO}_{2} \mathrm{Li}\right.$, and $\left.\mathrm{Li}_{2} \mathrm{C}_{2} \mathrm{O}_{4}\right)$ under the conditions of their experiments compared to the conditions of our experiments (reactions in a Li-ion cell versus a closed system with an abundance of $\mathrm{Li}$ ). In another example, Ota et al. have used FTIR to analyze VC-derived SEI layers formed on graphite in Li half-cells, ${ }^{47}$ including cells prepared with $1 \mathrm{~mol} \mathrm{dm}^{-3} \mathrm{LiPF}_{6} /$ pure VC electrolyte. Their spectrum showed absorption peaks assigned to poly(VC) $(1817,1147$, 1080, $\left.758 \mathrm{~cm}^{-1}\right)$, carboxylates $\left(1580,1413 \mathrm{~cm}^{-1}\right)$, and carbon double bonds $(1620,972$ $\mathrm{cm}^{-1}$ ). The absorption peaks strongly resemble those seen in the $\mathrm{VC}$ reduction product in this study. However, carbon double bonds were not detected in large quantities in our $\mathrm{VC}$ reduction products by any of our spectroscopy analysis, ruling out the presence of unsaturated lithium alkyl dicarbonate salts such as lithium vinylene dicarbonate (LVD) and lithium divinylene dicarbonate (LDVD), these SEI decomposition products being suggested by prior theoretical investigations (see Supporting Information for our estimated NMR shifts of these predicted products). ${ }^{20}$ They observed similar ${ }^{13} \mathrm{C}$ NMR 
peaks at $\sim 154$ and $\sim 70-80 \mathrm{ppm}$ in ${ }^{13} \mathrm{C}$ liquid NMR spectra of the SEI formed on the graphite electrode, dissolved in DMSO- $\mathrm{d}_{6}$, which they assigned to an oligomer of VC and/or poly(VC), the poly $(\mathrm{VC})$ assignment in agreement with the ssNMR results here (see Table 3.2, peaks $\mathrm{C}$ and $\mathrm{E}$ ); they also observed the distinctive ${ }^{13} \mathrm{C}$ ssNMR resonance at $\sim 100 \mathrm{ppm}$, seen in this study (see Table 3.2, peak D) which they assigned to an oligomer of VC. Here, we have assigned the $100 \mathrm{ppm}$ resonance to a cross-linking site of poly(VC) (see Scheme 3.1-i, Figure 3.5). We have also observed broad peaks at 36 and $40 \mathrm{ppm}$, indicating a distribution of $\mathrm{RCH}_{2} \mathrm{R}^{\prime}$ environments (see Table 3.2, peaks $\mathrm{F}$ and G), assigned to the cross-linking site. Finally, in our previous study of the SEI composition on $\mathrm{Si}$ anodes formed in the presence of FEC and VC additives, ${ }^{18}$ we have observed an FTIR adsorption peak at $\sim 1800 \mathrm{~cm}^{-1}$ increasing with additive concentration, the adsorption peak being assigned to poly(VC), as in this study.

The absence of the production of $\mathrm{CO}_{2}$ during the reduction of $\mathrm{VC}$, seen by GCMS, is in contrast to the literature. For example, the study by Ota et al., ${ }^{47}$ which used pure $\mathrm{VC}$ as an electrolyte solvent, observed $\mathrm{CO}_{2}$ as the major gaseous product and a small amount of $\mathrm{CO}$. Similarly, $\mathrm{CO}_{2}$ has been reported as the major gaseous product, when VC is used as an electrolyte additive. ${ }^{45,49}$ The discrepancy is likely due to the reduction of $\mathrm{CO}_{2}$ by excess $\mathrm{Li}$ napthalenide to generate $\mathrm{CO}, \mathrm{Li}_{2} \mathrm{CO}_{3}$, and $\mathrm{Li}_{2} \mathrm{C}_{2} \mathrm{O}_{4}$ (see Scheme 3.1iii) ${ }^{55}$ In the reduction of FEC, most of the Li-Nap is consumed to convert FEC to $\mathrm{VC}$ and $\mathrm{LiF}$ (see Scheme 3.1-ii). Thus, there is less residual $\mathrm{Li}$-Nap present to reduce the $\mathrm{CO}_{2}$ (Scheme 3.1-iii), resulting in the mixture of $\mathrm{CO}$ and $\mathrm{CO}_{2}$ measured by GC-MS in a ratio of 1:4.4, respectively. In contrast, $\mathrm{VC}$ is directly reduced by $\mathrm{Li}-\mathrm{Nap}$, and thus, there is excess Li-Nap present to reduce all of the $\mathrm{CO}_{2}$ to $\mathrm{CO}$ (Scheme 3.1-iii), 
resulting in more $\mathrm{Li}_{2} \mathrm{CO}_{3}$ in the $\mathrm{VC}$ precipitate compared with the FEC precipitate. The increased concentration of $\mathrm{Li}_{2} \mathrm{CO}_{3}$ in the $\mathrm{VC}$ precipitate was observed by XPS, ssNMR, and FTIR (Figures 3.1, 3.3, and 3.4). Furthermore, additional experiments (see Supporting Information) showed that decreasing to a half molar Li-Nap concentration decreased the FTIR peak intensities of $\mathrm{Li}_{2} \mathrm{CO}_{3}, \mathrm{Li}_{2} \mathrm{C}_{2} \mathrm{O}_{4}$, and $\mathrm{HCO}_{2} \mathrm{Li}$, relative to the peaks assigned to poly $(\mathrm{VC})$, indicating decreased reduction of $\mathrm{CO}_{2}$ (by the reactions of Scheme 3.1-iii).

While this study does not show the reduction reactions on an anode in a Li-ion cell, the chemical signatures of the reduction products seen here may serve as a useful reference for future studies where an SEI has been formed in a Li-ion cell in the presence of FEC and VC. We acknowledge that reactions in the cell may differ due to many factors such as the presence of additional cosolvents and the reactivity at the surface of the lithiated anode; under these considerations, it is interesting to reflect on the practical use of these additives in the context of the results here. FEC and VC have been shown to improve $\mathrm{Si}$ electrode capacity retention, ${ }^{5,12,13,16-18,29} \mathrm{Si}$ systems $\mathrm{su}^{\mathrm{ff}}$ ering from uncontrolled SEI growth due to the large volume expansion of the Si particles during lithiation, thought to result in cracking in the SEI. ${ }^{52}$ The poly(VC) formed by each of these additives would likely aid SEI elasticity helping to solve the problem. However, elasticity is not the only design requirement; $\mathrm{Li}^{+}$transport across the SEI to access the Si particles during electrochemical cycling is also critical. Therefore, increasing the polymer content may not be an adequate solution if the resulting SEI cannot facilitate transport. Grain boundaries and the mixture of polymerized chains with inorganic products may for example play a role in $\mathrm{Li}^{+}$transport across the SEI. With improved 
capacity retention being achieved by using FEC in higher concentrations vs VC (10-25 wt $\%$ FEC and 3-6 wt $\%$ VC in our previous study ${ }^{18}$ ), the relative mix of inorganics and organics may be an important SEI design parameter to consider. These results suggest that more $\mathrm{FEC}$ is required to form the same amount of poly $(\mathrm{VC})$; further work is ongoing to explore these ideas.

\section{CONCLUSIONS}

We have prepared reduction products of FEC and VC, capturing their spectral signatures by ssNMR, XPS, and FTIR. Our results indicate similar reduction products for FEC and $\mathrm{VC}$ but in differing relative quantities of $\mathrm{Li}_{2} \mathrm{CO}_{3}, \mathrm{Li}_{2} \mathrm{C}_{2} \mathrm{O}_{4}, \mathrm{HCO}_{2} \mathrm{Li}$, and poly $(\mathrm{VC})$. We have proposed a reaction scheme for the formation of poly $(\mathrm{VC})$, the poly $(\mathrm{VC})$ containing a cross-linking site. While the reaction scheme is a reasonable proposal, it is not definitive. Additional species may also be formed and lead to similar chemical signatures.

For the case of FEC reduction, the results suggest a mechanism where FEC reduces to form $\mathrm{LiF}$ and $\mathrm{VC}$, followed by subsequent $\mathrm{VC}$ reduction; when monitoring the reaction under dilute conditions by GC-MS, we observed the formation of VC in trace quantities. Interestingly, we did not detect any fluorinated organic species in large enough quantities for their definitive assignment in either of the ${ }^{19} \mathrm{~F}$ ssNMR or F 1s XPS spectra. With the majority of $\mathrm{Li}$ being consumed in the formation of LiF, only small quantities of $\mathrm{Li}_{2} \mathrm{CO}_{3}, \mathrm{Li}_{2} \mathrm{C}_{2} \mathrm{O}_{4}$, and $\mathrm{HCO}_{2} \mathrm{Li}$ were subsequently formed.

For the case of $\mathrm{VC}$ reduction, greater quantities of $\mathrm{Li}_{2} \mathrm{CO}_{3}, \mathrm{Li}_{2} \mathrm{C}_{2} \mathrm{O}_{4}$, and $\mathrm{HCO}_{2} \mathrm{Li}$ were seen. The different relative quantities of inorganic $\mathrm{Li}$ environments in the reduction products of $\mathrm{VC}$ and $\mathrm{FEC}$ may relate to their practical use in lower and higher 
concentrations as electrolyte additives, the relative quantities of inorganic and organic environments of the SEI formed in the presence of these additives likely having an impact on $\mathrm{Li}^{+}$transport.

\section{ASSOCIATED CONTENT}

The Supporting Information is available free of charge on the ACS Publications website at http://pubs.acs.org/doi/abs/10.1021/acs.chemmater.6b02282

\section{ACKNOWLEDGMENTS}

This work was partially supported by the Assistant Secretary for Energy Efficiency and Renewable Energy, Office of Vehicle Technologies of the U.S. Department of Energy under Contract No. DE-AC02-05CH11231, under the Batteries for Advanced Transportation Technologies (BATT) Program subcontract \#7057154. This work was partially supported by the U.S. Department of Energy EPSCoR Implementation Award Grant DE-SC0007074 for B.L.L., B.S.P., and T.Y. A.L.M. is an awardee of a Schiff Foundation Studentship and a nanoDTC Associate. M.L. is an

awardee of the Weizmann Institute of Science - National Postdoctoral Award for Advancing Women in Science and thanks the EU Marie Curie intra-European fellowship for funding.

\section{REFERENCES}

(1) $\mathrm{Xu}, \mathrm{K}$. Nonaqueous liquid electrolytes for lithium-based rechargeable batteries. Chem. Rev. 2004, 104, 4303-4418.

(2) Abe, K.; Yoshitake, H.; Kitakura, T.; Hattori, T.; Wang, H.; Yoshio, M. Additives-containing functional electrolytes for suppressing electrolyte decomposition in lithium-ion batteries. Electrochim. Acta 2004, 49, 4613-4622. 
(3) Tasaki, K.; Kanda, K.; Kobayashi, T.; Nakamura, S.; Ue, M. Theoretical studies on the reductive decompositions of solvents and additives for lithium-ion batteries near lithium anodes. J. Electrochem. Soc. 2006, 153, A2192-A2197.

(4) Zhang, S. S. A review on electrolyte additives for lithium-ion batteries. J. Power Sources 2006, 162, 1379-1394.

(5) $\mathrm{Xu}, \mathrm{K}$. Electrolytes and interphases in Li-Ion batteries and beyond. Chem. Rev. 2014, 114, 11503-11618.

(6) Peled, E. The electrochemical behavior of alkali and alkaline earth metals in nonaqueous battery systems-the solid electrolyte interphase model. J. Electrochem. Soc. 1979, 126, 2047-2051.

(7) Peled, E.; Golodnitsky, D.; Ardel, G. Advanced model for solid electrolyte interphase electrodes in liquid and polymer electrolytes. J. Electrochem. Soc. 1997, 144, L208-L210.

(8) Fong, R.; Von Sacken, U.; Dahn, J. R. Studies of lithium intercalation into carbons using nonaqueous electrochemical cells. J. Electrochem. Soc. 1990, 137, 2009-2013.

(9) Winter, M. The solid electrolyte interphase -the most important and the least understood solid electrolyte in rechargeable Li batteries. Z. Phys. Chem. 2009, 223, 1395-1406.

(10) $\mathrm{Xu}, \mathrm{K}$.; von Cresce, A. Interfacing electrolytes with electrodes in Li-ion batteries. J. Mater. Chem. 2011, 21, 9849-9864.

(11) Oesten, R.; Heider, U.; Schmidt, M. Advanced electrolytes. Solid State Ionics 2002, 148, 391-397. 
(12) Choi, N.-S.; Yew, K. H.; Lee, K. Y.; Sung, M.; Kim, H.; Kim, S.S. Effect of fluoroethylene carbonate additive on interfacial properties of silicon thin-film electrode. J. Power Sources 2006, 161, 1254-1259.

(13) Chen, L.; Wang, K.; Xie, X.; Xie, J. Effect of vinylene carbonate (VC) as electrolyte additive on electrochemical performance of Si film anode for lithium ion batteries. J. Power Sources 2007, 174, 538-543. (14) Xiong, D.; Burns, J. C.; Smith, A. J.; Sinha, N.; Dahn, J. R. A high precision study of the effect of vinylene carbonate (VC) additive in Ligraphite cells. J. Electrochem. Soc. 2011, 158, A1431-A1435.

(15) Chockla, A. M.; Klavetter, K. C.; Mullins, C. B.; Korgel, B. A. Solution-grown germanium nanowire anodes for lithium-ion batteries. ACS Appl. Mater. Interfaces 2012, 4, 4658-4664.

(16) Lin, Y.-M.; Klavetter, K. C.; Abel, P. R.; Davy, N. C.; Snider, J. L.; Heller, A.; Mullins, C. B. High performance silicon nanoparticle anode in fluoroethylene carbonate-based electrolyte for Li-ion batteries. Chem. Commun. 2012, 48, 7268-7270. (17) Ulldemolins, M.; Le Cras, F.; Pecquenard, B.; Phan, V. P.; Martin, L.; Martinez, H. Investigation on the part played by the solid electrolyte Interphase on the electrochemical performances of the silicon electrode for lithium-ion batteries. J. Power Sources 2012, 206, 245-252.

(18) Nguyen, C. C.; Lucht, B. L. Comparative study of fluoroethylene carbonate and vinylene carbonate for silicon anodes in lithium ion batteries. J. Electrochem. Soc. 2014, 161, A1933-A1938. 
(19) Aurbach, D.; Gamolsky, K.; Markovsky, B.; Gofer, Y.; Schmidt, M.; Heider, U. On the use of vinylene carbonate (VC) as an additive to electrolyte solutions for Li-ion batteries. Electrochim. Acta 2002, 47, 1423-1439.

(20) Wang, Y.; Nakamura, S.; Tasaki, K.; Balbuena, P. B. Theoretical studies to understand surface chemistry on carbon anodes for lithiumion batteries: how does vinylene carbonate play its role as an electrolyte additive? J. Am. Chem. Soc. 2002, 124, 4408-4421.

(21) El Ouatani, L.; Dedryvere, R.; Siret, C.; Biensan, P.; Reynaud, S.; Iratcabal, P.; Gonbeau, D. The effect of vinylene carbonate additive on surface film formation on both electrodes in Li-ion batteries. J. Electrochem. Soc. 2009, 156, A103-A113.

(22) Park, S.; Heon Ryu, J.; Oh, S. M. Passivating ability of surface film derived from vinylene carbonate on tin negative electrode. J. Electrochem. Soc. 2011, 158, A498-A503.

(23) Profatilova, I. A.; Stock, C.; Schmitz, A.; Passerini, S.; Winter, M. Enhanced thermal stability of a lithiated nano-silicon electrode by fluoroethylene carbonate and vinylene carbonate. J. Power Sources 2013, 222, 140-149.

(24) Leung, K.; Rempe, S. B.; Foster, M. E.; Ma, Y.; Martinez del la Hoz, J. M.; Sai, N.; Balbuena, P. B. Modeling electrochemical decomposition of fluoroethylene carbonate on silicon anode surfaces in lithium ion batteries. J. Electrochem. Soc. 2014, 161, A213-A221.

(25) Martínez de la Hoz, J. M.; Balbuena, P. B. Reduction mechanisms of additives on Si anodes of Li-ion batteries. Phys. Chem. Chem. Phys. 2014, 16, 17091-17098. 
(26) Soto, F. A.; Ma, Y.; Martínez de la Hoz, J. M.; Seminario, J. M.; Balbuena, P. B. Formation and growth mechanisms of solid-electrolyte interphase layers in rechargeable batteries. Chem. Mater. 2015, 27, 7990-8000.

(27) Profatilova, I. A.; Kim, S.-S.; Choi, N.-S. Enhanced thermal properties of the solid electrolyte interphase formed on graphite in an electrolyte with fluoroethylene carbonate. Electrochim. Acta 2009, 54, 4445-4450.

(28) Schroder, K.; Alvarado, J.; Yersak, T. A.; Li, J.; Dudney, N.; Webb, L. J.; Meng, Y. S.; Stevenson, K. J. The effect of fluoroethylene carbonate as an additive on the solid electrolyte interphase on silicon lithium-Ion electrodes. Chem. Mater. 2015, 27, $5531-5542$

(29) Etacheri, V.; Haik, O.; Goffer, Y.; Roberts, G. A.; Stefan, I. C.; Fasching, R.; Aurbach, D. Effect of fluoroethylene carbonate (FEC) on the performance and surface chemistry of Si-nanowire Li-ion battery anodes. Langmuir 2012, 28, 965-976.

(30) Schroder, K. W.; Celio, H.; Webb, L. J.; Stevenson, K. J. Examining solid electrolyte interphase formation on crystalline silicon electrodes: influence of electrochemical preparation and ambient exposure conditions. J. Phys. Chem. C 2012, $116,19737-19747$.

(31) Malmgren, S.; Ciosek, K.; Lindblad, R.; Plogmaker, S.; Kühn, J.; Rensmo, H.; Edström, K.; Hahlin, M. Consequences of air exposure on the lithiated graphite SEI. Electrochim. Acta 2013, 105, 83-91.

(32) Nie, M.; Chalasani, D.; Abraham, D. P.; Chen, Y.; Bose, A.; Lucht, B. L. Lithium ion battery graphite solid electrolyte interphase revealed by microscopy and spectroscopy. J. Phys. Chem. C 2013, 117, 1257-1267. 
(33) Morcombe, C. R.; Zilm, K. W. Chemical shift referencing in MAS solid state NMR. J. Magn. Reson. 2003, 162, 479-486.

(34) Apperley, D. C.; Harris, R. K.; Hodgkinson, P. Solid State NMR; Momentum Press: New York, 2012.

(35) Massiot, D.; Fayon, F.; Capron, M.; King, I.; Le Calve, S.; Alonso, B.; Durand, J.-O.; Bujoli, B.; Gan, Z.; Hoatson, G. Modelling one- and two-dimensional solid-state NMR spectra. Magn. Reson. Chem. 2002, 40, 70-76.

(36) Thakur, R. S.; Kurur, N. D.; Madhu, P. K. Swept-frequency twopulse phase modulation for heteronuclear dipolar decoupling in solidstate NMR. Chem. Phys. Lett. 2006, 426, 459-463.

(37) Opella, S. J.; Frey, M. H. Selection of nonprotonated carbon resonances in solidstate nuclear magnetic resonance. J. Am. Chem. Soc. 1979, 101, 5854-5856.

(38) Frisch, M. J. et al. Gaussian 09, Revision D.01; Gaussian Inc.: Wallingford CT, 2013.

(39) Lee, C.; Yang, W.; Parr, R. G. Development of the Colle-Salvetti correlationenergy formula into a functional of the electron density. Phys. Rev. B: Condens. Matter Mater. Phys. 1988, 37, 785-789.

(40) Becke, A. D. Density-functional thermochemistry. III. The role of exact exchange. J. Chem. Phys. 1993, 98, 5648-5652.

(41) Krishnan, R.; Binkley, J. S.; Seeger, R.; Pople, J. A. Selfconsistent molecular orbital methods. XX. A basis set for correlated wave functions. J. Chem. Phys. 1980, $72,650-654$. 
(42) Frisch, M. J.; Pople, J. A.; Binkley, J. S. Self-consistent molecular orbital methods 25. Supplementary functions for Gaussian basis sets. J. Chem. Phys. 1984, 80, $3265-3269$.

(43) Dedryvere, R.; Gireaud, L.; Grugeon, S.; Laruelle, S.; Tarascon, J. M.; Gonbeau, D. Characterization of lithium alkyl carbonates by Xray photoelectron spectroscopy: experimental and theoretical study. J. Phys. Chem. B 2005, 109, 15868-15875.

(44) Verma, P.; Maire, P.; Novak, P. A review of the features and analyses of the solid electrolyte interphase in Li-ion batteries. Electrochim. Acta 2010, 55, 6332-6341. (45) Madec, L.; Petibon, R.; Tasaki, K.; Xia, J.; Sun, J. P.; Hill, I. G.; Dahn, J. R. Mechanism of action of ethylene sulfite and vinylene carbonate electrolyte additives in LiNi 1/3Mn 1/3Co 1/3O 2/graphite pouch cells: electrochemical, GC-MS and XPS analysis. Phys. Chem. Chem. Phys. 2015, 17, 27062-27076.

(46) Chen, X.; Li, X.; Mei, D.; Feng, J.; Hu, M. Y.; Hu, J.; Engelhard, M.; Zheng, J.; Xu, W.; Xiao, J.; Liu, J.; Zhang, J.-G. Reduction mechanism of fluoroethylene carbonate for stable solid-electrolyte interphase film on silicon anode. ChemSusChem 2014, 7, $549-554$.

(47) Ota, H.; Sakata, Y.; Inoue, A.; Yamaguchi, S. Analysis of vinylene carbonate derived SEI layers on graphite anode. J. Electrochem. Soc. 2004, 151, A1659-A1669. (48) Madec, L.; Xia, J.; Petibon, R.; Nelson, K. J.; Sun, J.-P.; Hill, I. G.; Dahn, J. R. Effect of sulfate electrolyte additives on LiNi1/3Mn1/3Co1/3O2/graphite pouch cell Lifetime: correlation between XPS surface studies and electrochemical test results. J. Phys. Chem. C 2014, 118, 29608-29622. 
(49) Zhang, B.; Metzger, M.; Solchenbach, S.; Payne, M.; Meini, S.; Gasteiger, H. A.; Garsuch, A.; Lucht, B. L. Role of 1,3-propane sultone and vinylene carbonate in solid electrolyte interface formation and gas generation. J. Phys. Chem. C 2015, 119, 11337-11348.

(50) Leskes, M.; Moore, A. J.; Goward, G. R.; Grey, C. P. Monitoring the electrochemical processes in the lithium-air battery by solid state NMR spectroscopy. J. Phys. Chem. C 2013, 117, 26929-26939.

(51) Meyer, B. M.; Leifer, N.; Sakamoto, S.; Greenbaum, S. G.; Grey, C. P. High field multinuclear NMR investigation of the SEI layer in lithium rechargeable batteries. Electrochem. Solid-State Lett. 2005, 8, A145-A148.

(52) Michan, A. L.; Divitini, G.; Pell, A. J.; Leskes, M.; Ducati, C.; Grey, C. P. Solid electrolyte interphase growth and capacity loss in silicon electrodes. J. Am. Chem. Soc. 2016, 138, 7918-7931.

(53) Shkrob, I. A.; Wishart, J. F.; Abraham, D. P. What makes fluoroethylene carbonate different? J. Phys. Chem. C 2015, 119, 14954-14964.

(54) Jung, R.; Metzger, M.; Haering, D.; Solchenbach, S.; Marino, C.; Tsiouvaras, N.; Stinner, C.; Gasteiger, H. A. Consumption of fluoroethylene carbonate (FEC) on SiC composite electrodes for Li-ion batteries. J. Electrochem. Soc. 2016, 163, A1705-A1716.

(55) Zhao, Y.; Zhang, Z. Thermodynamic properties of CO2 conversion by sodium borohydride. Chem. Eng. Technol. 2015, 38, 110-116. 

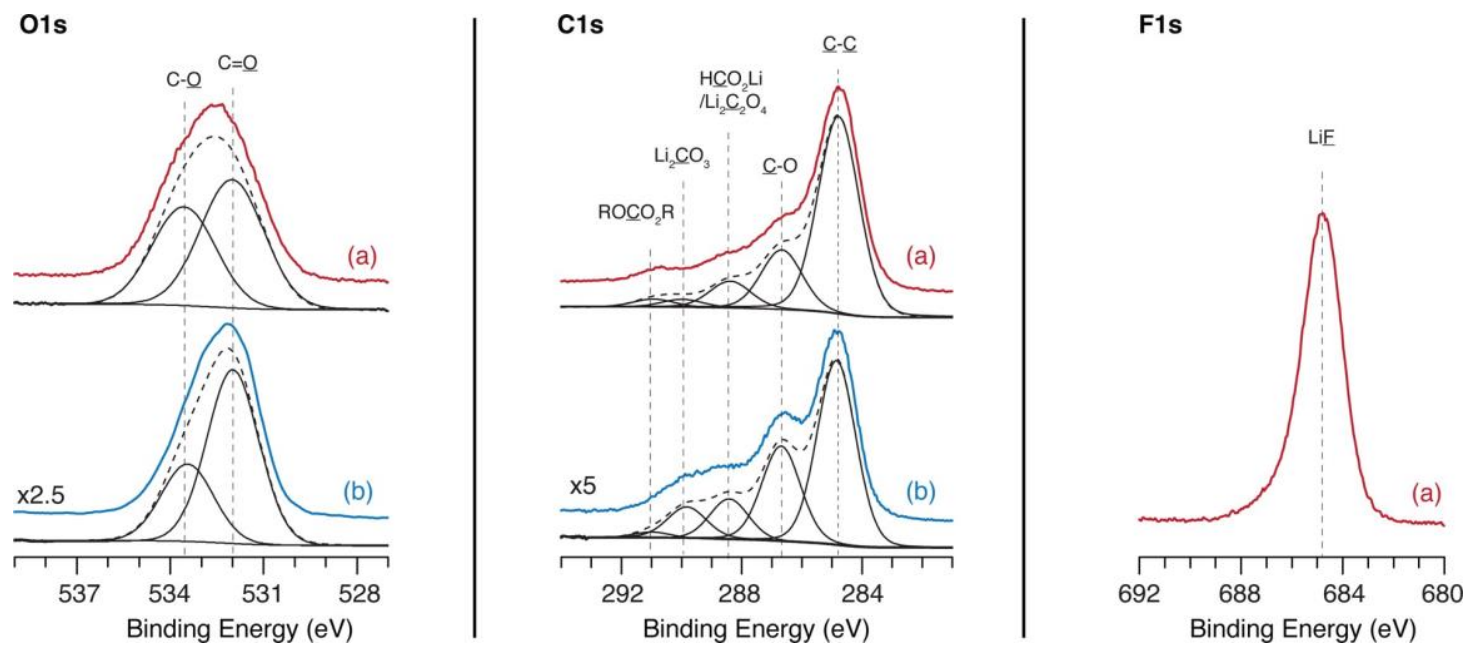

Figure 3.1. XPS spectra of the (a) FEC and (b) VC precipitates obtained through reduction of FEC and VC using deuterated naphthalene. Deconvolutions of the spectra are shown in black. 


\begin{tabular}{|c|c|c|}
\hline Element & FEC precipitate & VC precipitate \\
\hline O 1s & $16 \%$ & $35 \%$ \\
\hline C 1s & $41 \%$ & $52 \%$ \\
\hline Li 1s & $27 \%$ & $12 \%$ \\
\hline F 1s & $16 \%$ & \\
\hline
\end{tabular}

Table 3.1. Relative Elemental Concentrations from XPS Analysis 

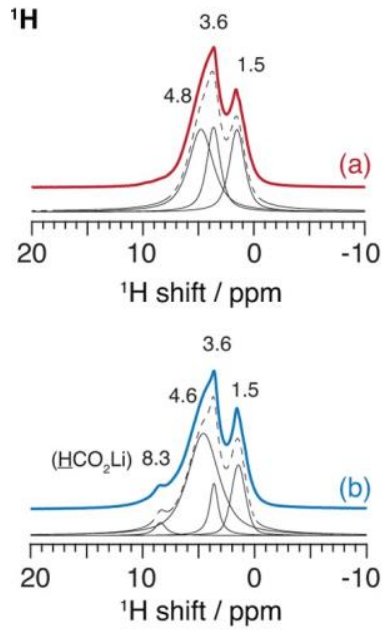

${ }^{7} \mathbf{L i}$
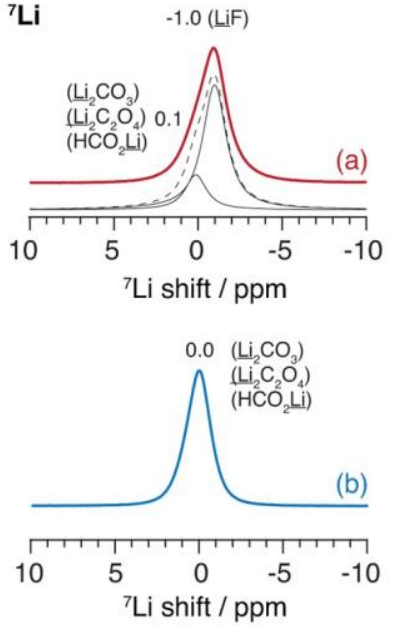

${ }^{19} \mathrm{~F}$

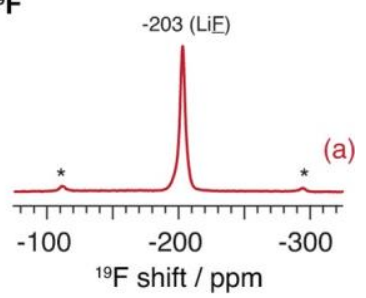

Figure 3.2. ssNMR spectra of the precipitates obtained through reduction of (a) FEC and (b) VC using deuterated naphthalene. ${ }^{1} \mathrm{H}$ Hahn echo, ${ }^{7} \mathrm{Li}$ single pulse, and ${ }^{19} \mathrm{~F}$ Hahn echo ssNMR experiments were performed. The spectra were acquired with $60 \mathrm{kHz}$ MAS and are scaled by maximum signal height. A simulated fit and deconvolution are presented under the experimentally obtained spectra. The asterisks in the ${ }^{19} \mathrm{~F}$ spectrum indicate ssNMR spinning sidebands. 

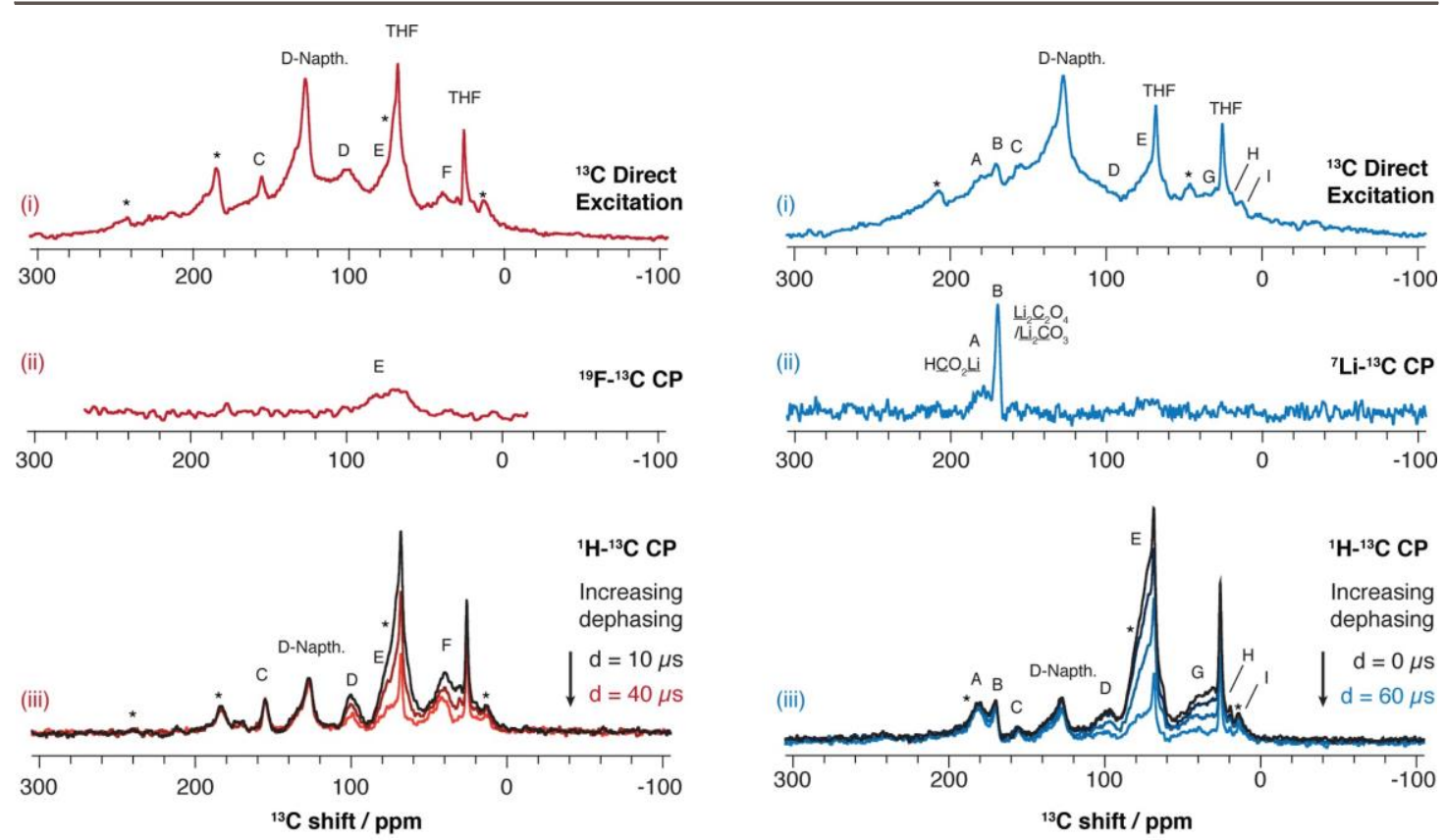

(a) FEC Precipitate

(b) VC Precipitate

Figure 3.3. ${ }^{13} \mathrm{C}$ ssNMR experiments performed on (a) FEC and (b) VC precipitates. (ai) ${ }^{13} \mathrm{C}$ single pulse, (a-ii) ${ }^{19} \mathrm{~F}-{ }^{13} \mathrm{C}$ cross-polarization, $\mathrm{CP}$, with contact time of $1000 \mu \mathrm{s}$, (a-iii) dipolar dephasing (interrupted decoupling) contact time of $1000 \mu \mathrm{s}$ and interrupted delay times of $\mathrm{d}=40,20$, and $10 \mu \mathrm{s}$. (b-i) ${ }^{13} \mathrm{C}$ single pulse, (b-ii) ${ }^{7} \mathrm{Li}-{ }^{13} \mathrm{C} \mathrm{CP}$ with contact time of $2000 \mu \mathrm{s}$, (b-iii) dipolar dephasing with contact time of $1000 \mu \mathrm{s}$ and delay times of $\mathrm{d}=60,20,10$, and $0 \mu \mathrm{s}$. When delay times are varied in the dipolar dephasing experiment, different $\mathrm{C}$ functional groups can be identified on the basis of their attenuation rates. See Supporting Information for ssNMR pulse sequence details. Spectra were acquired with $10 \mathrm{kHz}$ MAS at $500 \mathrm{MHz}$ (b-i, b-ii) and $700 \mathrm{MHz}$ (a-i, a-ii, a,b-iii) and are scaled by maximum intensity. All of the experiments were measured on samples prepared with deuterated naphthalene with the exception of (a-ii). Additional experiments confirm the residual naphthalene assignment and are available in the Supporting Information. 


\begin{tabular}{|c|c|c|}
\hline Resonance & Shift/ppm & Fragment \\
\hline$\overline{\mathrm{A}: \mathrm{VC}}$ & 179 & $\mathrm{HCO}_{2} \mathrm{Li}$ \\
\hline B: VC & $170 / 172$ & $\mathrm{Li}_{2} \underline{C} \mathrm{O}_{3} / \mathrm{Li}_{2} \underline{C}_{2} \mathrm{O}_{4}$ \\
\hline C: VC/FEC & 155 & $\mathrm{RO} \underline{C} \mathrm{O}_{2} \mathrm{R}$ \\
\hline D: VC/FEC & 100 & $-\underline{\mathrm{CH}}_{-}^{\prime}$ \\
\hline E: VC/FEC & 74 & $\mathrm{CH}-\mathrm{O}-$ \\
\hline F: FEC & 40 & $\mathrm{R} \underline{C} \mathrm{H}_{2} \mathrm{R}^{\prime}$ \\
\hline G: VC & 36 & $\mathrm{R} \underline{C} \mathrm{H}_{2} \mathrm{R}^{\prime}$ \\
\hline H: VC & 20 & $\mathrm{CH}_{3} \underline{C} \mathrm{H}_{2} \mathrm{R}$ or \\
\hline I: VC & 13 & $\begin{array}{l}\underline{\mathrm{CH}_{3} \mathrm{CH}^{-}}- \\
\underline{\underline{C}} \mathrm{H}_{3} \mathrm{R}\end{array}$ \\
\hline
\end{tabular}

Table 3.2. ${ }^{13} \mathrm{C}$ ssNMR Assignment for Peaks A-I Labeled in Figure 3.3 


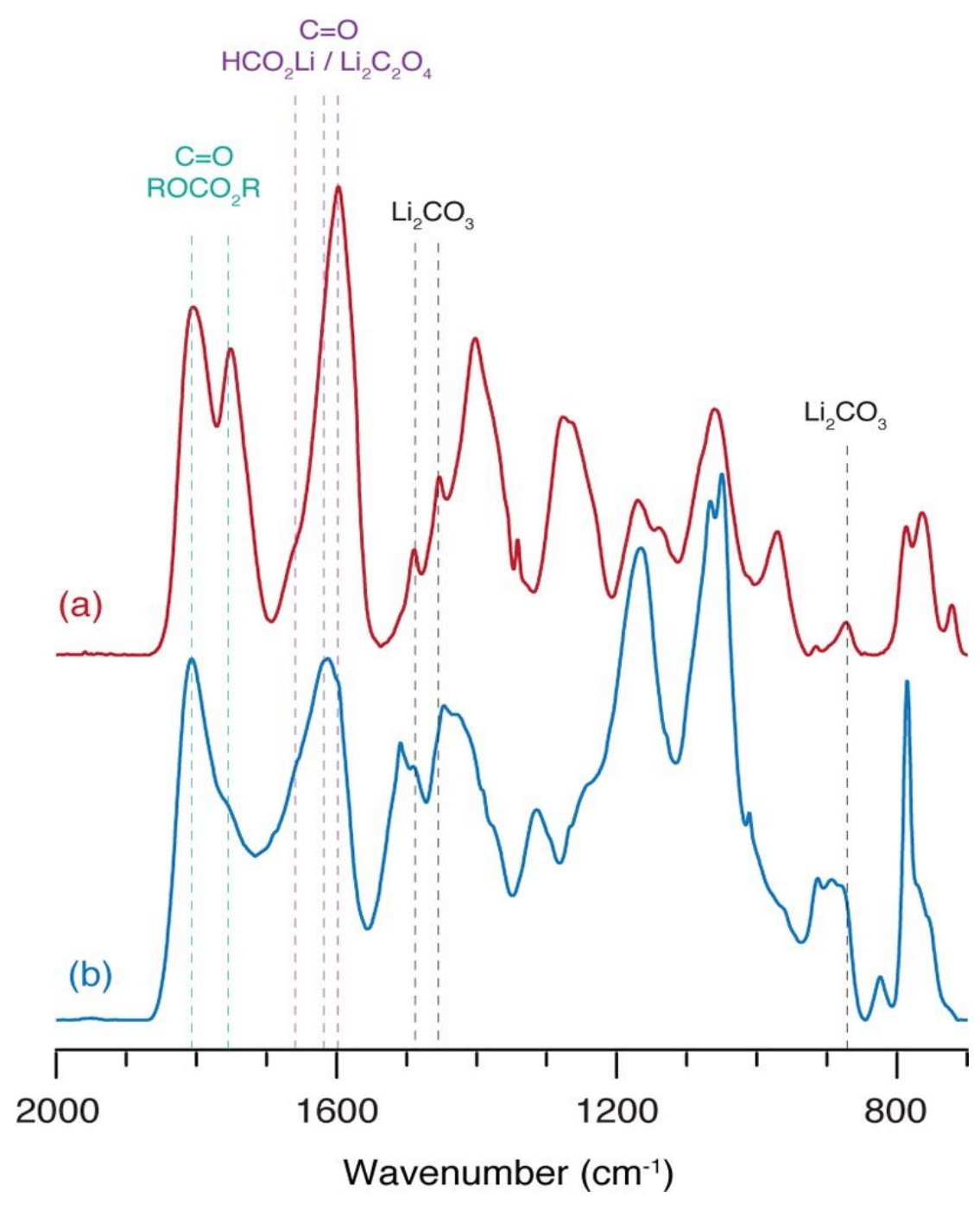

Figure 3.4. FTIR spectra of the precipitates obtained through reduction of (a) FEC and (b) VC using nondeuterated naphthalene. 


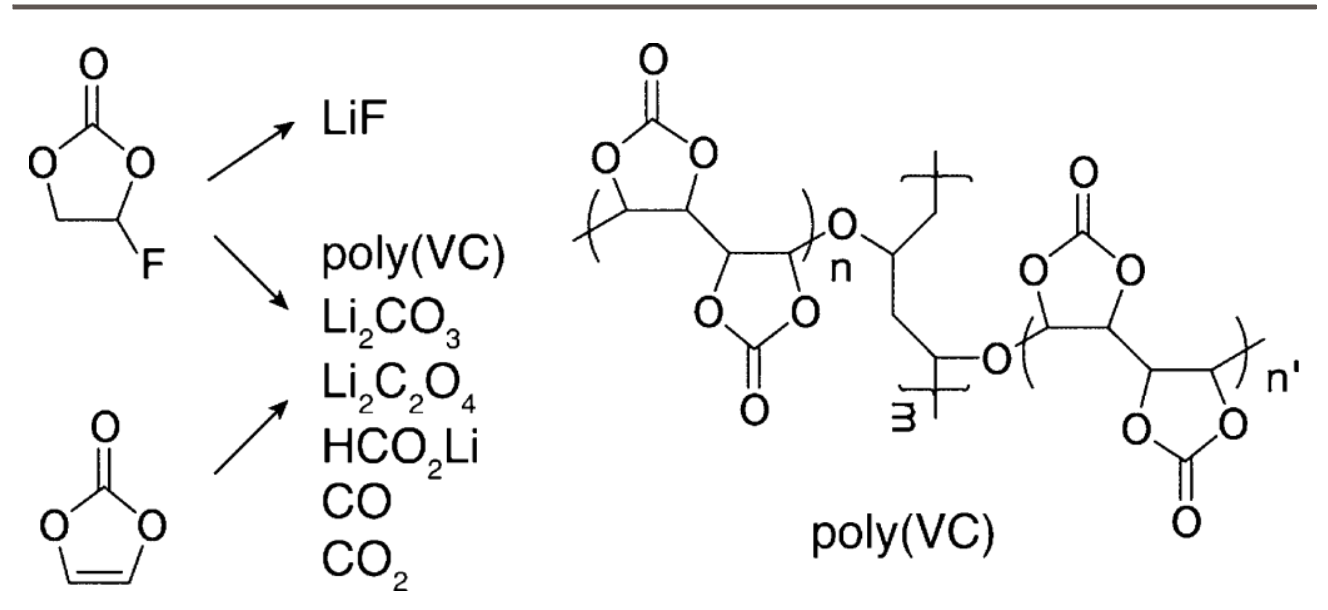

Figure 3.5. Proposed FEC/VC reduction products. A possible structure for a crosslinking site of poly(VC) is indicated. 
(i)

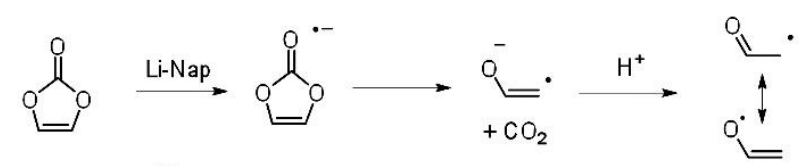<smiles>C=COC1OC(=O)OC1OC=C</smiles>

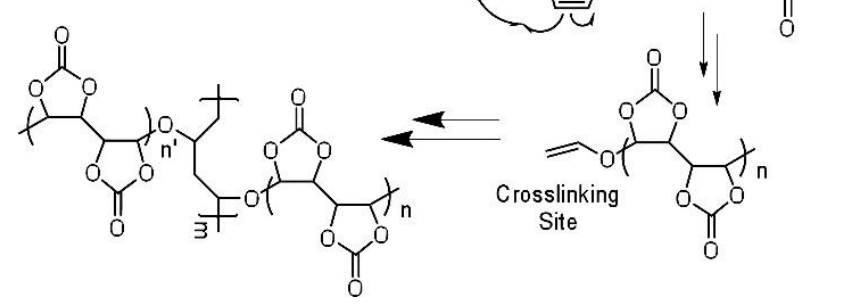

(ii)<smiles>O=C1OCC(F)O1</smiles>

(iii) $2 \times \mathrm{CO}_{2} \stackrel{2 \times \mathrm{Li}-\mathrm{Nap}}{\longrightarrow} \mathrm{Li}_{2} \mathrm{C}_{2} \mathrm{O}_{4}$ $2 \times \mathrm{CO}_{2} \stackrel{2 \times \mathrm{Li}-\mathrm{Nap}}{\longrightarrow} \mathrm{Li}_{2} \mathrm{CO}_{3}+\mathrm{CO}$ $\mathrm{CO}_{2} \underset{1 / 2 \mathrm{H}_{2}}{\stackrel{\mathrm{Li}-\mathrm{Nap}}{\longrightarrow}} \mathrm{HCO}_{2} \mathrm{Li}$

Scheme 3.1. Possible Reaction Schemes Consistent with the Chemical Signatures Detected by XPS, ssNMR, FTIR, and GC-MS 


\title{
CHAPTER 4 - REDUCTION REACTIONS OF ELECTROLYTE SALTS FOR
}

LITHIUM ION BATTERIES: $\mathrm{LiBF}_{4}$, LiDFOB, LiBOB, $\mathrm{LiPF}_{6} \&$ LiTFSI

\author{
B. S. Parimalam and B. L. Lucht.
}

Department of Chemistry, University of Rhode Island, Kingston, Rhode Island 02881.

The following is prepared for submission to the Journal of Physical Chemistry C, and is presented here in manuscript format. 


\section{ABSTRACT}

Lithium naphthalenide has been investigated as a reducing agent for electrolyte salts used in lithium ion batteries. The solids obtained through reduction were analyzed with solution NMR, FTIR-ATR and XPS. Number of electrons transferred for the reduction and molar equivalents of $\mathrm{LiF}$ generated were estimated through quantitative NMR analysis. All the fluorine containing salts generate LiF upon reduction. In addition to $\mathrm{LiF}, \mathrm{LiBF}_{4}$ generates $\mathrm{Li}_{\mathrm{x}} \mathrm{BF}_{\mathrm{y}}$ species; $\mathrm{LiBOB}$ and LiDFOB generate lithium oxalate and oxalatoborate oligomers; $\mathrm{LiPF}_{6}$ yields $\mathrm{LiPF}_{2}$; and LiTFSI produces lithium bis[N(trifluoromethylsulfonylimino)] trifluoromethanesulfonate upon reduction.

\section{INTRODUCTION}

A typical lithium-ion battery contains a graphite anode, a lithiated transition metal oxide cathode, and an electrolyte solution composed of inorganic lithium salts dissolved in a mixture of organic carbonate solvents. ${ }^{1}$ The long-term cyclability of the lithium-ion battery is dependent upon the anode SEI(solid electrolyte interphase), formed due to the electrochemical reduction of the electrolyte solution. ${ }^{2}$ Understanding the mechanisms of the reduction reactions along with the products of the reactions is essential for the development of better lithium-ion batteries and it has been investigated for many years. The SEI has been proposed to contain lithium alkyl carbonates, lithium carbonate, lithium oxalate, lithium alkoxides, and lithium oxide from the carbonate solvents and LiF, fluorophosphates, fluoroborates, lithium oxalate, various oligomers, lithium sulfide, lithium sulfites and lithium nitride from the reduction of electrolyte salts, depending upon the salt utilitzed. ${ }^{3-19}$ Despite the efforts, the formation of the SEI is not well understood. We have reported a detailed analysis of binder free graphitic anodes 
cycled in simplified electrolytes and the results suggest that the initial reduction reaction of the carbonates generate lithium alkyl carbonates and $\mathrm{LiF}$ as the predominant components of the anode SEI. ${ }^{20}$ Synthesis of initial SEI components from carbonate solvents in high yield through reduction of the solvents with lithium naphthalenide has been reported. Reduction of cyclic carbonates result in lithium alkylene dicarbonates and alkenes, whereas the reduction of dialkyl carbonates result in lithium alkyl carbonates and alkanes. ${ }^{21}$ As an expansion of these investigations, some of the most robust electrolyte salts have been reduced with lithium naphthalenide. All reactions result in precipitation. The precipitates have been analyzed by solution Nuclear Magnetic Resonance (NMR) Spectroscopy, solid-state Infra-Red spectroscopy in Attenuated Total Reflectance Mode (IR-ATR) and X-ray Photoelectron Spectroscopy (XPS). The results provide insight into the formation mechanism of the anode SEI.

\section{EXPERIMENTAL}

Battery-grade lithium tetrafluoroborate $\left(\mathrm{LiBF}_{4}\right)$, lithium bis(oxalato)borate (LiBOB), lithium difluoro(oxalato)borate (LiDFOB), lithium hexafluorophosphate $\left(\mathrm{LiPF}_{6}\right)$ and lithium bis(trifluoromethylsulfonyl)imide (LiTFSI) (Figure 4.1) were obtained from BASF. Diethyl ether $\left(\mathrm{Et}_{2} \mathrm{O}\right)$, tetrahydrofuran (THF), and naphthalene were purchased from Sigma-Aldrich. Lithium discs were obtained from MTI corporation. All the reagents were stored in argon filled glove box at room temperature and used without further purification. Lithium naphthalenide solution (Li[NAP]) in THF or $\mathrm{Et}_{2} \mathrm{O}$ was prepared with $10 \mathrm{~mol} \%$ excess naphthalene. Lithium foils were added to naphthalene solution of $\mathrm{THF} / \mathrm{Et}_{2} \mathrm{O}$ and stirred for 3 days at room temperature. The 
solution turned green/purple in a few minutes after the addition of lithium metal and became dark green/purple after stirring for 3 days.

Number of electrons required for the complete reduction of electrolyte salts was evaluated with quantitative NMR analysis. Electrolyte salts dissolved in $\mathrm{THF} / \mathrm{Et}_{2} \mathrm{O}$ were reacted with different molar equivalents of $\mathrm{Li}[\mathrm{NAP}]$, a one electron reducing agent, at room temperature overnight. The resulting reaction mixtures were transferred into clean dry NMR tubes along with capillaries. The capillaries were filled with deuterated DMSO and one of the internal standards: LiTFSI; hexafluoro benzene; or LiBF 4 . The internal standards were chosen carefully to avoid any overlapping peak with the products/ starting materials. The samples were analyzed with ${ }^{19} \mathrm{~F} /{ }^{11} \mathrm{~B}$ NMR spectroscopy and the concentrations of the unreacted electrolyte salts were estimated in reference to the internal standard.

Electrolyte salts $\left(\mathrm{LiBF}_{4}, \mathrm{LiBOB}, \mathrm{LiDFOB}, \mathrm{LiPF}_{6} \&\right.$ LiTFSI) were dissolved in $\mathrm{Et}_{2} \mathrm{O}$ and reduced with appropriate molar equivalents of Li[NAP] in larger scale. The evolved gasses and volatiles in the reaction mixtures were analyzed with GC-MS. The solid residues were washed with $\mathrm{Et}_{2} \mathrm{O}$ three times, dried overnight at room temperature, and analyzed with FTIR, solution NMR and XPS. All the reactions were conducted inside a nitrogen filled glovebox. XPS and FTIR analyses were conducted with no exposure to air. NMR, GC-MS were conducted with minimal exposure to air.

GC-MS analyses were conducted on an Agilent 6890-5973N GC equipped with an G973N mass selective detector. Liquid samples were diluted with dichloromethane, mixed with distilled water to remove the residual electrolyte salts and non-volatile inorganic components, and the organic phases were utilized for the analyses. Helium 
was used as carrier gas at a flow rate of $24 \mathrm{~mL} / \mathrm{min}$. The initial column temperature was $40^{\circ} \mathrm{C}$ and the temperature was ramped at $10^{\circ} \mathrm{C} / \mathrm{min}$ to $200^{\circ} \mathrm{C}$ and held at that temperature for 2 minutes with the total run time of 18 minutes. The mass spectra obtained were compared to the NIST library to determine their molecular structures. $\mathrm{THF}, \mathrm{Et}_{2} \mathrm{O}$ (solvents) and naphthalene (starting material) and were the only volatile components present in the reaction mixtures. The gas analyses were performed by sampling the head spaces of the reaction mixtures in RB flasks with a $10 \mu \mathrm{L}$ GC syringe. Helium was used as the carrier gas at a flow rate of $1.5 \mathrm{~mL} / \mathrm{min}$. The initial column temperature was set to $40{ }^{\circ} \mathrm{C}$, and the temperature was ramped at $1{ }^{\circ} \mathrm{C} / \mathrm{min}$ to $43^{\circ} \mathrm{C}$ and held at that temperature for $2 \mathrm{~min}$ with the total run time of $5 \mathrm{~min}$. The mass spectra obtained were compared to the NIST library to determine their molecular structures.

IR-ATR spectra of the dried solid residues were acquired on a Bruker Tensor 27 spectrometer equipped with a germanium crystal in attenuated total reflectance (IRATR) mode. Samples were transferred using air-tight vials and the spectrometer was operated inside a nitrogen filled glovebox to avoid air exposure. Each spectrum was acquired with $128 \mathrm{scans}$ from $700 \mathrm{~cm}^{-1}$ to $4000 \mathrm{~cm}^{-1}$ at the spectral resolution of $4 \mathrm{~cm}^{-}$ 1. The data were processed and analyzed using the OPUS and Originlab software.

NMR spectra of the samples were collected with a Bruker Avance III $300 \mathrm{MHz}$ NMR spectrometer at room temperature. The solids were dissolved in $\mathrm{D}_{2} \mathrm{O}$ in the nitrogen filled glovebox and ${ }^{19} \mathrm{~F},{ }^{31} \mathrm{P},{ }^{11} \mathrm{~B}, \&{ }^{13} \mathrm{C}$ NMR spectra of the solutions were acquired. The spectra were processed and analyzed using MestReNova 10.0.2.

XPS spectra of the dried precipitates were acquired using a Thermo Scientific K-alpha XPS. Samples were made into circular pellets with a press or stuck on a 
conductive carbon tape as a thin layer and transferred from the glovebox to the XPS chamber using a vacuum transfer module without exposure to air. An argon flood gun was used to avoid surface charge accumulation during sample analysis. The binding energy was corrected based on the $\mathrm{C} 1 \mathrm{~s}$ of hydrocarbon at $284.8 \mathrm{eV}$. The data were processed and analyzed using the Thermo Avantage, XPS Peak 4.1 and the Originlab software.

\section{RESULTS}

Reduction of electrolyte salts

The number of electrons required for the complete reduction of electrolyte salts was investigated with quantitative NMR analysis. Electrolyte salts dissolved in $\mathrm{THF} / \mathrm{Et}_{2} \mathrm{O}$ were reduced with different molar equivalents of $\mathrm{Li}[\mathrm{NAP}]$ at room temperature overnight. Addition of one molar equivalent of $\mathrm{Li}[\mathrm{NAP}]$ to $\mathrm{LiBOB}$, LiDFOB and LiTFSI solutions results in immediate discoloration of $\mathrm{Li}[\mathrm{NAP}]$ and precipitation of solid products, however discoloration in $\mathrm{LiBF}_{4}$ and $\mathrm{LiPF}_{6}$ samples take roughly an hour suggesting slower reduction kinetics, as the color change is due to the consumption of $\mathrm{Li}[\mathrm{NAP}]$ in the reduction of the electrolyte salts. Upon incorporation of higher concentrations of $\mathrm{Li}[\mathrm{NAP}],>1$ molar equivalent, similar discoloration is observed. However, upon color retention for more than 24 hours, the quantity of $\mathrm{Li}[\mathrm{NAP}]$ required to complete reduce the salt has been exceeded. The reaction mixtures were transferred into NMR tubes and a capillary, filled with hexafluoro benzene or $\mathrm{LiBF}_{4} / \mathrm{DMSO}_{6}$, was added into each tube. The samples were analyzed with ${ }^{19} \mathrm{~F} /{ }^{11} \mathrm{~B}$ NMR spectroscopy and the concentration of the remaining electrolyte salts were determined via integration of the NMR peaks compared to hexafluoro benzene or $\mathrm{LiBF}_{4}$. 
Reduction of $\mathrm{LiBF}_{4}$ with 1, 2, and 3 equivalents of $\mathrm{Li}[\mathrm{NAP}]$ results in consumption of approximately 40, 69, and $96 \pm 4 \%$ of the $\mathrm{LiBF}_{4}$, respectively, suggesting $3 \mathrm{e}^{-}$are required for quantitative reduction. Similarly, numbers of equivalents of Li[NAP] required for the reduction of $\mathrm{LiBOB}, \mathrm{LiDFOB}$, and LiTFSI were estimated to be $2 \mathrm{e}^{-}$, $2 \mathrm{e}^{-}$, and $12 \mathrm{e}^{-}$, respectively. The number of equivalents of Li[NAP] required for complete reduction of $\mathrm{LiPF}_{6}$ could not be measured reliably with quantitative NMR spectroscopy. However, in all cases low concentrations of residual salt are observed after the reduction reactions and some of the reduction products may precipitate prior to complete reduction, so the number of electrons required for reduction of the different salts should be viewed as approximate.

The electrolyte salts were then treated with a sufficient quantity of Li[NAP] to fully reduce the salt. All reactions result in a significant quantity of precipitate. The remaining solution was analyzed by GC-MS and NMR spectroscopy. The only component remaining in solution is a low concentration of the unreacted salt. In addition, analysis of the headspace of the samples detected no gaseous products resulting from the reduction reactions. The results suggest that all of the reduction products of the lithium salts are insoluble. Thus, the Li[NAP] reduction of all lithium salts investigated results in quantitative conversion to organic solvent insoluble components.

\section{NMR analysis of the solids}

The residual organic solvent insoluble solids have been analyzed via a combination of solution NMR spectroscopy in $\mathrm{D}_{2} \mathrm{O}$, Infrared spectroscopy with attenuated total reflectance (IR-ATR), and X-ray photo electron spectroscopy. The 
residual solids have been dissolved in $\mathrm{D}_{2} \mathrm{O}$ for NMR analysis. While most of the residual solids dissolve in $\mathrm{D}_{2} \mathrm{O}$, some of the solid does not readily dissolve. Some of the reduction products may react with water to generate subsequent hydrolysis products. The dissolved solids were analyzed via a combination of ${ }^{11} \mathrm{~B},{ }^{13} \mathrm{C},{ }^{19} \mathrm{~F}$, and ${ }^{31} \mathrm{P}$ NMR spectroscopy. Representative NMR spectra of the solids are provided in Figure 4.2.

The ${ }^{19} \mathrm{~F}$ NMR spectrum of the reduction product from $\mathrm{LiPF}_{6}$ displays a strong singlet corresponding to $\mathrm{LiF}$ at -122 and a medium singlet at -128.5 ppm corresponding to $\mathrm{HF}$. While $\mathrm{LiF}$ is frequently reported as a reduction product of $\mathrm{LiPF}_{6}, \mathrm{HF}$ is mostly likely to be generated from the hydrolysis of unreacted $\mathrm{LiPF}_{6}$ in $\mathrm{D}_{2} \mathrm{O}$. In addition, a doublet is observed at at $-81.3 \mathrm{ppm}$ in the ${ }^{19} \mathrm{~F}$ NMR spectrum which has a corresponding triplet at $-15.7 \mathrm{ppm}$ in the ${ }^{31} \mathrm{P}$ NMR spectrum. The chemical shifts of these peaks and a coupling constant, $962 \mathrm{~Hz}$, is characteristic of $\mathrm{LiPO}_{2} \mathrm{~F}_{2}$. The presence of $\mathrm{LiPO}_{2} \mathrm{~F}_{2}$ likely results from the hydrolysis of $\mathrm{LiPF}_{2}$ upon addition of the residual solid to $\mathrm{D}_{2} \mathrm{O}$, since no extractable oxygen is present in the reaction media. The XPS data, as discussed below, provides further support for this assignment.

The ${ }^{19} \mathrm{~F}$ NMR spectrum of the residual solids from the reduction of $\mathrm{LiBF}_{4}$ contains a strong singlet at -122 ppm characteristic of LiF. In addition, the sample exhibits a weak set of peaks at $-149 \mathrm{ppm}$ in the ${ }^{19} \mathrm{~F}$ NMR spectrum characteristic of residual $\mathrm{LiBF}_{4}$. A single peak is observed in the ${ }^{11} \mathrm{~B}$ NMR spectrum peak at $1.5 \mathrm{ppm}$ characteristic of residual $\mathrm{LiBF}_{4}$.

The ${ }^{13} \mathrm{C}$ NMR spectrum of the residual solids obtained from reduction of LiBOB displays a strong singlet at $173.2 \mathrm{ppm}$ characteristic of in lithium oxalate. The other peaks observed in the ${ }^{13} \mathrm{C}$ NMR spectra are characteristic of residual solvents, THF and 
$\mathrm{Et}_{2} \mathrm{O}$, used for the reduction reaction. The peaks at 67.8 and $25.0 \mathrm{ppm}$ are characteristic of residual THF while the peaks at 66.0 and $14.1 \mathrm{ppm}$ are characteristic of residual $\mathrm{Et}_{2} \mathrm{O}$. There are no peaks observed for residual LiBOB in either the ${ }^{11} \mathrm{~B}$ or ${ }^{13} \mathrm{C}$ NMR spectra consistent with quantitative reduction of $\mathrm{LiBOB}$ under the reaction conditions.

The NMR spectrum of the residual solid from the reduction of LiDFOB is similar to the reduction products of $\mathrm{LiBF}_{4}$ and $\mathrm{LiBOB}$. The ${ }^{19} \mathrm{~F}$ NMR spectrum is dominated by $\mathrm{LiF}$ at $-122 \mathrm{ppm}$, but also contains small sets of peaks at -147 and -149 ppm characteristic of residual LiDFOB and $\mathrm{LiBF}_{4}$, respectively. The corresponding peaks characteristic of LiDFOB and $\mathrm{LiBF}_{4}$ are observed in the ${ }^{11} \mathrm{~B}$ NMR spectra at 2.9 ppm and $1.5 \mathrm{ppm}$, respectively. The ${ }^{13} \mathrm{C}$ NMR spectrum contains a strong peak at 173.2 ppm characteristic of lithium oxalate, along with peaks characteristic of residual THF and $\mathrm{Et}_{2} \mathrm{O}$. However, unlike LiBOB some residual LiDFOB is observed at $161.1 \mathrm{ppm}$.

The ${ }^{19} \mathrm{~F}$ NMR spectrum of the solids from the reduction of LiTFSI shows a strong singlet corresponding to LiF. In addition, two strong peaks at $-75.6 \mathrm{ppm}$ and $72.7 \mathrm{ppm}$ with peak areas in 2:1 ratio. The integrated peak are of 2:1 is independent of the quantity of Li[NAP] added suggesting that they arise from a single molecular species. The spectral data is consistent with lithium bis[N(trifluoromethylsulfonylimino)] trifluoromethanesulfonate $\left(\mathrm{LiOS}\left(\mathrm{CF}_{3}\right)\left(\mathrm{NSO}_{2} \mathrm{CF}_{3}\right)_{2}\right.$ as previously reported. ${ }^{22}$ No residual Li TFSI is observed at $-79.4 \mathrm{ppm}$ in the ${ }^{19} \mathrm{~F}$ NMR spectrum.

FTIR analysis of the solids

In an effort to further understand the composition of the solids obtained from reduction, the reduction products of salts have been analyzed with IR-ATR. The IR- 
ATR spectra of the solids generated from the reduction of LiBOB and LiDFOB are provided in Figure 4.3. IR-ATR spectra of the residual solids for the other salts were also acquired, but the spectra were dominated by residual solvent and naphthalene since the decomposition products do not contain any functional groups which strongly absorb IR radiation, consistent with the observation of LiF, in NMR analysis.

The reduction product of LiBOB exhibits strong absorptions around 1670, 1330 and $780 \mathrm{~cm}^{-1}$ characteristic of lithium oxalate. The twin peaks at 1805 and $1770 \mathrm{~cm}^{-1}$ are characteristic of $-\mathrm{CO}_{2}-\mathrm{B}-\mathrm{CO}_{2}$ - oscillations and the peak at $1250 \mathrm{~cm}^{-1}$ corresponds to combination of $\mathrm{O}-\mathrm{C}-\mathrm{C}$ asymmetric stretching and $\mathrm{O}-\mathrm{B}-\mathrm{O}$ bending, suggesting the presence of boron-oxalato-ester species, likely a combination of residual LiBOB and oligomeric borates as previously reported. ${ }^{23,24} \mathrm{~A}$ weak broad absorption is also observed between 1400 and $1500 \mathrm{~cm}^{-1}$, consistent with the presence of $\mathrm{Li}_{2} \mathrm{CO}_{3}$. In addition to the reduction products, absorptions corresponding to residual THF at $1070 \mathrm{~cm}^{-1} \& 910 \mathrm{~cm}^{-}$ ${ }^{1}$ are also observed. Reduction product of LiDFOB displays IR absorptions very similar to the solids from LiBOB consistent with the presence of lithium oxalate, boraneoxalato-ester species, and $\mathrm{Li}_{2} \mathrm{CO}_{3}$, except the intensity of the broad absorption characteristic of $\mathrm{Li}_{2} \mathrm{CO}_{3}$ is greater.

X-ray Photoelectron Spectroscopy of the solids

The solids generated from the reduction of $\mathrm{LiBF}_{4}$ and $\mathrm{LiPF}_{6}$ were analyzed with XPS and the spectra are displayed in Figure 4.4. XPS analysis of the other residual solids was attempted, but the insoluble reduction products contain residual solvent and naphthalene which cannot be removed which resulted in long term contamination of the 
XPS analysis chamber. Thus, we were unable to obtain XPS spectra of the other reduction products.

The F1s spectrum of the residual solid from the reduction of $\mathrm{LiPF}_{6}$ is dominated by a peak at $685 \mathrm{eV}$ characteristic of LiF. The shoulder at 688.3 is characteristic of P-F species in $\mathrm{LiPF}_{2}$ and $\mathrm{Li}_{\mathrm{x}} \mathrm{PO}_{\mathrm{y}} \mathrm{F}_{\mathrm{z}}$. The $\mathrm{P} 2 \mathrm{p}$ spectrum contains a strong peak at $130.0 \mathrm{eV}$ corresponding to $\mathrm{LiPF}_{2}$ species and the small peak at $136.0 \mathrm{eV}$ is characteristic of $\mathrm{Li}_{x} \mathrm{PO}_{y} \mathrm{~F}_{z}$. The low concentration of $\mathrm{Li}_{x} \mathrm{PO}_{y} \mathrm{~F}_{z}$ most likely results from reaction of $\mathrm{LiPF}_{2}$ with trace oxygen. The Lils spectrum exhibits a broad peak around $56.3 \mathrm{eV}$ corresponding to combination of $\mathrm{LiF}, \mathrm{LiPF}_{2}$, and $\mathrm{Li}_{x} \mathrm{PO}_{\mathrm{y}} \mathrm{F}_{\mathrm{z}}$. No residual $\mathrm{LiPF}_{6}(\mathrm{~F} 1 \mathrm{~s}$, $687.6 \mathrm{eV} ; \mathrm{P} 2 \mathrm{p}, 137.8 \mathrm{eV}$ ) is observed.

The $\mathrm{F} 1 \mathrm{~s}$ spectrum of the residual solids from the reduction of $\mathrm{LiBF}_{4}$ is dominated by a peak at $685 \mathrm{eV}$ characteristic of LiF. A shoulder is observed at 687.5 is characteristic of $\mathrm{B}-\mathrm{F}$ species in $\mathrm{Li}_{\mathrm{x}} \mathrm{BF}_{\mathrm{y}}$ and residual $\mathrm{LiBF}_{4}$. The $\mathrm{B} 1 \mathrm{~s}$ spectrum is dominated by a peak at $190.5 \mathrm{eV}$ corresponding to $\mathrm{Li}_{\mathrm{x}} \mathrm{B}_{\mathrm{y}} \mathrm{F}_{\mathrm{z}}$ species with a small peak at $195.7 \mathrm{eV}$ is characteristic of residual $\mathrm{LiBF}_{4}$. The Li1s spectrum exhibits a broad peak around $56.3 \mathrm{eV}$ corresponding to combination of $\mathrm{LiF}$, residual $\mathrm{LiBF}_{4}$ and $\mathrm{Li}_{x} \mathrm{BF}_{\mathrm{y}}$.

\section{DISCUSSION}

The reduction products of some of the most common electrolyte salts have been investigated by a combination of NMR, GC-MS, IR-ATR, and XPS analyses. All the fluorine containing salts generate $\mathrm{LiF}$ upon reduction. Reduction of $\mathrm{LiPF}_{6}$ yields primarily $\mathrm{LiF}$ and $\mathrm{LiPF}_{2}$ species. $\mathrm{LiF}$ is the dominant fluorine species observed in NMR and F1s XPS analyses. $\mathrm{LiPF}_{2}$ is observed as the dominant phosphorous containing species observed in the P2p XPS spectrum and the small amount of observed $\mathrm{Li}_{x} \mathrm{PO}_{y} \mathrm{~F}_{z}$, 
is most likely resulting from the reaction of $\mathrm{LiPF}_{2}$ with trace water or oxygen. Upon preparation of the samples for $\mathrm{NMR}$ analysis the $\mathrm{LiPF}_{2}$ is converted to $\mathrm{LiPO}_{2} \mathrm{~F}_{2}$ via hydrolysis. The observations are consistent with and complementary to previous reports. ${ }^{10}$

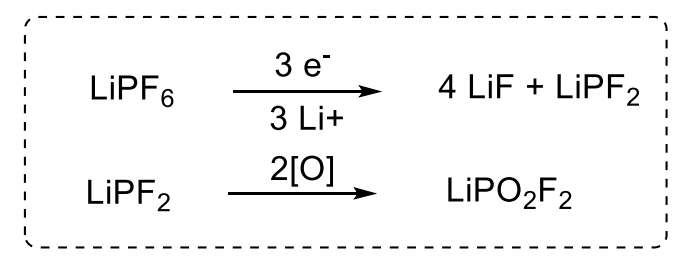

$\mathrm{LiBF}_{4}$ is estimated to undergo $3 \mathrm{e}^{-}$electron reduction via quantitative solution NMR, with LiF being the predominant product as observed in solution NMR and XPS spectra. In addition, reduced fluoroboron species $\left(\mathrm{Li}_{\mathrm{x}} \mathrm{BF}_{\mathrm{y}}\right)$ is observed with XPS analysis. $\mathrm{Li}_{\mathrm{x}} \mathrm{BF}$ y is likely a crosslinked, insoluble compound as it is not observed in ${ }^{11} \mathrm{~B}$ NMR spectrum, despite exhibiting a strong signal in B1s XPS spectrum. Observations are consistent with and complementary to previous reports. ${ }^{25,26}$

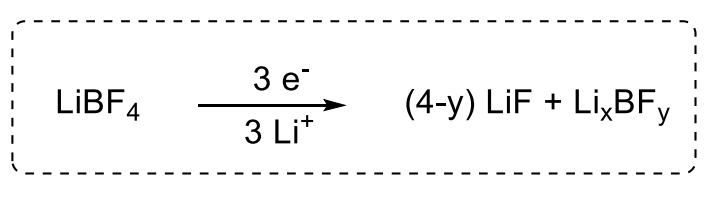

Reduction of LiBOB results in primarily lithium oxalate and small amounts of lithium carbonate as observed in NMR spectroscopy and IR spectroscopy. Roughly two electrons are consumed in the reduction process as estimated through quantitative solution NMR. Boron-oxalatoester species observed in the IR spectrum is likely crosslinked hence insoluble as it is not observed with solution NMR spectroscopy. Observations are consistent with and complementary to previous reports. ${ }^{27} \mathrm{CO}_{2}$ was not 
observed by GC-MS analysis, but the presence of $\mathrm{Li}_{2} \mathrm{CO}_{3}$ in the solid residue is likely the result of $\mathrm{CO}_{2}$ reduction. ${ }^{28}$

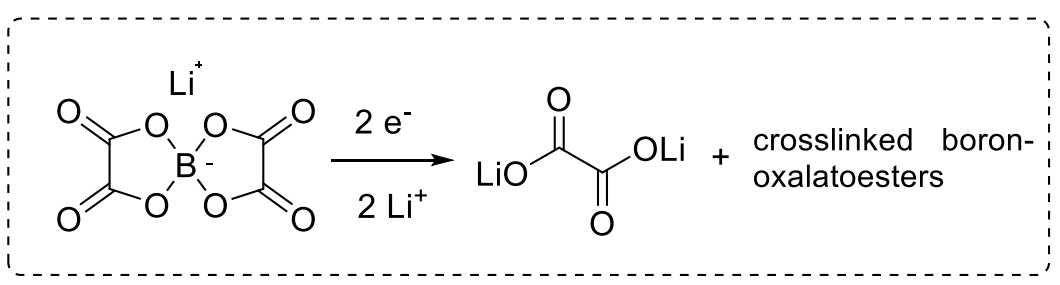

Reduction of LiDFOB results in lithium oxalate, LiF and small amounts of lithium carbonate as observed in NMR spectroscopy and IR spectroscopy. Roughly two electrons are consumed in the reduction process as estimated through quantitative solution NMR. Boron-oxalatoester (possibly fluorinated) species is likely crosslinked hence insoluble, as it is not observed with solution NMR spectroscopy, despite exhibiting detectable peaks in IR spectroscopy. Again, no $\mathrm{CO}_{2}$ was observed, but the presence of $\mathrm{Li}_{2} \mathrm{CO}_{3}$ likely results from $\mathrm{CO}_{2}$ reduction. ${ }^{28}$

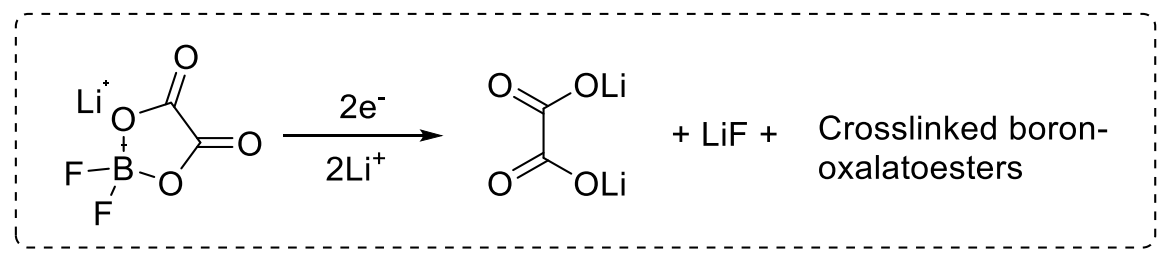

Reduction of LiTFSI results in primarily lithium fluoride and lithium bis[N(trifluoromethylsulfonylimino)] trifluoromethanesulfonate as observed in NMR spectroscopy. lithium bis[N-(trifluoromethylsulfonylimino)] trifluoromethanesulfonate is likely be formed through reductive cleavage of N-S bond, consistent with previous theoretical predictions. ${ }^{14,15} \mathrm{Li}_{2} \mathrm{~S}, \mathrm{Li}_{2} \mathrm{~S}_{2} \mathrm{O}_{4}, \mathrm{Li}_{2} \mathrm{SO}_{3}, \mathrm{Li}_{3} \mathrm{~N}, \mathrm{LiF}$, and $\mathrm{C}_{2} \mathrm{~F}_{\mathrm{x}} \mathrm{Li}_{\mathrm{y}}$ have been reported to result from reduction of LiTFSI on negative electrode surfaces. ${ }^{14,29}$ Number of electron required for the complete reduction of LiTFSI is estimated to be $\sim 12$ with quantitative NMR analysis. The estimate is consistent with cleavage of N-S bond 
followed by step by step reduction of fragments yielding, various sulfites, sulfide and nitride species. The source of $\mathrm{Li}_{2} \mathrm{CO}_{3}$ is not identified, but unlikely to result from the reduction of LiTFSI.

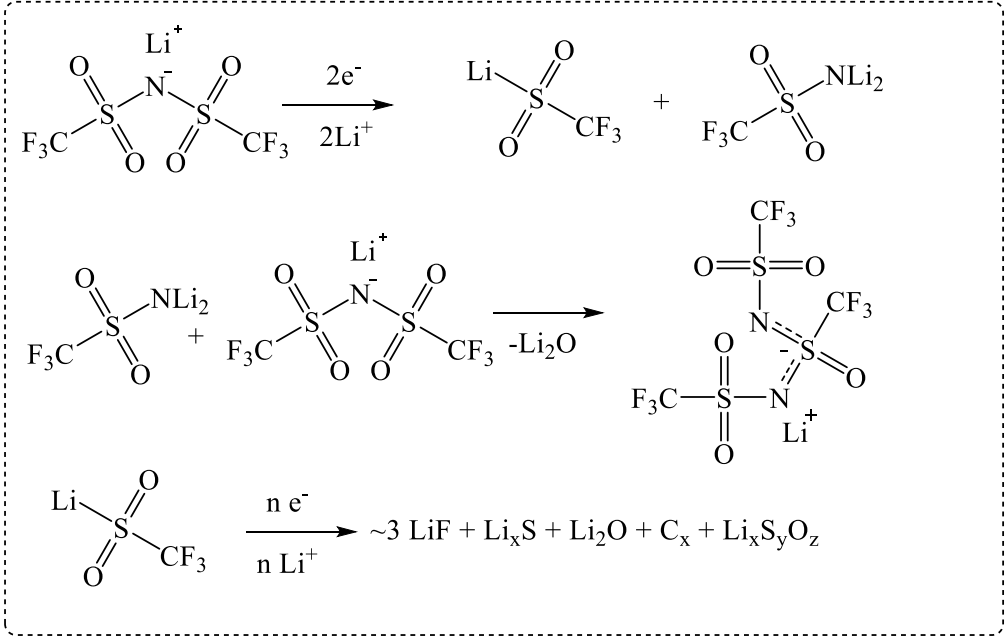

CONCLUSIONS

Reduction reactions of some of the most robust electrolyte salts for lithium-ion batteries were investigated and significant new insights were gained. $\mathrm{LiBF}_{4}$ undergoes a three-electron reduction mechanism and generates $\mathrm{LiF}$ and insoluble $\mathrm{Li}_{\mathrm{x}} \mathrm{BF}_{\mathrm{y}}$ species. LiBOB and LiDFOB undergo two-electron reduction and generate lithium oxalate and boron-oxalato-esters. In addition, LiDFOB generates $\mathrm{LiF}$ as well. Reduction of $\mathrm{LiPF}_{6}$ results in $\mathrm{LiF}$ and $\mathrm{LiPF}_{2}$ species. $\mathrm{Li}_{x} \mathrm{BF}_{\mathrm{y}}$ and $\mathrm{LiPF}_{2}$ could abstract oxygen from carbonate solvents and form fluoroborates and fluorophosphates, respectively. LiTFSI undergoes a twelve-electron reduction. LiF and lithium bis[N(trifluoromethylsulfonylimino)] trifluoromethanesulfonate are observed with NMR spectroscopy. Other likely products include, lithium sulfur oxides, lithium sulfides, lithium nitrides and lithium oxide.

ACKNOWLEDGMENT 
The authors gratefully acknowledge funding from Department of Energy Office of Basic Energy Sciences EPSCoR Implementation award (DE-SC0007074).

\section{REFERENCES}

(1) $\mathrm{Xu}, \mathrm{K}$. Nonaqueous Liquid Electrolytes for Lithium-Based Rechargeable Batteries. Chem. Rev. 2004, 104, 4303-4418.

(2) Aurbach, D.; Markovsky, B.; Shechter, A.; Ein-Eli, Y.; Cohen, H. A

Comparative Study of Synthetic Graphite and Li Electrodes in Electrolyte Solutions Based on Ethylene Carbonate-Dimethyl Carbonate Mixtures. $J$. Electrochem. Soc. 1996, 143, 3809-3820.

(3) Ein-Eli, Y. A New Perspective on the Formation and Structure of the Solid Electrolyte Interface at the Graphite Anode of Li-Ion Cells. Electrochem. solidstate Lett. 1999, 2, 212-214.

(4) Zhuang, G. V; Ross, P. N. Analysis of the Chemical Composition of the Passive Film on Li-Ion Battery Anodes Using Attentuated Total Reflection Infrared Spectroscopy. Electrochem. Solid-State Lett. 2003, 6, A136--A139.

(5) Xu, K.; Zhuang, G. V; Allen, J. L.; Lee, U.; Zhang, S. S.; Ross, P. N.; Jow, T. R. Syntheses and Characterization of Lithium Alkyl Mono-and Dicarbonates as Components of Surface Films in Li-Ion Batteries. J. Phys. Chem. B 2006, 110, 7708-7719.

(6) Gireaud, L.; Grugeon, S.; Laruelle, S.; Pilard, S.; Tarascon, J.-M. Identification of Li Battery Electrolyte Degradation Products through Direct Synthesis and Characterization of Alkyl Carbonate Salts. J. Electrochem. Soc. 2005, 152, A850--A857. 
(7) Laruelle, S.; Pilard, S.; Guenot, P.; Grugeon, S.; Tarascon, J.-M. Identification of Li-Based Electrolyte Degradation Products through DEI and ESI HighResolution Mass Spectrometry. J. Electrochem. Soc. 2004, 151, A1202--A1209.

(8) Verma, P.; Maire, P.; Novák, P. A Review of the Features and Analyses of the Solid Electrolyte Interphase in Li-Ion Batteries. Electrochim. Acta 2010, 55, 6332-6341.

(9) Peled, E. The Electrochemical Behavior of Alkali and Alkaline Earth Metals in Nonaqueous Battery Systems the Solid Electrolyte Interphase Model. $J$. Electrochem. Soc. 1979, 126, 2047-2051.

(10) Aurbach, D. Review of Selected Electrode--Solution Interactions Which Determine the Performance of Li and Li Ion Batteries. J. Power Sources 2000, 89, 206-218.

(11) Winter, M. The Solid Electrolyte Interphase--the Most Important and the Least Understood Solid Electrolyte in Rechargeable Li Batteries. Zeitschrift für Phys. Chemie Int. J. Res. Phys. Chem. Chem. Phys. 2009, 223, 1395-1406.

(12) Herstedt, M.; Abraham, D. P.; Kerr, J. B.; Edström, K. X-Ray Photoelectron Spectroscopy of Negative Electrodes from High-Power Lithium-Ion Cells Showing Various Levels of Power Fade. Electrochim. Acta 2004, 49, 50975110.

(13) Zhuang, G. V; Xu, K.; Yang, H.; Jow, T. R.; Ross, P. N. Lithium Ethylene Dicarbonate Identified as the Primary Product of Chemical and Electrochemical Reduction of EC in 1.2 M LiPF6/EC: EMC Electrolyte. J. Phys. Chem. B 2005, $109,17567-17573$. 
(14) Aurbach, D.; Weissman, I.; Schechter, A.; Cohen, H. X-Ray Photoelectron

Spectroscopy Studies of Lithium Surfaces Prepared in Several Important

Electrolyte Solutions. A Comparison with Previous Studies by Fourier

Transform Infrared Spectroscopy. Langmuir 1996, 12, 3991-4007.

(15) Howlett, P. C.; Izgorodina, E. I.; Forsyth, M.; MacFarlane, D. R.

Electrochemistry at Negative Potentials in Bis (Trifluoromethanesulfonyl)

Amide Ionic Liquids. Zeitschrift für Phys. Chemie 2006, 220, 1483-1498.

(16) Yan, G.; Li, X.; Wang, Z.; Guo, H.; Peng, W.; Hu, Q. Lithium Difluoro

(Oxalato) Borate as an Additive to Suppress the Aluminum Corrosion in

Lithium Bis (Fluorosulfony) Imide-Based Nonaqueous Carbonate Electrolyte.

J. Solid State Electrochem. 2016, 20, 507-516.

(17) Gauthier, M.; Carney, T. J.; Grimaud, A.; Giordano, L.; Pour, N.; Chang, H.-H.;

Fenning, D. P.; Lux, S. F.; Paschos, O.; Bauer, C.; et al. Electrode--Electrolyte Interface in Li-Ion Batteries: Current Understanding and New Insights. J. Phys.

Chem. Lett. 2015, 6, 4653-4672.

(18) Zhuang, G. V; Xu, K.; Jow, T. R.; Ross, P. N. Study of SEI Layer Formed on Graphite Anodes in PC/LiBOB Electrolyte Using IR Spectroscopy.

Electrochem. solid-state Lett. 2004, 7, A224--A227.

(19) Xu, M.; Zhou, L.; Dong, Y.; Chen, Y.; Garsuch, A.; Lucht, B. L. Improving the Performance of graphite/LiNi0. 5Mn1. 5O4 Cells at High Voltage and Elevated Temperature with Added Lithium Bis (Oxalato) Borate (LiBOB). $J$.

Electrochem. Soc. 2013, 160, A2005--A2013.

(20) Nie, M.; Chalasani, D.; Abraham, D. P.; Chen, Y.; Bose, A.; Lucht, B. L. 
Lithium Ion Battery Graphite Solid Electrolyte Interphase Revealed by Microscopy and Spectroscopy. J. Phys. Chem. C 2013, 117, 1257-1267.

(21) Seo, D. M.; Chalasani, D.; Parimalam, B. S.; Kadam, R.; Nie, M.; Lucht, B. L. Reduction Reactions of Carbonate Solvents for Lithium Ion Batteries. ECS Electrochem. Lett. 2014, 3, A91--A93.

(22) Garlyauskayte, R. Y.; Chernega, A. N.; Michot, C.; Armand, M.; Yagupolskii, Y. L.; Yagupolskii, L. M. Synthesis of New Organic Super acids?N(Trifluoromethylsulfonyl) Imino Derivatives of Trifluoromethanesulfonic Acid and Bis (Trifluoromethylsulfonyl) Imide. Org. Biomol. Chem. 2005, 3, 22392243.

(23) Shkrob, I. A.; Zhu, Y.; Marin, T. W.; Abraham, D. P. Mechanistic Insight into the Protective Action of Bis (Oxalato) Borate and Difluoro (Oxalate) Borate Anions in Li-Ion Batteries. J. Phys. Chem. C 2013, 117, 23750-23756.

(24) Xu, K.; Lee, U.; Zhang, S.; Wood, M.; Jow, T. R. Chemical Analysis of Graphite/electrolyte Interface Formed in LiBOB-Based Electrolytes. Electrochem. Solid-State Lett. 2003, 6, A144-A148.

(25) Kanamura, K.; Tamura, H.; Shiraishi, S.; Takehara, Z. XPS Analysis of Lithium Surfaces Following Immersion in Various Solvents Containing LiBF4. J. Electrochem. Soc. 1995, 142, 340-347.

(26) Andersson, A. M.; Herstedt, M.; Bishop, A. G.; Edström, K. The Influence of Lithium Salt on the Interfacial Reactions Controlling the Thermal Stability of Graphite Anodes. Electrochim. Acta 2002, 47, 1885-1898.

(27) Xu, K.; Lee, U.; Zhang, S.; Wood, M.; Jow, T. R. Chemical Analysis of 
Graphite/electrolyte Interface Formed in LiBOB-Based Electrolytes.

Electrochem. Solid-State Lett. 2003, 6, A144--A148.

(28) Michan, A. L.; Parimalam, B. S.; Leskes, M.; Kerber, R. N.; Yoon, T.; Grey, C. P.; Lucht, B. L. Fluoroethylene Carbonate and Vinylene Carbonate Reduction: Understanding Lithium-Ion Battery Electrolyte Additives and Solid Electrolyte Interphase Formation. Chem. Mater 2016, 28, 8149-8159.

(29) Xu, C.; Sun, B.; Gustafsson, T.; Edström, K.; Brandell, D.; Hahlin, M. Interface Layer Formation in Solid Polymer Electrolyte Lithium Batteries: An XPS Study. J. Mater. Chem. A 2014, 2, 7256-7264. 

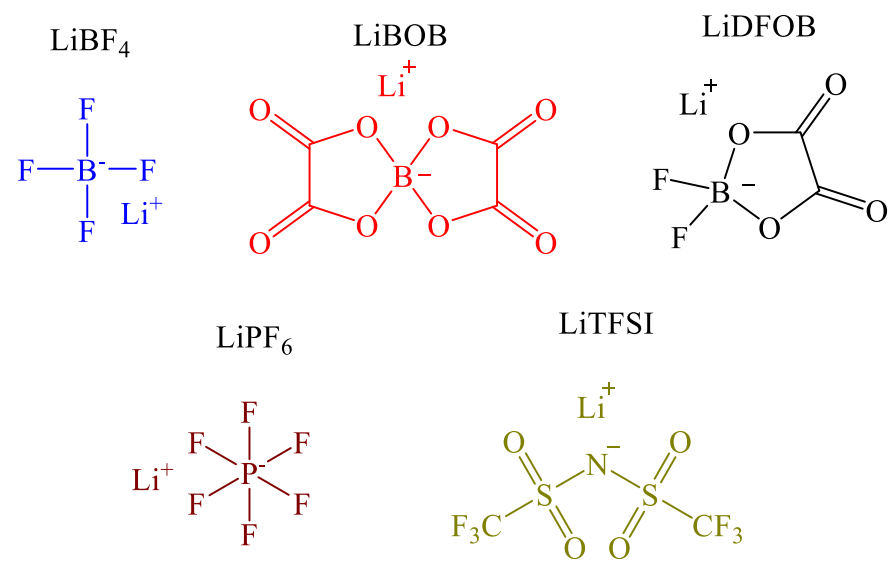

Figure 4.1. Structures of the electrolyte salts 


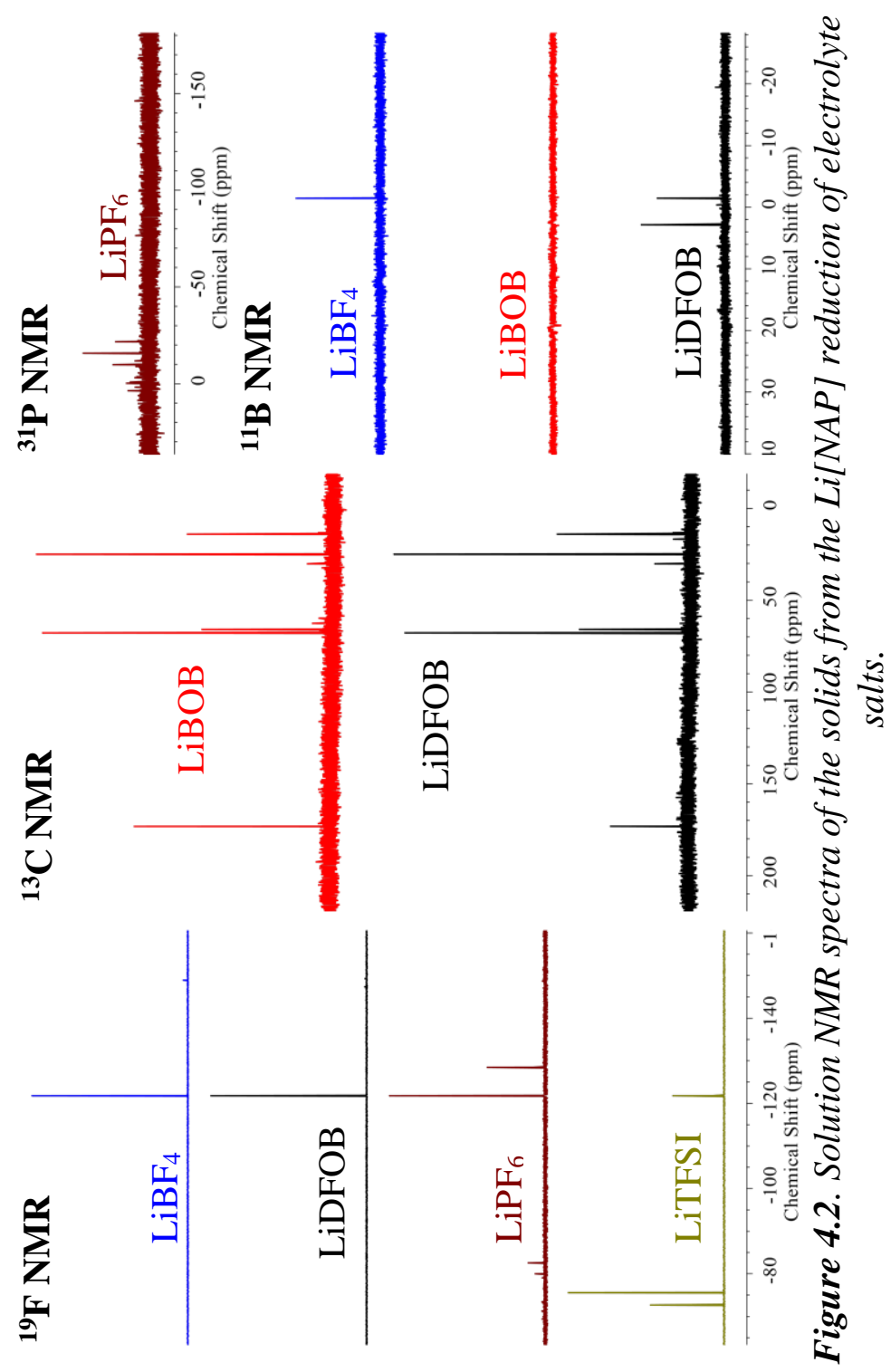




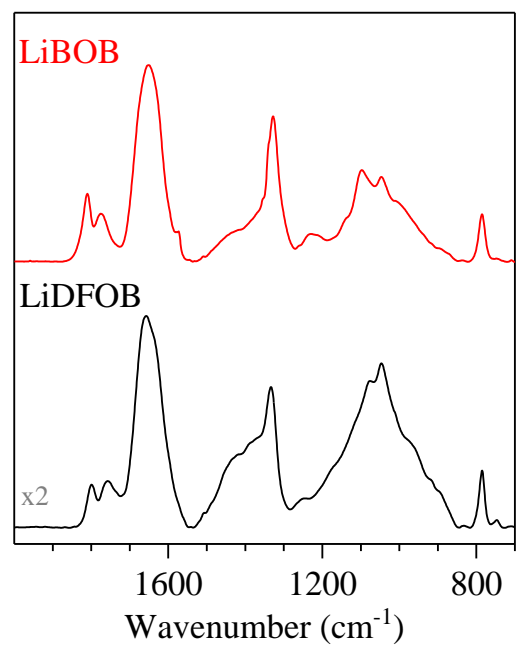

Figure 4.3. FTIR spectra of the solids from the Li[NAP] reduction of LiBOB and $\mathrm{LiDFOB}$ 


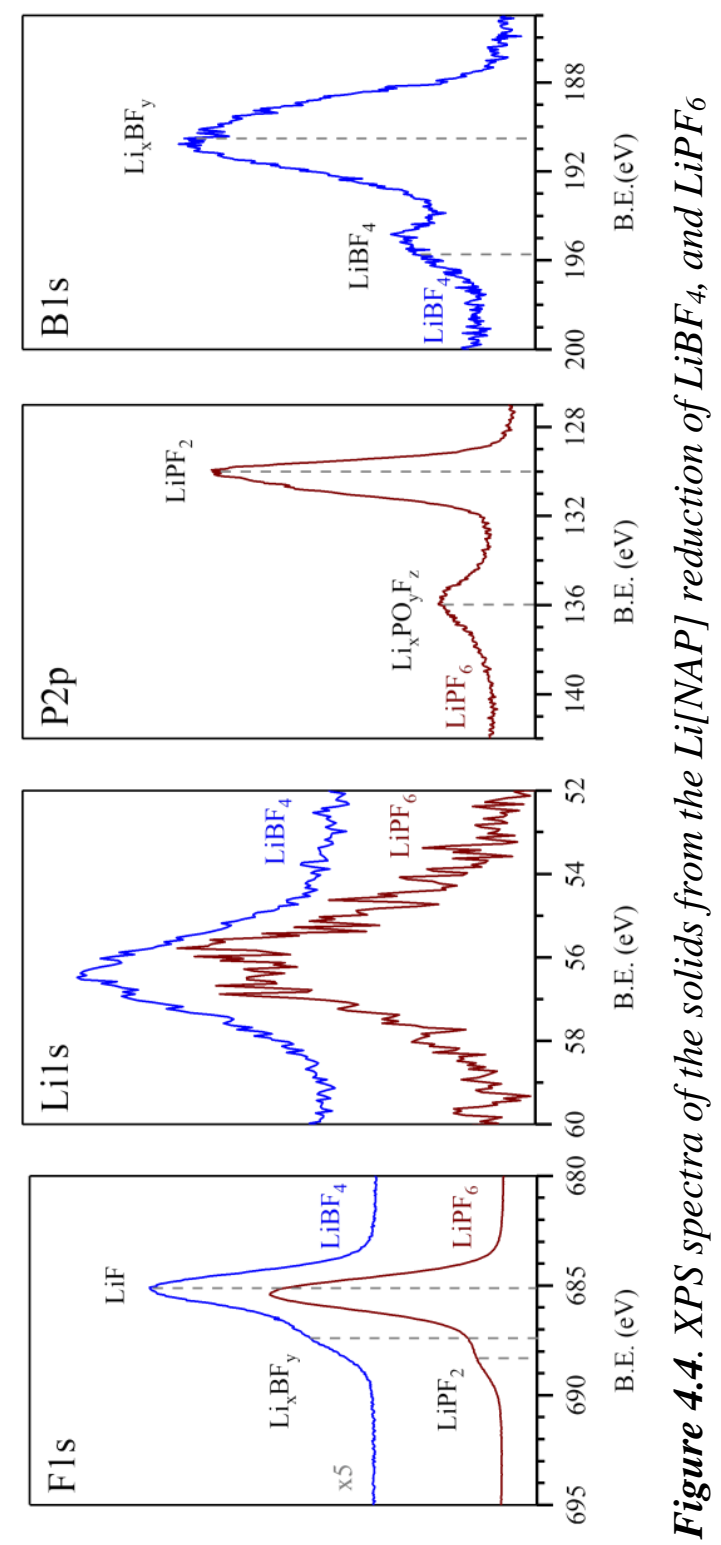


CHAPTER 5 - DECOMPOSITION REACTIONS OF ANODE SOLID ELECTROLYTE INTERPHASE (SEI) COMPONENTS WITH LiPF 6

Bharathy S. Parimalam, Alex D. MacIntosh, Rahul Kadam and Brett L. Lucht*

Department of Chemistry, University of Rhode Island, Kingston RI, 02881 USA

The following is published in the Journal of Physical Chemistry C, and is presented here in manuscript format. 


\section{ABSTRACT}

The anode solid electrolyte interface (SEI) on the anode of lithium ion batteries contains lithium carbonate $\left(\mathrm{Li}_{2} \mathrm{CO}_{3}\right)$, lithium methyl carbonate (LMC), and lithium ethylene dicarbonate (LEDC). The development of a strong physical understanding of the properties of the SEI requires a strong understanding of the evolution of the SEI composition over extended timeframes. The thermal stability of $\mathrm{Li}_{2} \mathrm{CO}_{3}, \mathrm{LMC}$, and LEDC in the presence of $\mathrm{LiPF}_{6}$ in dimethyl carbonate (DMC), a common salt and solvent, respectively, in lithium ion battery electrolytes, has been investigated to afford a better understanding of the evolution of the SEI. The residual solids from the reaction mixtures have been characterized by a combination of X-ray photoelectron spectroscopy (XPS) and infrared spectroscopy with attenuated total reflectance (IRATR) while the solution and evolved gasses have been investigated by nuclear magnetic resonance (NMR) spectroscopy and gas chromatography with mass selective detection (GC-MS). The thermal decomposition of $\mathrm{Li}_{2} \mathrm{CO}_{3}$ and $\mathrm{LiPF}_{6}$ in $\mathrm{DMC}$ yields $\mathrm{CO}_{2}, \mathrm{LiF}$, and $\mathrm{F}_{2} \mathrm{PO}_{2} \mathrm{Li}$. The thermal decomposition of $\mathrm{LMC}$ and $\mathrm{LEDC}$ with $\mathrm{LiPF}_{6}$ in $\mathrm{DMC}$ results in the generation of a complicated mixture including $\mathrm{CO}_{2}, \mathrm{LiF}$, ethers, phosphates, and fluorophosphates. 


\section{INTRODUCTION}

Lithium-ion batteries (LIB) are widely used as energy storage devices in portable electronics ${ }^{1}$ and increasingly in electric vehicles due to their high energy density. However, LIB exhibit poor capacity retention at moderately elevated temperatures, ${ }^{2}$ which is undesirable for many of the intended applications. Impedance growth and loss of cyclable lithium are reported to be the main contributors to capacity fade..$^{3-5}$

Lithium-ion batteries typically contain a graphite negative electrode, a lithiated transition metal oxide positive electrode, and an electrolyte composed of $\mathrm{LiPF}_{6}$ dissolved in a mixture of organic carbonate solvents. ${ }^{6}$ The SEI (solid electrolyte interphase) is formed on the surface of the anode from the electrochemical reduction of the electrolyte and plays a crucial role in the long-term cyclability of LIB. ${ }^{7}$ While the SEI has been reported to be a complex mixture of compounds, the initially formed components of the SEI are dominated by $\mathrm{LiF}, \mathrm{Li}_{2} \mathrm{CO}_{3}$, lithium ethylene dicarbonate $\left(\left(\mathrm{CH}_{2} \mathrm{OCO}_{2} \mathrm{Li}\right)_{2}, \mathrm{LEDC}\right)$ and lithium alkyl carbonates $\left(\mathrm{ROCO}_{2} \mathrm{Li}\right){ }^{7-11}$ The poor thermal stability of the SEI layer has been attributed to exothermal reactions between lithium alkyl carbonates and $\mathrm{LiPF}_{6} .{ }^{12,13}$ While the relationship between capacity fade and SEI instability is clear, ${ }^{12-14}$ and there have been some investigations of SEI component evolution $^{15,16}$ the mechanism of SEI component decomposition is complicated by the presence of many different components. The limited understanding of the evolution of the SEI components over time has significantly limited efforts to understand the

mechanism of ion transport through the SEI via computational modeling. ${ }^{17-25}$ A more comprehensive understanding of the decomposition reactions will aid computational 
scientists to develop a better physical understanding of the evolution of ion conducting mechanisms in the SEI and will help to improve the calendar life of lithium-ion batteries.

The SEI components lithium ethylene dicarbonate (LEDC), and lithium methyl carbonate (LMC) were independently synthesized by reduction of EC and DMC with lithium naphthalenide. ${ }^{10}$ The decomposition reactions of $\mathrm{Li}_{2} \mathrm{CO}_{3}$, LEDC and $\mathrm{LMC}$ in the presence of $\mathrm{LiPF}_{6}$ have been investigated. The decomposition products were analyzed via a combination of nuclear resonance spectroscopy (NMR), infrared spectroscopy with attenuated total reflectance (IR-ATR), X-ray photoelectron spectroscopy (XPS) and gas chromatography with mass selective detection (GC-MS). Experimental

Battery-grade $\mathrm{DMC}$ and $\mathrm{LiPF}_{6}$ were obtained from BASF. $\mathrm{Li}_{2} \mathrm{CO}_{3}$ was purchased from Sigma-Aldrich. LMC and LEDC were synthesized and purified as previously described. ${ }^{26}$ All the reagents were stored in nitrogen filled glove box at room temperature and used without further purification.

The concentrations of $\mathrm{LiPF}_{6}$ and lithium carbonates were fixed at $0.65 \mathrm{mmol} / \mathrm{mL}$ in DMC. Samples were prepared inside the nitrogen filled glovebox. The samples were added to dry NMR tubes with DMSO-d6 capillaries, sealed with rubber septa, transferred out of the glovebox, flame sealed without air exposure, and analyzed by NMR spectroscopy. The samples were then stored at $55^{\circ} \mathrm{C}$ for 48 hours in an oil bath followed by analysis with NMR and GC-MS. Comparable samples were prepared on larger scale in glass ampules for the analysis of the solid resides. The solid residues were washed with DMC three times, dried overnight at room temperature, and analyzed 
with IR-ATR and XPS. Comparable samples were prepared in a Schlenk tube for overhead gas analyses by GC-MS. Comparable samples were prepared in stainless steel coin cells with comparable results to confirm that the glass containers play no role in the observed reactions.

NMR spectra of the samples were collected with a Bruker Avance III $300 \mathrm{MHz}$ NMR spectrometer at room temperature before and after the high-temperature storage with and without proton decoupling. ${ }^{19} \mathrm{~F}$ NMR resonances were referenced to $\mathrm{LiPF}_{6}$ at -72.4 ppm and ${ }^{31} \mathrm{P}$ NMR spectra were referenced to $\mathrm{LiPF}_{6}$ at $-146.1 \mathrm{ppm}$. The chemical shifts and coupling constants of $\mathrm{OP}\left(\mathrm{OCH}_{3}\right)_{3}, \mathrm{~F}_{2} \mathrm{PO}_{2} \mathrm{Li}$, and $\mathrm{LiF}$ were confirmed through NMR analyses of the corresponding pure compounds dissolved in $0.65 \mathrm{M} \mathrm{LiPF}_{6} / \mathrm{DMC}_{\text {. }}$ The spectra were processed and analyzed using MestReNova 10.0.2.

GC-MS analyses were conducted with Agilent 6890-5973N GC equipped with an Agilent G973N mass selective detector. Liquid samples were diluted with dichloromethane, quenched with water to remove inorganic components, and the organic phase was utilized for the analysis. Helium was used as carrier gas at a flow rate of $24 \mathrm{~mL} / \mathrm{min}$. The initial column temperature was $40^{\circ} \mathrm{C}$ and the temperature was ramped at $10^{\circ} \mathrm{C} / \mathrm{min}$ to $200^{\circ} \mathrm{C}$ and held at that temperature for 2 minutes with the total run time of 18 minutes. The gas analyses were performed by sampling the head spaces of a Schlenk tubes with a $10 \mu \mathrm{L}$ GC syringe. Helium was used as carrier gas at a flow rate of $1.5 \mathrm{~mL} / \mathrm{min}$. The initial column temperature was set to $40^{\circ} \mathrm{C}$, and the temperature was ramped at $1{ }^{\circ} \mathrm{C} / \mathrm{min}$ to $43{ }^{\circ} \mathrm{C}$ and held at that temperature for 2 min with the total run time of $5 \mathrm{~min}$. The mass spectra obtained were compared to the NIST library to determine their molecular structures. 
FTIR spectra of the dried solid residues were acquired on a Bruker Tensor 27 spectrometer equipped with a germanium crystal in attenuated total reflectance (IRATR) mode. Samples were transferred using air-tight vials and the spectrometer was operated inside a nitrogen filled glovebox to avoid air exposure. Each spectrum was acquired with 128 scans from $700 \mathrm{~cm}^{-1}$ to $4000 \mathrm{~cm}^{-1}$ at the spectral resolution of $4 \mathrm{~cm}^{-}$

${ }^{1}$. The data were processed and analyzed using the OPUS and Originlab software.

XPS spectra of the dried precipitates were acquired using a Thermo Scientific K-alpha XPS. Samples were made into circular pellets with a press or stuck on a conductive carbon tape as a thin layer and transferred from the glovebox to the XPS chamber using a vacuum transfer module without exposure to air. An argon flood gun was used to avoid surface charge accumulation during sample analysis. The binding energy was corrected based on the $\mathrm{C} 1 \mathrm{~s}$ of hydrocarbon at $284.8 \mathrm{eV}$. The data were processed and analyzed using the Thermo Avantage, XPS Peak 4.1 and the Originlab software.

\section{RESULTS}

Reactivity of lithium carbonates with $\mathrm{LiPF}_{6}$ in DMC.

In an effort to better understand the stability and decomposition products of components of the anode SEI with the electrolyte, the reactions of three different lithium carbonates, $\mathrm{Li}_{2} \mathrm{CO}_{3}, \mathrm{LMC}$, and $\mathrm{LEDC}$ with $\mathrm{LiPF}_{6}$ have been investigated in DMC. LEDC and LMC have been independently prepared via the chemical reduction by lithium naphthalenide while $\mathrm{Li}_{2} \mathrm{CO}_{3}$ is commercially available. ${ }^{9-11}$

The stability of $\mathrm{Li}_{2} \mathrm{CO}_{3}$ has been investigated in DMC with and without added LiPF. Upon incorporation of $\mathrm{Li}_{2} \mathrm{CO}_{3}$ into $\mathrm{DMC}$ very little $\mathrm{Li}_{2} \mathrm{CO}_{3}$ appears to dissolve 
in the DMC and the solvent remains colorless. Upon storage of the sample at $55^{\circ} \mathrm{C}$ for two days there is no visible change to the sample. Initial incorporation of $\mathrm{Li}_{2} \mathrm{CO}_{3}$ and $\mathrm{LiPF}_{6}$ in DMC is similar to that observed for $\mathrm{Li}_{2} \mathrm{CO}_{3}$ in DMC. Very little $\mathrm{Li}_{2} \mathrm{CO}_{3}$ is dissolved and the solution remains clear. Very different results are observed upon storage at $55^{\circ} \mathrm{C}$ for two days. The sample becomes dark brown and cloudy.

Very similar visual observations are made with both LMC and LEDC. Upon incorporation of either LMC or LEDC into DMC very little LMC or LEDC appear to dissolve in the DMC and the solvent remains colorless upon storage at $55{ }^{\circ} \mathrm{C}$ for two days. Incorporation of $\mathrm{LMC}$ or $\mathrm{LEDC}$ and $\mathrm{LiPF}_{6}$ in $\mathrm{DMC}$ followed by storage at $55{ }^{\circ} \mathrm{C}$ for two days results in the generation of a cloudy dark brown mixture. In order to develop a better understanding of the changes to the mixtures, the soluble portion was analyzed by solution NMR spectroscopy and GC-MS, the residual solids were analyzed by XPS and IR-ATR, and the headspace gas was analyzed by GC-MS.

NMR Spectroscopy of the solutions

All of the samples were analyzed by ${ }^{19} \mathrm{~F}$ and ${ }^{31} \mathrm{P}$ NMR spectroscopy before and after storage at elevated temperature. The NMR spectra after storage at $55^{\circ} \mathrm{C}$ are provided in Figure 5.1 and the spectral data listed in Table 5.1. The ${ }^{19} \mathrm{~F}$ and ${ }^{31} \mathrm{P}$ NMR spectra of $0.65 \mathrm{M} \mathrm{LiPF}_{6}$ in $\mathrm{DMC}$ contains a doublet at $-72.4 \mathrm{ppm}(706 \mathrm{~Hz})$ in the ${ }^{19} \mathrm{~F}$ spectrum and a septet at $-146.1 \mathrm{ppm}(706 \mathrm{~Hz})$ in the ${ }^{31} \mathrm{P}$ NMR spectrum characteristic of $\mathrm{LiPF}_{6}$. The ${ }^{19} \mathrm{~F}$ and ${ }^{31} \mathrm{P}$ NMR spectra of $0.65 \mathrm{M} \mathrm{LiPF}_{6}$ in DMC with added LEDC, $\mathrm{LMC}$, and $\mathrm{Li}_{2} \mathrm{CO}_{3}$ before storage at $55{ }^{\circ} \mathrm{C}$ are all identical to the sample of $0.65 \mathrm{M} \mathrm{LiPF}_{6}$ in DMC. Upon storage of $0.65 \mathrm{M} \mathrm{LiPF}_{6}$ in $\mathrm{DMC}$ at $55{ }^{\circ} \mathrm{C}$ there is no change to the NMR spectra and the same resonances characteristic of $\mathrm{LiPF}_{6}$ are observed (Figure 5.1). 
Upon storage of $0.65 \mathrm{M} \mathrm{LiPF}_{6}$ in $\mathrm{DMC}$ with added $\mathrm{Li}_{2} \mathrm{CO}_{3}$ at $55^{\circ} \mathrm{C}$, in addition to the peaks characteristic of $\mathrm{LiPF}_{6}$ new peaks are observed in both the ${ }^{19} \mathrm{~F}$ and ${ }^{31} \mathrm{P}$ NMR spectra. The ${ }^{19}$ FNMR spectrum contains a new doublet at $-83.6 \mathrm{ppm}(940 \mathrm{~Hz})$ coupled to a new triplet in the ${ }^{31} \mathrm{P}$ NMR spectrum at $-20.4 \mathrm{ppm}(940 \mathrm{~Hz})$. The resonances match the NMR spectra of lithium difluoro phosphate, $\mathrm{F}_{2} \mathrm{PO}_{2} \mathrm{Li}$. In addition, a singlet is observed at $-153.9 \mathrm{ppm}$ in the ${ }^{19} \mathrm{~F}$ NMR spectrum corresponding to LiF. Interestingly, integration of the ${ }^{31} \mathrm{P}$ NMR spectra reveal that when the molar ratio of $\mathrm{Li}_{2} \mathrm{CO}_{3}: \mathrm{LiPF}_{6}$ is $1: 1, \sim 50 \%$ of the $\mathrm{LiPF}_{6}$ is converted to $\mathrm{F}_{2} \mathrm{PO}_{2} \mathrm{Li}$.

Storage of $\mathrm{LiPF}_{6}$ in DMC with added $\mathrm{LMC}$ or LEDC results in much more complicated ${ }^{19} \mathrm{~F}$ and ${ }^{31} \mathrm{P}$ NMR spectra (Figure 5.1). Upon incorporation of LMC and $\mathrm{LiPF}_{6}$ in $\mathrm{DMC}$ followed by storage at $55^{\circ} \mathrm{C}$, new peaks characteristic of $\mathrm{OP}\left(\mathrm{OCH}_{3}\right)_{3}$ $\left({ }^{31} \mathrm{P},-0.6 \mathrm{ppm}, \mathrm{s}\right), \mathrm{OPF}\left(\mathrm{OCH}_{3}\right)_{2}\left({ }^{19} \mathrm{~F},-85.9 \mathrm{ppm}, \mathrm{d} ;{ }^{31} \mathrm{P},-9.4 \mathrm{ppm}, \mathrm{d} ; 965 \mathrm{~Hz}\right)$, $\mathrm{OPF}_{2}\left(\mathrm{OCH}_{3}\right)\left({ }^{19} \mathrm{~F},-86.1 \mathrm{ppm}, \mathrm{d} ;{ }^{31} \mathrm{P},-20.1 \mathrm{ppm}, \mathrm{t} ; 1007 \mathrm{~Hz}\right), \mathrm{LiF}\left({ }^{19} \mathrm{~F},-153.9 \mathrm{ppm}\right)$, and $\mathrm{HF}\left({ }^{19} \mathrm{~F},-189 \mathrm{ppm}, \mathrm{s}\right)$ are observed, in addition to $\mathrm{LiPF}_{6}{ }^{27}$ Storage of LEDC with LiPF 6 in $\mathrm{DMC}$ at $55^{\circ} \mathrm{C}$ produces new peaks corresponding to a more complicated mixture of compounds including $\mathrm{OP}\left(\mathrm{OCH}_{3}\right)_{3}, \mathrm{OPF}\left(\mathrm{OCH}_{3}\right)_{2}, \mathrm{OPF}_{2}\left(\mathrm{OCH}_{3}\right), \mathrm{F}_{2} \mathrm{PO}_{2} \mathrm{Li}, \mathrm{HF}$, and $\mathrm{LiF}$. In addition, broad ${ }^{19} \mathrm{~F}$ and ${ }^{31} \mathrm{P}$ peaks with similar coupling constants and patterns are observed consistent with the presence of fluourophosphates with oligoethylene oxide substituents, such as $\mathrm{OPF}_{2}\left(\mathrm{OCH}_{2} \mathrm{CH}_{2} \mathrm{O}\right)_{n} \mathrm{CH}_{3}$.

GCMS analyses of volatiles and evolved gases

All samples were analyzed by GC-MS after storage at $55^{\circ} \mathrm{C}$ for two days. Both the headspace was analyzed for evolved gases and the solution was investigated for volatile compounds. There were no detectible gasses observed in the headspace of the 
$\mathrm{LiPF}_{6}$ in DMC samples after storage while the only detectible volatile compound in the solution is DMC. These results suggest that there is no reaction of $\mathrm{LiPF}_{6}$ in $\mathrm{DMC}$ under the storage conditions. Upon storage of $\mathrm{LiPF}_{6}$ in $\mathrm{DMC}$ with added $\mathrm{Li}_{2} \mathrm{CO}_{3}$, carbon dioxide is detected in the headspace, consistent with previous reports. ${ }^{28,29} \mathrm{DMC}$ is the only volatile component observed in the solution for $\mathrm{Li}_{2} \mathrm{CO}_{3}$ and $\mathrm{LiPF}_{6}$ in $\mathrm{DMC}$ samples, consistent with the NMR results since $\mathrm{F}_{2} \mathrm{PO}_{2} \mathrm{Li}$ is not volatile.

Upon storage of $\mathrm{LiPF}_{6}$ and $\mathrm{LMC}$ in $\mathrm{DMC}$, the headspace contains $\mathrm{CO}_{2}$ and dimethyl ether $\left(\mathrm{CH}_{3} \mathrm{OCH}_{3}\right)$. The solution phase of $\mathrm{LiPF}_{6}$ and $\mathrm{LMC}$ in DMC contains $\mathrm{OP}\left(\mathrm{OCH}_{3}\right)_{3}$ and $\mathrm{OPF}\left(\mathrm{OCH}_{3}\right)_{2}$, as observed by NMR spectroscopy, along with $\mathrm{CH}_{3} \mathrm{OCH}_{3}$. Upon storage of $\mathrm{LiPF}_{6}$ and LEDC in DMC, the headspace contains $\mathrm{CH}_{3} \mathrm{OCH}_{3}$ and $\mathrm{CO}_{2}$. We should note that ethylene, a possible decomposition product from $\mathrm{LEDC}$ and $\mathrm{LiPF}_{6}$ in $\mathrm{DMC}$, may go undetected if present in small quantities since the molar mass is the same as atmospheric nitrogen which is observed under our sampling protocol. The solution phase of $\mathrm{LiPF}_{6}$ and $\mathrm{LEDC}$ in DMC contains $\mathrm{OP}\left(\mathrm{OCH}_{3}\right)_{3}$ and $\mathrm{OPF}\left(\mathrm{OCH}_{3}\right)_{2}$, as observed by NMR spectroscopy, along and fluourophosphates with oligoethylene oxide substituted ethers or phosphate esters, as previously reported for the thermal decomposition of $\mathrm{EC}$ in $\mathrm{LiPF}_{6}$ containing electrolytes. $^{19}$

FTIR Spectroscopy of the solid residues

The IR-ATR spectra of $\mathrm{Li}_{2} \mathrm{CO}_{3}, \mathrm{LEDC}$, and $\mathrm{LMC}$ before and the residue after reaction of the different lithium carbonates with $\mathrm{LiPF}_{6}$ in $\mathrm{DMC}$ are provided in Figure 5.2. The IR spectrum of $\mathrm{Li}_{2} \mathrm{CO}_{3}$ contains two strong peaks centered at 1490 and 1450 $\mathrm{cm}^{-1}$ and a weak peak at $858 \mathrm{~cm}^{-1}$. After storage of $\mathrm{Li}_{2} \mathrm{CO}_{3}$ in the presence of DMC for 
2 days at $55^{\circ} \mathrm{C}$, the insoluble residue was isolated. The IR-ATR spectrum exhibits essentially the same absorbance patterns as of pure $\mathrm{Li}_{2} \mathrm{CO}_{3}$ starting material, indicating little reactivity between lithium carbonate and DMC under the storage conditions. However, after storage of $\mathrm{Li}_{2} \mathrm{CO}_{3}$ in the presence of $0.65 \mathrm{M} \mathrm{LiPF}_{6}$ in $\mathrm{DMC}$ under similar conditions, the residue does not exhibit any peaks associated with $\mathrm{Li}_{2} \mathrm{CO}_{3}$ and instead contain several weak absorbances at 1300,1162 , and $758 \mathrm{~cm}^{-1}$. The structure of the compound associated with these IR absorbances is unclear, but the absence of $\mathrm{Li}_{2} \mathrm{CO}_{3}$ in the residual solid is very clear. Similarly, the characteristic peak of lithium alkyl carbonates, corresponding to $\mathrm{C}=\mathrm{O}$ bonds, is observed at $1650 \mathrm{~cm}^{-1}$. The residues obtained from samples containing LMC or LEDC in DMC exhibit IR absorptions similar to the starting material, whereas IR-ATR spectra of the residues obtained from samples containing $\mathrm{LMC}$ or $\mathrm{LEDC}$ and $\mathrm{LiPF}_{6}$ in $\mathrm{DMC}$ contain no peaks associated with LMC or LEDC, respectively. Absorptions are observed in the $720-740 \mathrm{~cm}^{-1}$ region which remain unidentified, but the absence of the lithium alkyl carbonates is clear. The absence of LMC or LEDC in the precipitate suggests that the majority of the lithium carbonates react with $\mathrm{LiPF}_{6}$ in $\mathrm{DMC}$ during storage at $55^{\circ} \mathrm{C}$.

$X$-ray photoelectron spectroscopy of the residues

The XPS spectra of the residues after reaction of the different lithium carbonates with $\mathrm{LiPF}_{6}$ in DMC are provided in Figure 5.3. The XPS spectrum of the residue from the reaction of $\mathrm{Li}_{2} \mathrm{CO}_{3}$ with $\mathrm{LiPF}_{6}$ has a very high concentration of $\mathrm{Li}$ and $\mathrm{F}, 38$ and 42 $\%$, respectively, and very low concentrations of $\mathrm{C}, \mathrm{O}$, and $\mathrm{P} 8,6$, and $6 \%$ respectively. The F $1 \mathrm{~s}$ spectrum is dominated by a peak at $685 \mathrm{eV}$ and the $\mathrm{Li} 1 \mathrm{~s}$ spectrum is dominated by a peak at $56.4 \mathrm{eV}$ coupled with the $\sim 1: 1$ ratio of $\mathrm{F}$ to Li suggest that the residue is 
predominantly $\mathrm{LiF}$. The F1s spectrum also contains a small shoulder at $687.5 \mathrm{eV}$ along with related $\mathrm{O} 1 \mathrm{~s}$ and $\mathrm{P} 2 \mathrm{p}$ peaks at 533 and $136 \mathrm{eV}$, respectively, consistent with the presence of a low concentration of $\mathrm{Li}_{\mathrm{x}} \mathrm{PF}_{\mathrm{y}} \mathrm{O}_{\mathrm{z}}$. The $\mathrm{C} 1 \mathrm{~s}$ spectrum is dominated by a peak at $285 \mathrm{eV}$ which likely results primarily from residual naphthalene or hydrocarbon contamination. There is no evidence for any residual $\mathrm{Li}_{2} \mathrm{CO}_{3}$ at $\sim 290 \mathrm{eV}$ in the $\mathrm{C} 1 \mathrm{~s}$ XPS spectra, consistent with the IR-ATR spectra.

The XPS spectra of the residue from the reactions of LEDC or LMC with $\mathrm{LiPF}_{6}$ are very similar to the XPS spectra of the residue from the reaction of $\mathrm{Li}_{2} \mathrm{CO}_{3}$. The XPS spectra are dominated by $\mathrm{F} 1 \mathrm{~s}$ and $\mathrm{Li}$ 1s peaks characteristic of LiF. However, the concentrations of $\mathrm{C}$ and $\mathrm{O}$ are slightly higher suggesting that there may be a higher concentration of lithium alkoxides or related organic species. The XPS peak characteristic of the $-\mathrm{CO}_{3}$ group in $\mathrm{LMC}$ and $\mathrm{LEDC}$ at $\sim 290 \mathrm{eV}$ is not observed in any of the residual precipitates.

\section{DISCUSSION}

The thermal stability of common SEI components, $\mathrm{Li}_{2} \mathrm{CO}_{3}$, LMC, and LEDC, in the presence of the most common salt for lithium ion battery electrolytes, $\mathrm{LiPF}_{6}$, has been investigated by a combination of IR-ATR, XPS, solution NMR, and GC-MS. In all cases the presence of $\mathrm{LiPF}_{6}$ significantly decreases the stability of the lithium carbonates. While the products of the reactions are similar for all lithium carbonates investigated the thermal decomposition of $\mathrm{Li}_{2} \mathrm{CO}_{3}$ is the most straightforward.

The reaction of $\mathrm{Li}_{2} \mathrm{CO}_{3}$ with $\mathrm{LiPF}_{6}$ results in the quantitative decomposition of the $\mathrm{Li}_{2} \mathrm{CO}_{3}$. A single gas, $\mathrm{CO}_{2}$, is observed by GC-MS. The residual solid from the reaction is predominantly $\mathrm{LiF}$, as supported by XPS and IR-ATR. The solution phase 
contains a single decomposition product, $\mathrm{F}_{2} \mathrm{PO}_{2} \mathrm{Li}$ consistent with previous reports. ${ }^{30}$ The low concentration of $\mathrm{P}$ in the residual solid is consistent with the generation of a soluble $\mathrm{P}$ containing species, $\mathrm{F}_{2} \mathrm{PO}_{2} \mathrm{Li}$. The generation of soluble $\mathrm{P}$ containing species is the likely reason that the composition of the SEI typically has a much higher ratio of $\mathrm{F}: \mathrm{P}$ than the $6: 1$ expected for $\mathrm{LiPF}_{6}$. When a $1: 1$ stoichiometry of $\mathrm{Li}_{2} \mathrm{CO}_{3}$ to $\mathrm{LiPF}_{6}$ is used, $\sim 50 \%$ of the $\mathrm{LiPF}_{6}$ is converted to $\mathrm{F}_{2} \mathrm{PO}_{2} \mathrm{Li}$ and $\mathrm{LiF}$. This reaction is consistent with the equation 1.

$$
\mathrm{LiPF}_{6}+2 \mathrm{Li}_{2} \mathrm{CO}_{3} \rightarrow 2 \mathrm{CO}_{2}+4 \mathrm{LiF}+\mathrm{F}_{2} \mathrm{PO}_{2} \mathrm{Li}
$$

A similar, but slightly more complicated, decomposition reaction is observed for LMC with LiPF6. In addition to $\mathrm{CO}_{2}$ and $\mathrm{LiF}$, phosphates and fluorophosphates, $\mathrm{OP}\left(\mathrm{OCH}_{3}\right)_{3}, \mathrm{OPF}\left(\mathrm{OCH}_{3}\right)_{2}$, and $\mathrm{OPF}_{2}\left(\mathrm{OCH}_{3}\right)$, are observed in solution by $\mathrm{NMR}$ and GC-MS instead of $\mathrm{F}_{2} \mathrm{PO}_{2} \mathrm{Li}$. Since the transesterification reactions are not observed for $\mathrm{Li}_{2} \mathrm{CO}_{3}$, the presence of the alkoxy group is required to initiate transesterification. Dimethyl ether is also observed from the decomposition of $\mathrm{LMC}$ with $\mathrm{LiPF}_{6}$ in $\mathrm{DMC}$, suggesting competitive acid mediated ether exchange reactions. It is important to note that no methyl fluoride $\left(\mathrm{CH}_{3} \mathrm{~F}\right)$ is observed suggesting that the reaction does not involve an Arbuzov rearrangement. The reaction is consistent with equation 2. The initially formed $\mathrm{OPF}_{2}\left(\mathrm{OCH}_{3}\right)$ continues further transesterification reactions with LMC to generate $\mathrm{OPF}\left(\mathrm{OCH}_{3}\right)_{2}$ and $\mathrm{OP}\left(\mathrm{OCH}_{3}\right)_{3}$ along with more $\mathrm{LiF}$ and $\mathrm{CO}_{2}$, as depicted in equation 3. The importance of the alkoxy group was verified via the reaction of $\mathrm{LiPF}_{6}$ with $\mathrm{Li}_{2} \mathrm{CO}_{3}$ and $\mathrm{LiOCH}_{3}$, which results in the generation of the decomposition products of both $\mathrm{LMC}$ and $\mathrm{Li}_{2} \mathrm{CO}_{3}$ with $\mathrm{LiPF}_{6}$. The presence of $\mathrm{LiPF}_{6}$ and dissociation into $\mathrm{LiF}$ and the strong Lewis acid $\mathrm{PF}_{5}$ likely mediates the generation of the alkoxide involved 
in the transesterification and ether formation reactions (equation 4). A detailed mechanistic investigation of the reactions is beyond the scope of this manuscript, but the reactions depicted in Eq 2-4 are likely combinations of well-known organic chemistry reactions: transesterification, etherfication, and decarbonylation. ${ }^{31}$

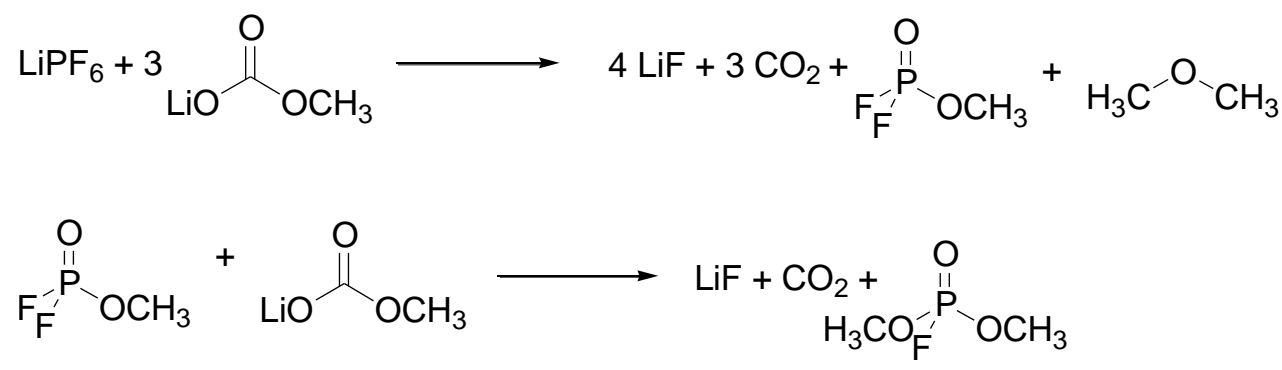

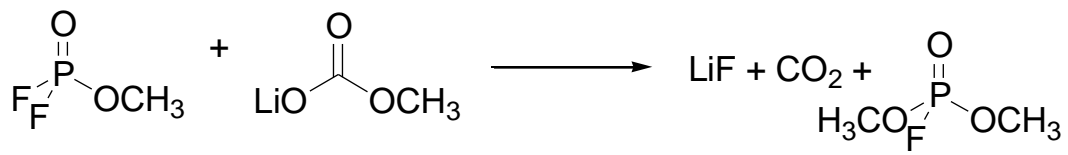

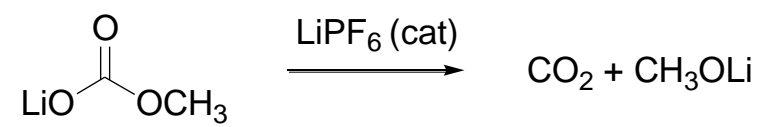

Similar, but more complicated, decomposition reactions are observed for the reaction of LEDC with $\mathrm{LiPF}_{6}$. All of the species observed from the decomposition reactions of $\mathrm{Li}_{2} \mathrm{CO}_{3}$ and $\mathrm{LMC}$ with $\mathrm{LiPF}_{6}\left(\mathrm{CO}_{2}, \mathrm{LiF}, \mathrm{CH}_{3} \mathrm{OCH}_{3}, \mathrm{OP}\left(\mathrm{OCH}_{3}\right)_{3}\right.$, $\mathrm{OPF}\left(\mathrm{OCH}_{3}\right)_{2}, \mathrm{OPF}_{2}\left(\mathrm{OCH}_{3}\right)$, and $\left.\mathrm{F}_{2} \mathrm{PO}_{2} \mathrm{Li}\right)$ are observed for the decomposition of LEDC with $\mathrm{LiPF}_{6}$, suggesting similar reactions to those depicted in equations 1-4. This is consistent with transient generation lithium alkoxides leading to transesterification and ether exchange reactions of the methoxy substituents of the DMC solvent. The presence of oligoethylene oxide substituted phosphates and oligoethylene oxide ethers suggests that the LEDC decomposes via equation 5, which is analogous to equation 2 for LMC. 


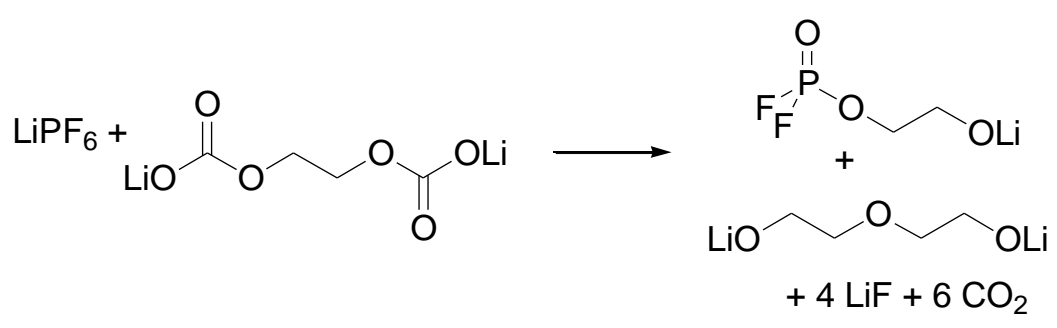

Finally, $\mathrm{HF}$ is observed with both $\mathrm{LEDC}$ and $\mathrm{LMC}$ but not with $\mathrm{Li}_{2} \mathrm{CO}_{3}$. While HF generation could result from decomposition of the alkoxy substituent, the deprotonation of a methyl group in LMC or DMC would be unusual. Unfortunately, the source of the HF remains unclear at this time.

\section{CONCLUSIONS}

The stability of lithium carbonates, $\mathrm{Li}_{2} \mathrm{CO}_{3}, \mathrm{LMC}$, and $\mathrm{LEDC}$, in the presence of $\mathrm{LiPF}_{6}$ in DMC has been investigated by a combination of NMR, GC-MS, IR-ATR and XPS. All of the lithium carbonates are stable upon storage in DMC for 48 hours at $55{ }^{\circ} \mathrm{C}$. Addition of $\mathrm{LiPF}_{6}$ to lithium carbonates in $\mathrm{DMC}$ results in quantitative decomposition of the lithium carbonates upon storage at $55^{\circ} \mathrm{C}$ for 48 hours. The decomposition of $\mathrm{Li}_{2} \mathrm{CO}_{3}$ generates only three products in high yield, $\mathrm{CO}_{2}, \mathrm{LiF}$, and $\mathrm{F}_{2} \mathrm{PO}_{2} \mathrm{Li}$. The decomposition reactions of LMC and LEDC are more complicated due to the presence of the alkoxy substituent of the lithium alkyl carbonates. The decomposition generates a complicated mixture of $\mathrm{CO}_{2}, \mathrm{LiF}$, ethers, phosphates, and fluorophosphates. The $\mathrm{LiPF}_{6}$ mediated decomposition of lithium carbonates, a common component of the SEI on the anode of lithium ion batteries, provides insight into the mechanism of changes of the anode SEI upon long term cycling of lithium ion batteries. 


\section{ACKNOWLEDGEMENT}

The authors gratefully acknowledge funding from Department of Energy Office of Basic Energy Sciences EPSCoR Implementation award (DE-SC0007074)

\section{REFERENCES}

(1) Wakihara, M.; Yamamoto, O.; Wakihara, M; Yamamoto, O. Lithium Ion Batteries Fundamentals and Performance; John Wiley \& Sons: Weinheim, 1998.

(2) Ramadass, P.; Haran, B.; White, R.; Popov, B. N. Capacity Fade of Sony 18650 Cells Cycled at Elevated Temperatures: Part II. Capacity Fade Analysis. J. Power Sources 2002, 112, 614-620.

(3) Arora, P.; White, R. E.; Doyle, M. Capacity Fade Mechanisms and Side Reactions in Lithium-Ion Batteries. J. Electrochem. Soc. 1998, 145, 3647-3667.

(4) Spotnitz, R. Simulation of Capacity Fade in Lithium-Ion Batteries. J. Power Sources 2003, 113, 72-80.

(5) Vetter, J.; Novák, P.; Wagner, M. R.; Veit, C.; Möller, K.-C.; Besenhard, J. O.; Winter, M.; Wohlfahrt-Mehrens, M.; Vogler, C.; Hammouche, A. Ageing Mechanisms in Lithium-Ion Batteries. J. Power Sources 2005, 147, 269-281.

(6) $\mathrm{Xu}, \mathrm{K}$. Nonaqueous Liquid Electrolytes for Lithium-Based Rechargeable Batteries. Chem. Rev. 2004, 104, 4303-4418.

(7) Aurbach, D.; Markovsky, B.; Shechter, A.; Ein-Eli, Y.; Cohen, H. A Comparative Study of Synthetic Graphite and Li Electrodes in Electrolyte Solutions Based on Ethylene Carbonate-Dimethyl Carbonate Mixtures. J. Electrochem. Soc. 1996, 143, 3809-3820.

(8) Shu, Z. X.; McMillan, R. S.; Murray, J. J. Electrochemical Intercalation of 
Lithium into Graphite. J. Electrochem. Soc. 1993, 140, 922-927.

(9) Aurbach, D.; Ein-Eli, Y.; Chusid, O.; Carmeli, Y.; Babai, M.; Yamin, H. The Correlation Between the Surface Chemistry and the Performance of Li-Carbon Intercalation Anodes for Rechargeable "Rocking-Chair"Type Batteries. J. Electrochem. Soc. 1994, 141, 603-611.

(10) Nie, M.; Chalasani, D.; Abraham, D. P.; Chen, Y.; Bose, A.; Lucht, B. L. Lithium Ion Battery Graphite Solid Electrolyte Interphase Revealed by Microscopy and Spectroscopy. J. Phys. Chem. C 2013, 117, 1257-1267.

(11) Xu, K.; Zhuang, G. V; Allen, J. L.; Lee, U.; Zhang, S. S.; Ross, P. N.; Jow, T. R. Syntheses and Characterization of Lithium Alkyl Mono-and Dicarbonates as Components of Surface Films in Li-Ion Batteries. J. Phys. Chem. B 2006, 110, $7708-7719$.

(12) Ryou, M.-H.; Lee, J.-N.; Lee, D. J.; Kim, W.-K.; Jeong, Y. K.; Choi, J. W.; Park, J.-K.; Lee, Y. M. Effects of Lithium Salts on Thermal Stabilities of Lithium Alkyl Carbonates in SEI Layer. Electrochim. Acta 2012, 83, 259-263.

(13) Herstedt, M.; Abraham, D. P.; Kerr, J. B.; Edström, K. X-Ray Photoelectron Spectroscopy of Negative Electrodes from High-Power Lithium-Ion Cells Showing Various Levels of Power Fade. Electrochim. Acta 2004, 49, 5097-5110.

(14) Guéguen, A.; Streich, D.; He, M.; Mendez, M.; Chesneau, F. F.; Novák, P.; Berg, E. J. Decomposition of LiPF6 in High Energy Lithium-Ion Batteries Studied with Online Electrochemical Mass Spectrometry. J. Electrochem. Soc. 2016, 163, A1095--A1100.

(15) Gachot, G.; Grugeon, S.; Armand, M.; Pilard, S.; Guenot, P.; Tarascon, J.-M.; 
Laruelle, S. Deciphering the Multi-Step Degradation Mechanisms of CarbonateBased Electrolyte in Li Batteries. J. Power Sources 2008, 178, 409-421.

(16) Gachot, G.; Grugeon, S.; Eshetu, G. G.; Mathiron, D.; Ribière, P.; Armand, M.; Laruelle, S. Thermal Behaviour of the Lithiated-Graphite/electrolyte Interface through GC/MS Analysis. Electrochim. Acta 2012, 83, 402-409.

(17) Jorn, R.; Kumar, R.; Abraham, D. P.; Voth, G. A. Atomistic Modeling of the Electrode--Electrolyte Interface in Li-Ion Energy Storage Systems: Electrolyte Structuring. J. Phys. Chem. C 2013, 117, 3747-3761.

(18) Leung, K. Electronic Structure Modeling of Electrochemical Reactions at Electrode/electrolyte Interfaces in Lithium Ion Batteries. J. Phys. Chem. C 2012, $117,1539-1547$.

(19) Leung, K.; Soto, F.; Hankins, K.; Balbuena, P. B.; Harrison, K. L. Stability of Solid Electrolyte Interphase Components on Lithium Metal and Reactive Anode Material Surfaces. J. Phys. Chem. C 2016, 120, 6302-6313.

(20) Bedrov, D.; Borodin, O.; Hooper, J. B. Li+ Transport and Mechanical Properties of Model Solid Electrolyte Interphases (SEI): Insight from Atomistic Molecular Dynamics Simulations. J. Phys. Chem. C 2017, 121, 16098-16109.

(21) Borodin, O.; Zhuang, G. V; Ross, P. N.; Xu, K. Molecular Dynamics Simulations and Experimental Study of Lithium Ion Transport in Dilithium Ethylene Dicarbonate. J. Phys. Chem. C 2013, 117, 7433-7444.

(22) Shi, S.; Lu, P.; Liu, Z.; Qi, Y.; Hector Jr, L. G.; Li, H.; Harris, S. J. Direct Calculation of Li-Ion Transport in the Solid Electrolyte Interphase. J. Am. Chem. Soc. $2012,134,15476-15487$. 
(23) Iddir, H.; Curtiss, L. A. Li Ion Diffusion Mechanisms in Bulk Monoclinic Li2CO3 Crystals from Density Functional Studies. J. Phys. Chem. C 2010, 114, 20903-20906.

(24) Shi, S.; Qi, Y.; Li, H.; Hector Jr, L. G. Defect Thermodynamics and Diffusion Mechanisms in Li2CO3 and Implications for the Solid Electrolyte Interphase in Li-Ion Batteries. J. Phys. Chem. C 2013, 117, 8579-8593.

(25) Li, Y.; Leung, K.; Qi, Y. Computational Exploration of the Li-Electrode| Electrolyte Interface in the Presence of a Nanometer Thick Solid-Electrolyte Interphase Layer. Acc. Chem. Res. 2016, 49, 2363-2370.

(26) Seo, D. M.; Chalasani, D.; Parimalam, B. S.; Kadam, R.; Nie, M.; Lucht, B. L. Reduction Reactions of Carbonate Solvents for Lithium Ion Batteries. ECS Electrochem. Lett. 2014, 3, A91--A93.

(27) Campion, C. L.; Li, W.; Lucht, B. L. Thermal Decomposition of LiPF[sub 6]Based Electrolytes for Lithium-Ion Batteries. J. Electrochem. Soc. 2005, 152, A2327.

(28) Wang, Q.; Ping, P.; Zhao, X.; Chu, G.; Sun, J.; Chen, C. Thermal Runaway Caused Fire and Explosion of Lithium Ion Battery. J. Power Sources 2012, 208, $210-224$.

(29) Onuki, M.; Kinoshita, S.; Sakata, Y.; Yanagidate, M.; Otake, Y.; Ue, M.; Deguchi, M. Identification of the Source of Evolved Gas in Li-Ion Batteries Using\# 2\# 1-Labeled Solvents. J. Electrochem. Soc. 2008, 155, A794--A797.

(30) Kato, R.; Suzuki, H. Method for Producing Difluorophosphate, Nonaqueous Electrolyte Solution for Secondary Battery and Nonaqueous Electrolyte 
Secondary Battery. U.S. Patent No. 8,076,033 2011.

(31) Smith, M. B.; March, J. March's Advanced Organic Chemistry: Reactions, Mechanisms, and Structure; John Wiley \& Sons: Hoboken, New Jersey, 2007. 


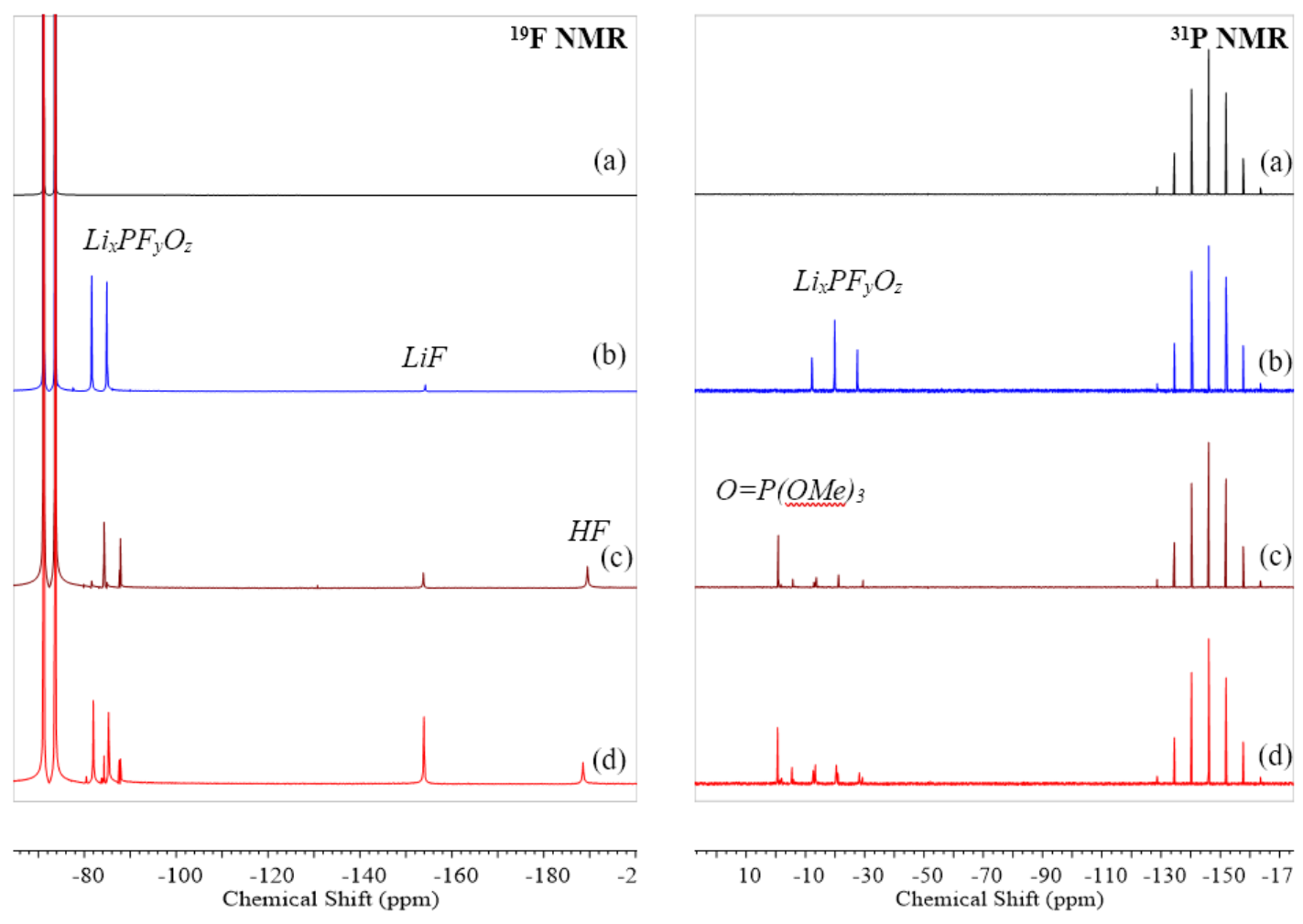

Figure 5.1. ${ }^{19} \mathrm{~F}$ and ${ }^{31} \mathrm{P}$ NMR spectra of sample (a) $0.65 \mathrm{M} \mathrm{LiPF}_{6} / \mathrm{DMC}$ (b) $\mathrm{Li}_{2} \mathrm{CO}_{3}$ in $0.65 \mathrm{M} \mathrm{LiPF}_{6} / \mathrm{DMC}$ (c) $\mathrm{LMC}$ in $0.65 \mathrm{M} \mathrm{LiPF}_{6} / \mathrm{DMC}$ and (d) LEDC in $0.65 \mathrm{M}$ $\mathrm{LiPF}_{6} / \mathrm{DMC} \mathrm{s}$ after 48 hours of storage at $55^{\circ} \mathrm{C}$ 


\begin{tabular}{|c|c|c|}
\hline Species & ${ }^{19} \mathbf{F} \delta$ (mult, JFP) & ${ }^{31} \mathbf{P} \delta$ (mult, JFP) \\
\hline $\mathrm{LiPF}_{6}$ & $-72.4(\mathrm{~d}, \mathrm{~J}=706 \mathrm{~Hz})$ & $-146.1(\mathrm{sept}, \mathrm{J}=706 \mathrm{~Hz})$ \\
\hline $\mathrm{F}_{2} \mathrm{PO}_{2} \mathrm{Li}$ & $-83.6(\mathrm{~d}, \mathrm{~J}=940 \mathrm{~Hz})$ & $-20.4(\mathrm{t}, \mathrm{J}=940 \mathrm{~Hz})$ \\
\hline $\mathrm{O}=\mathrm{P}(\mathrm{OMe})_{3}$ & - & $-0.6(\mathrm{~s})$ \\
\hline $\mathrm{O}=\mathrm{PF}(\mathrm{OMe})_{2}$ & $-85.9(\mathrm{~d}, \mathrm{~J}=965 \mathrm{~Hz})$ & $-9.4(\mathrm{~d}, \mathrm{~J}=965 \mathrm{~Hz})$ \\
\hline $\mathrm{O}=\mathrm{PF}_{2}(\mathrm{OMe})$ & $-86.1(\mathrm{~d}, \mathrm{~J}=1007 \mathrm{~Hz})$ & $-20.1(\mathrm{t}, \mathrm{J}=1007 \mathrm{~Hz})$ \\
\hline $\mathrm{LiF}$ & $-153.9(\mathrm{~s})$ & - \\
\hline $\mathrm{HF}$ & $-189(\mathrm{~s})$ & - \\
\hline
\end{tabular}

Table 5.1. ${ }^{19} \mathrm{~F}$ and ${ }^{31} \mathrm{P}$ NMR spectral data of the decomposition products 


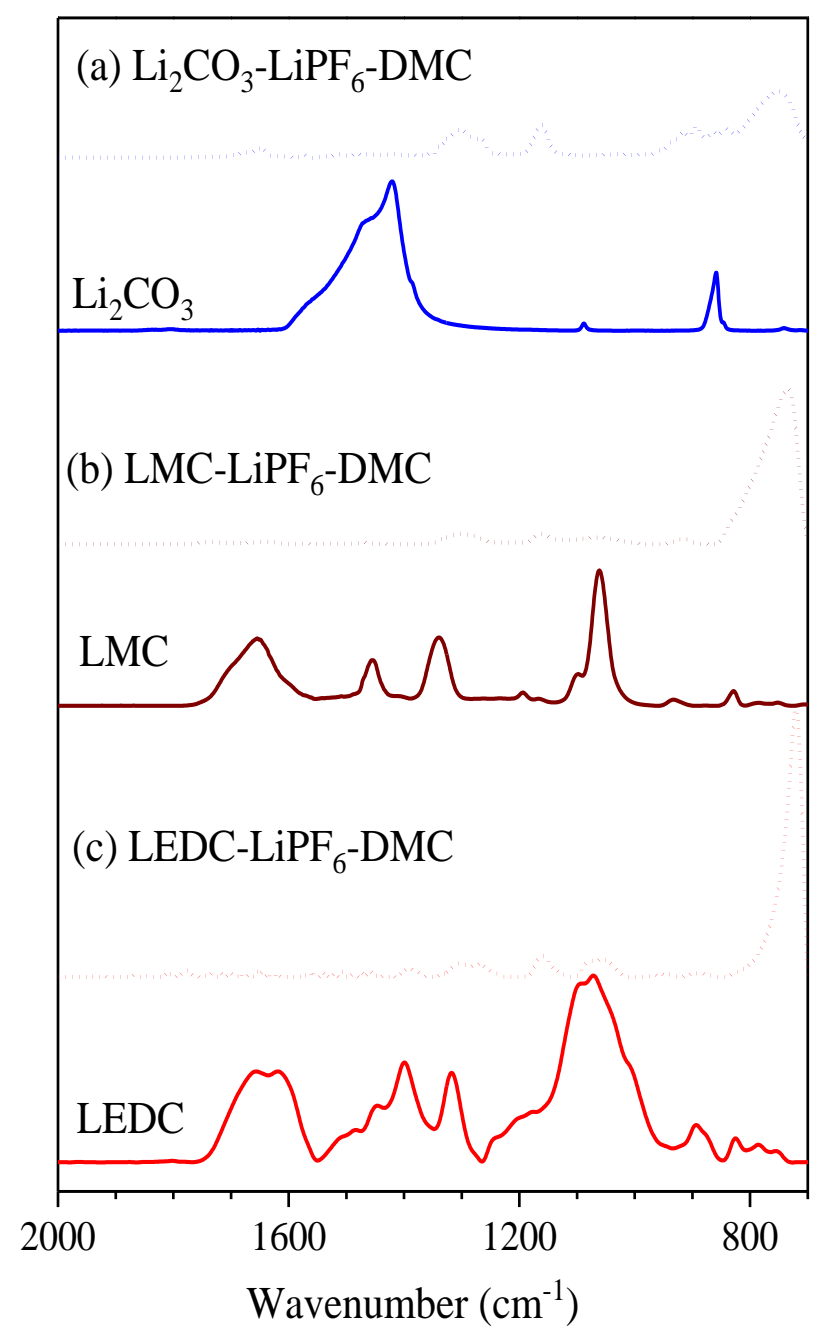

Figure 5.2. FTIR spectra of the pure $\mathrm{Li}_{2} \mathrm{CO}_{3}, \mathrm{LMC}$, LEDC, and dried precipitates

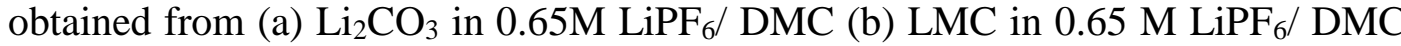
and (c) LEDC in $0.65 \mathrm{M} \mathrm{LiPF}_{6} / \mathrm{DMC}$ samples after 48 hours of storage at $55^{\circ} \mathrm{C}$ 


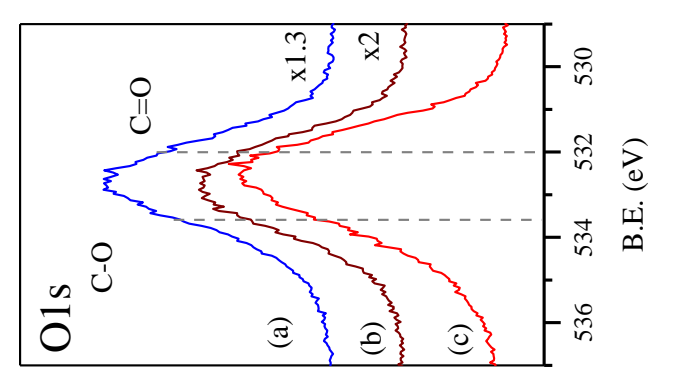

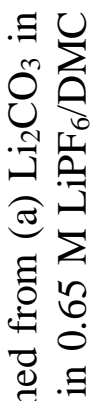

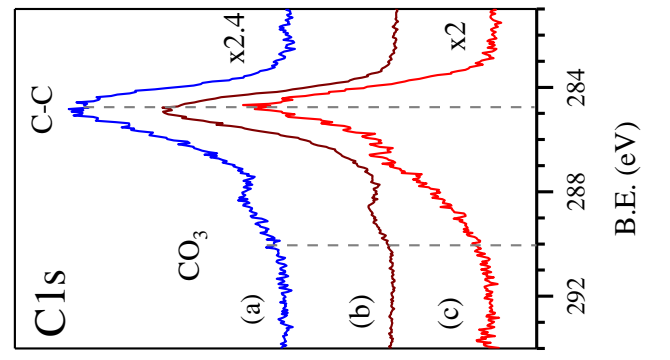

흉

\&

훙

ส

导

苞

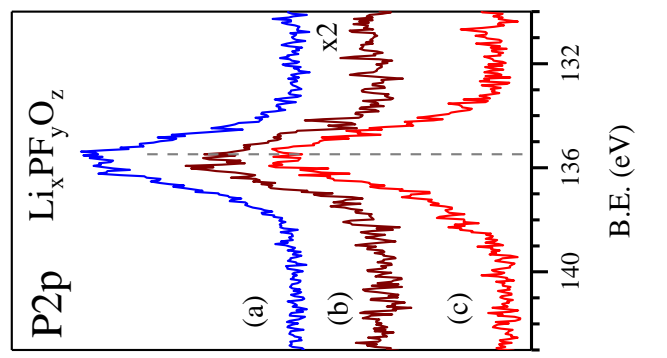

की

实

क 6

0

范帒

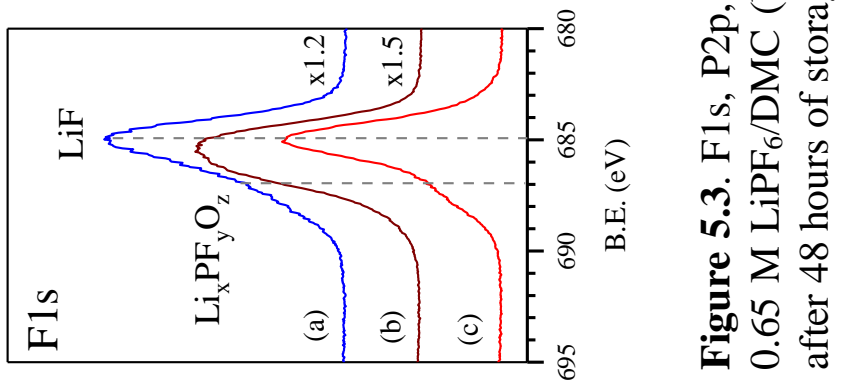

